A NEW MODAL SUPERPOSITION METHOD FOR NONLINEAR VIBRATION ANALYSIS OF STRUCTURES USING HYBRID MODE SHAPES

A THESIS SUBMITTED TO

THE GRADUATE SCHOOL OF NATURAL AND APPLIED SCIENCES

$\mathrm{OF}$

MIDDLE EAST TECHNICAL UNIVERSITY

BY

ERHAN FERHATOĞLU

IN PARTIAL FULFILLMENT OF THE REQUIREMENTS

FOR

THE DEGREE OF MASTER OF SCIENCE

IN

MECHANICAL ENGINEERING

DECEMBER 2017 



\section{A NEW MODAL SUPERPOSITION METHOD FOR NONLINEAR VIBRATION ANALYSIS OF STRUCTURES USING HYBRID MODE SHAPES}

submitted by ERHAN FERHATOĞLU in partial fulfillment of the requirements for the degree of Master of Science in Mechanical Engineering Department, Middle East Technical University by,

Prof. Dr. Gülbin Dural Ünver

Dean, Graduate of Natural and Applied Sciences

Prof. Dr. M. A. Sahir Arıkan

Head of Department, Mechanical Engineering

Prof. Dr. H. Nevzat Özgüven

Supervisor, Mechanical Engineering Dept., METU

Assoc. Prof. Dr. Ender Ciğeroğlu

Co-Supervisor, Mechanical Engineering Dept., METU

\section{Examining Committee Members:}

Assoc. Prof. Dr. Ender Ciğeroğlu

Mechanical Engineering Dept., METU

Prof. Dr. H. Nevzat Özgüven

Mechanical Engineering Dept., METU

Assist. Prof. Dr. M. Bülent Özer

Mechanical Engineering Dept., METU

Assist. Prof. Dr. Orkun Özşahin

Mechanical Engineering Dept., METU

Assist. Prof. Dr. Can U. Doğruer

Mechanical Engineering Dept., Hacettepe University

Date: 
I hereby declare that all information in this document has been obtained and presented in accordance with academic rules and ethical conduct. I also declare that, as required by these rules and conduct, I have fully cited and referenced all material and results that are not original to this work.

Name, Last name : Erhan Ferhatoğlu

Signature 


\title{
ABSTRACT \\ A NEW MODAL SUPERPOSITION METHOD FOR NONLINEAR VIBRATION ANALYSIS OF STRUCTURES USING HYBRID MODE SHAPES
}

\author{
Ferhatoğlu, Erhan \\ MSc., Department of Mechanical Engineering \\ Supervisor: Prof. Dr. H.Nevzat Özgüven \\ Co-Supervisor : Assoc. Prof. Dr. Ender Ciğeroğlu
}

December 2017, 80 pages

In this thesis, a new modal superposition method based on a hybrid mode shape concept is developed for the determination of steady state vibration response of nonlinear structures. The method is developed specifically for systems having nonlinearities where the stiffness of the system may take different limiting values. Stiffness variation of these nonlinear systems enables one to define different linear systems corresponding to each value of the limiting equivalent stiffness. Moreover, the response of the nonlinear system is bounded by the confinement of these linear systems. In this study, a modal superposition method utilizing novel hybrid mode shapes which are defined as linear combinations of the modal vectors of the limiting linear systems is proposed to determine periodic response of nonlinear systems. In this method the response of the nonlinear system is written in terms of hybrid modes instead of the modes of the underlying linear system. This provides decrease of the number of modes that should be retained for an accurate solution, which in turn reduces the number of nonlinear equations to be solved. In this way, computational time for response calculation is directly curtailed. In the solution, the equations of motion are converted to a set of nonlinear algebraic equations by using describing function approach, and the numerical solution is obtained by using Newton's method with arc-length continuation. The method developed is applied on two different systems: a lumped parameter model and a finite element model. Several case studies are performed and the accuracy and computational efficiency of the proposed modal 
superposition method with hybrid mode shapes are compared with those of the classical modal superposition method which utilizes the mode shapes of the underlying linear system.

Keywords: Modal Superposition Method, Hybrid Mode Shapes, Nonlinear Vibrations, Describing Function Method, Reduced Order Model. 


\title{
YAPILARIN DOĞRUSAL OLMAYAN TITTESŞIM ANALIZİ ICÇIN HIBBRIT MOD ŞEKILLERINII KULLANAN YENI BíR MOD SÜPERPOZISYON YÖNTEMI
}

\author{
Ferhatoğlu, Erhan \\ Yüksek Lisans, Makina Mühendisliği Bölümü \\ Tez Yöneticisi: Prof. Dr. H. Nevzat Özgüven \\ Ortak Tez Yöneticisi: Doç. Dr. Ender Ciğeroğlu
}

Aralik 2017, 80 sayfa

$\mathrm{Bu}$ tezde, doğrusal olmayan yapıların kararlı hallerindeki titreşim cevaplarını belirlemek için hibrit mod şekli kavramını kullanan yeni bir modal süperpozisyon yöntemi geliştirilmiştir. Yöntem özellikle, direngenliği farklı sınırlayıcı değerler alabilen doğrusal olmayan elemanları içeren sistemler için geliştirilmiştir. $\mathrm{Bu}$ doğrusal olmayan sistemlerin direngenlik değişimi, her bir sınırlayıcı direngenlik değerine karşılık gelen farklı doğrusal sistemler tanımlamaya imkan kılar. Buna ek olarak, doğrusal olmayan sistemin cevabı bu doğrusal sistemlerin kısıtlamalarıyla sınırlandırılmıştır. Bu çalışmada, sınırlayıcı doğrusal sistemlerin modal vektörlerinin doğrusal kombinasyonu olarak tanımlanan hibrit mod yöntemini kullanan modal süperpozisyon yöntemi önerilmiştir. Yöntemde, doğrusal olmayan sistemlerin cevapları, altında yatan doğrusal sistem modları yerine hibrit modları kullanarak yazılmıştır. Bu, doğru bir cevap hesaplamasında kullanılması gereken mod sayısını azaltmasının yanında çözülecek doğrusal olmayan denklem sayısını da düşürür. $\mathrm{Bu}$ yolla, cevap hesaplama süresi doğrudan kısaltılır. Çözüm için, hareket denklemleri tanımlayıcı fonksiyon yöntemini kullanarak doğrusal olmayan cebirsel denklem dizisine dönüştürülmüş ve sayısal çözüm, yay uzunluk takibini kullanarak Newton'un yöntemiyle elde edilmiştir. Geliştirilen yöntem iki farklı sistem üzerine uygulanmıştır: bir toplanmış parametreli sistem ve bir sonlu elemanlar modeli. $\mathrm{Bu}$ sistemler kullanılarak çeşitli örnekler sunulmuş ve hibrit mod ile önerilen modal 
süperpozisyon yönteminin hassaslık seviyesi ve hesaplama verimliliği, esas doğrusal sistemin modlarını kullanarak çözüme giden modal süperpozisyon yöntemininkilerle kıyaslanmıştır.

Anahtar Sözcükler: Modal Süperpozisyon Yöntemi, Hibrit Mod Şekli, Doğrusal Olmayan Tireşimler, Tanımlayıcı Fonksiyon Yöntemi, İndirgenmiş Model 
To My Brother Alper 


\section{ACKNOWLEDGMENTS}

First of all, I would like to express my deepest gratitude to my parents for their endless encouragement, patience and love throughout my life. This thesis is a result of their perpetual support behind me.

I would like to express my sincere appreciation to my supervisor, Prof. Dr. H. Nevzat Özgüven for his crucial criticism, leading guidance and supervision. It is my honor to study with him and grab a chance to be his student.

I would also like to express my grateful appreciation to my co-supervisor, Assoc. Prof. Dr. Ender Ciğeroğlu for his excellent help, advice and guidance. This work would not be completed without his technical support and instructions.

I am grateful to my friend Cihan Y1ldırım for his help and support throughout the study. Special thanks to Ali Çağrı Batıhan and Uğur Hayırlı for their criticism and useful discussions. I am also grateful to my friends Burak Gülsaçan, Serdar Hiçdurmaz and Sedat Pala for their moral and support not only for this thesis but also hard times in this period.

Finally, I would like to thank Turkish Aerospace Industries for giving me support throughout this work.

"Not what we have, but what we enjoy, constitutes our abundance."

Epicurus 


\section{TABLE OF CONTENTS}

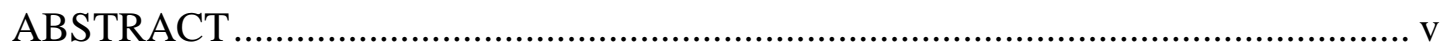

ÖZ

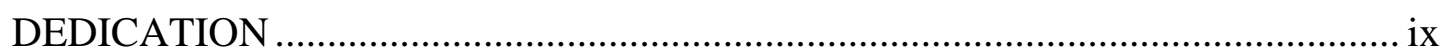

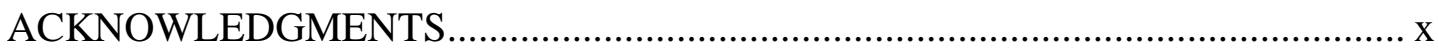

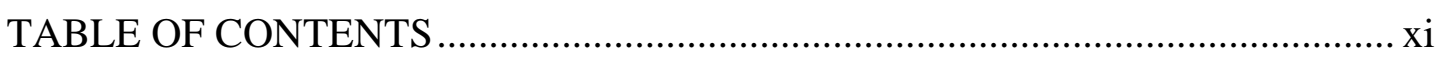

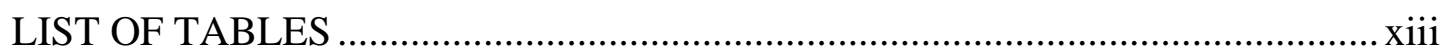

LIST OF FIGURES .............................................................................

LIST OF ABBREVIATIONS .................................................................. xvi

CHAPTERS

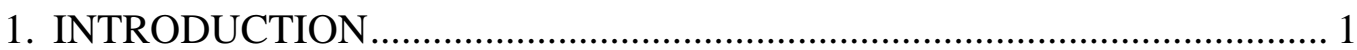

1.1. Nonlinearity in Structures.............................................................. 1

1.2. Literature Survey .................................................................... 4

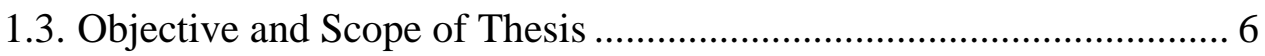

1.4. Outline of the Thesis ....................................................................... 7

2. DYNAMIC RESPONSE ANALYSIS OF NONLINEAR SYSTEMS........... 9

2.1. Nonlinear Vibration Analysis Under Harmonic Excitation ................ 9

2.2. Expression of Nonlinear Harmonics by Using Describing Function

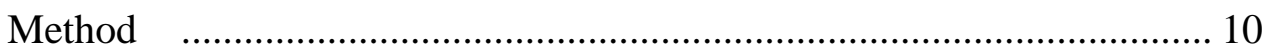

2.3. Modal Superposition Approach to Nonlinear Systems ..................... 12

2.4. Solution of Nonlinear Algeabric Equations ................................... 13

3. THEORY OF A NEW MODAL TECHNIQUE FOR DYNAMIC ANALYSIS OF NONLINEAR SYSTEMS ............................................... 17

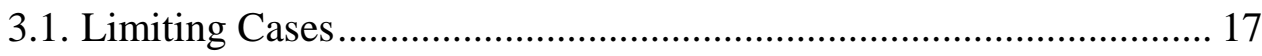




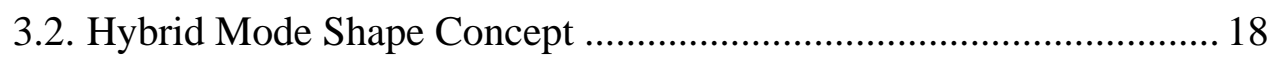

3.3. New Modal Superposition Method Using Hybrid Mode Shapes ....... 22

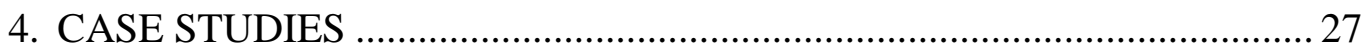

4.1. Lumped Parameter Model ........................................................... 28

4.1.1. Case Study 1: Piecewise Linear Stiffness Element................. 29

4.1.2. Case Study 2: Dry Friction Element ...................................... 38

4.1.3. Case Study 3: Gap and Dry Friction Elements Together.......... 44

4.1.4. Case Study 4: Cubic Stiffness Element................................... 48

4.2. Finite Element Model ..................................................................... 51

4.2.1. Case Study 5: Dry Friction Element ...................................... 53

4.2.2. Case Study 6: Gap Element..................................................... 56

4.2.3. Case Study 7: Gap and Dry Friction Elements Together.......... 66

5. DISCUSSION AND CONCLUSION …..................................................... 71

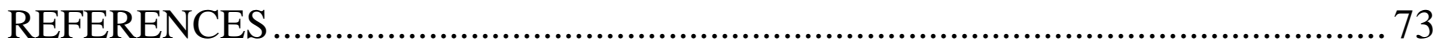

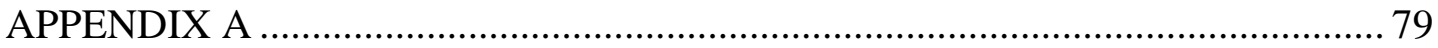




\section{LIST OF TABLES}

\section{TABLES}

Table 1 Nonlinear Element Types Used in the Case Studies.................................. 28

Table 2 Error analysis for the $9^{\text {th }}$ DOF around the first resonance ........................... 34

Table 3 Error analysis for the $9^{\text {th }}$ DOF around the second resonance........................ 35

Table 4 Error analysis for the $10^{\text {th }}$ DOF around the first resonance for the first slip

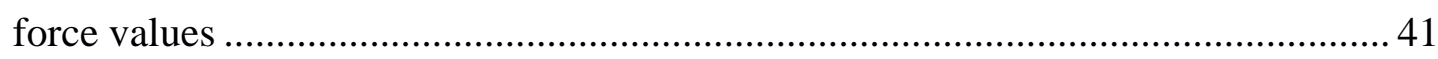

Table 5 Error analysis for the $10^{\text {th }}$ DOF around the first resonance for the second slip

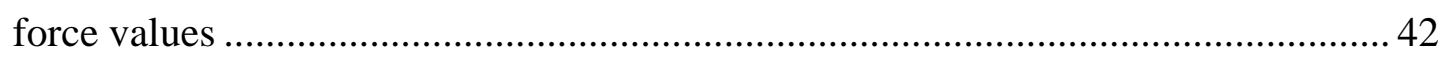

Table 6 Error analysis for the $10^{\text {th }}$ DOF around the first resonance for the third slip

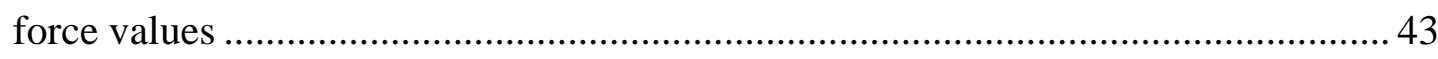

Table 7 Error analysis for the $12^{\text {th }}$ DOF around the first resonance .........................48

Table 8 Error analysis for the $12^{\text {th }}$ DOF around the first resonance ......................... 51

Table 9 Nonlinear Element Types Used in the Case Studies................................. 52

Table 10 Error analysis for the response node around the first resonance.................56

Table 11 Error analysis for the response node around the first resonance................59

Table 12 Error analysis for the $1^{\text {st }}$ point around the first resonance ......................... 61

Table 13 Error analysis for the $2^{\text {nd }}$ point around the first resonance ........................6 61

Table 14 Error analysis for the response node around the first resonance.................6 64

Table 15 Error analysis for the response node around the second resonance............ 64

Table 16 Error analysis for the response node around the third resonance ...............65

Table 17 Error analysis for the response node around the fourth resonance ..............66 66

Table 18 Error analysis for the response node around the first resonance.................69 


\section{LIST OF FIGURES}

\section{FIGURES}

Figure 1 Idealized forms of various types of nonlinearities [1] ............................... 3

Figure 2 A Nonlinear System with Gap Nonlinearity ............................................ 18

Figure 3 Internal Nonlinear Force of Nonlinearities with respect to Displacement .. 27

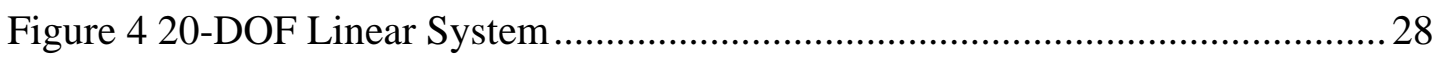

Figure 5 Displacement amplitude of the $9^{\text {th }}$ DOF with respect to frequency............. 30

Figure 6 Effect of modes used on the displacement amplitude of the $9^{\text {th }}$ DOF around the first resonance.

Figure 7 Effect of modes used on the displacement amplitude of the $9^{\text {th }}$ DOF around

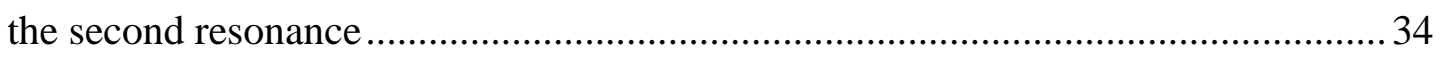

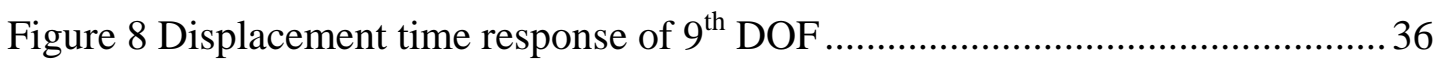

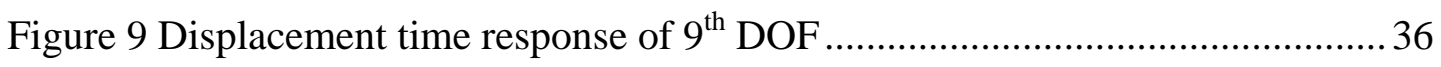

Figure 10 Displacement amplitude of the $9^{\text {th }}$ DOF with respect to frequency............ 37

Figure 11 Displacement amplitudes of the $10^{\text {th }}$ DOF vs. frequency ........................... 39

Figure 12 Effect of modes used on the displacement amplitude of the $10^{\text {th }}$ DOF around the first resonance for the first slip force values ...................................... 40

Figure 13 Effect of modes used on the displacement amplitude of the $10^{\text {th }}$ DOF around the first resonance for the second slip force values.

Figure 14 Effect of modes used on the displacement amplitude of the $10^{\text {th }}$ DOF around the first resonance for the third slip force values ...................................... 43

Figure 15 Variation of weighting factor $\alpha$ with respect to frequency ..................... 44

Figure 16 Displacement amplitudes of the $12^{\text {th }}$ DOF vs. frequency ..........................46

Figure 17 Effect of number of modes used on the displacement amplitude of the $12^{\text {th }}$

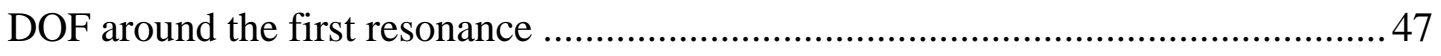

Figure 18 Effect of number of modes used on the displacement amplitude of the $12^{\text {th }}$

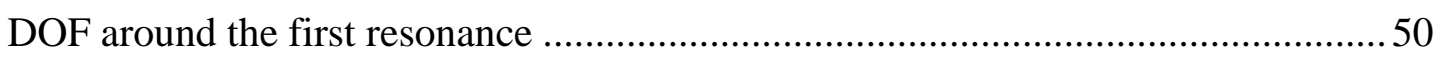

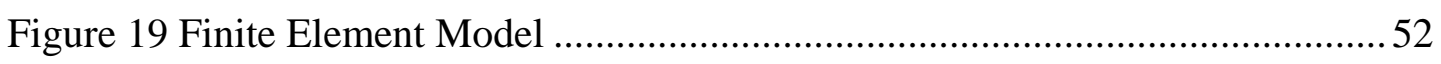

Figure 20 Displacement amplitude of $\mathrm{X}$ component of response node with respect to

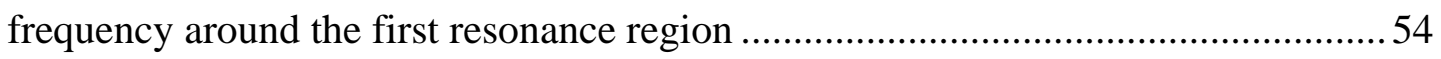


Figure 21 Effect of number of modes used on the displacement amplitude of the response node in X-direction around the first resonance ....................................... 55

Figure 22 Variation of weighting factor $\alpha$ with respect to frequency .....................56 Figure 23 Displacement amplitude of $\mathrm{X}$ component of response node with respect to

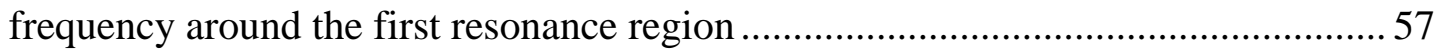

Figure 24 Effect of number of modes used on the displacement amplitude of the response node in X-direction around the first resonance ....................................... 59

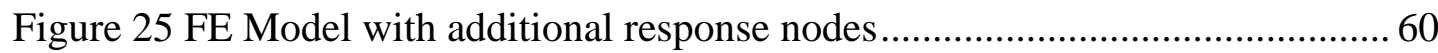

Figure 26 Displacement amplitude of $\mathrm{X}$ component of the $1^{\text {st }}$ point vs. frequency... 60 Figure 27 Displacement amplitude of $X$ component of the $2^{\text {nd }}$ point vs. frequency.. 61

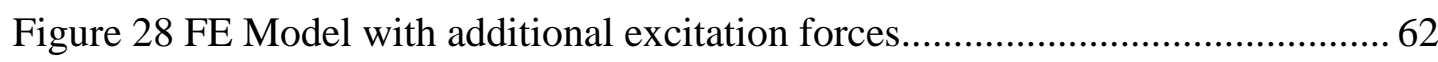
Figure 29 Displacement amplitude of $\mathrm{X}$ component of response node with respect to

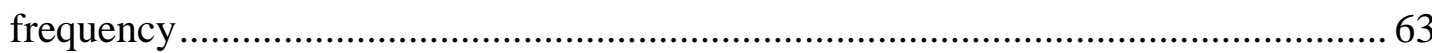

Figure 30 Displacement amplitude of $\mathrm{X}$ component of response node with respect to frequency around the first resonance 63

Figure 31 Displacement amplitude of $\mathrm{X}$ component of response node with respect to frequency around the second resonance. 64

Figure 32 Displacement amplitude of $\mathrm{X}$ component of response node with respect to frequency around the third resonance 65

Figure 33 Displacement amplitude of $\mathrm{X}$ component of response node with respect to frequency around the fourth resonance 66

Figure 34 Displacement amplitude of $\mathrm{X}$ component of response node with respect to frequency around first resonance region 67

Figure 35 Effect of number of modes used on the displacement amplitude of the response node in $\mathrm{X}$-direction around the first resonance 69 


\section{LIST OF ABBREVIATIONS}

DF Describing Function

DFM Describing Function Method

DOF Degree of Freedom

FEM Finite Element Model

FRF Frequency Response Function

HBM Harmonic Balance Method

LC Limiting Case

MDOF Multi Degree of Freedom

NNM Nonlinear Normal Mode 


\section{CHAPTER 1}

\section{INTRODUCTION}

\subsection{Nonlinearity in Structures}

Modal analysis is a well-established and widely used technique for the dynamic analysis of linear systems. It enables one to obtain dynamic characteristics of very large structures quite efficiently. However, its direct application to nonlinear systems is not possible. Therefore, there has been considerable effort to determine dynamic response of structures where nonlinear effects cannot be ignored.

On the other hand, nonlinearity is an unavoidable phenomenon in the all applications of real life. Neglecting nonlinearity in structures may be acceptable if it does not cause drastic changes in dynamic behavior. However, there are frequent occurrences of nonlinearity that should be considered in the design phase of most of the engineering structure. For instance, friction at turbine blades, self-excited vibration phenomenon seen at brake squeal, ground resonance in helicopters, viscoelastic mounts, systems having gap, contacts and hardening nonlinearities.

Deviation of system behavior from linearity is mostly caused by three nonlinear effects.

The first one is geometric nonlinearities where the response of the system is under large deformations. The stiffness of the structure can differ according to the changing geometric configuration. Hardening phenomenon, which is also referred to as stress stiffening, is a widely seen example of this nonlinearity type. The system reacts with high stiffness at large deformation, whereas it exhibits low stiffness at relatively low displacement values. 
Second type of nonlinearity is material nonlinearity. If a system includes an element showing nonlinear behavior such as rubber which has nonlinear stress-strain curve, its dynamic response is controlled by nonlinear effects.

The last kind of nonlinearity is due to contacts. Close touch of two bodies leads to change in stiffness and/or damping. Dry friction is a very-well known nonlinearity of this type.

These cases and further sources of nonlinear behavior cause systems to deviate significantly from linearity, which make the determination of dynamic characteristics troublesome, since nonlinear systems do not exhibit the properties of linear systems. The main distinctions of nonlinear systems from linear systems can be briefly summarized as follows:

- The principle of superposition and proportionality do not hold.

- Higher and lower harmonics appear.

- Self-excited oscillations are possible where small initial conditions grow to a periodic limit cycle.

- Chaotic response can be obtained by deterministic input.

- More than one equilibrium state is possible.

Modelling nonlinearities of real life applications is a challenging issue. In literature, simple nonlinear element models, which are shown in Figure 1, are used to represent nonlinearity. 

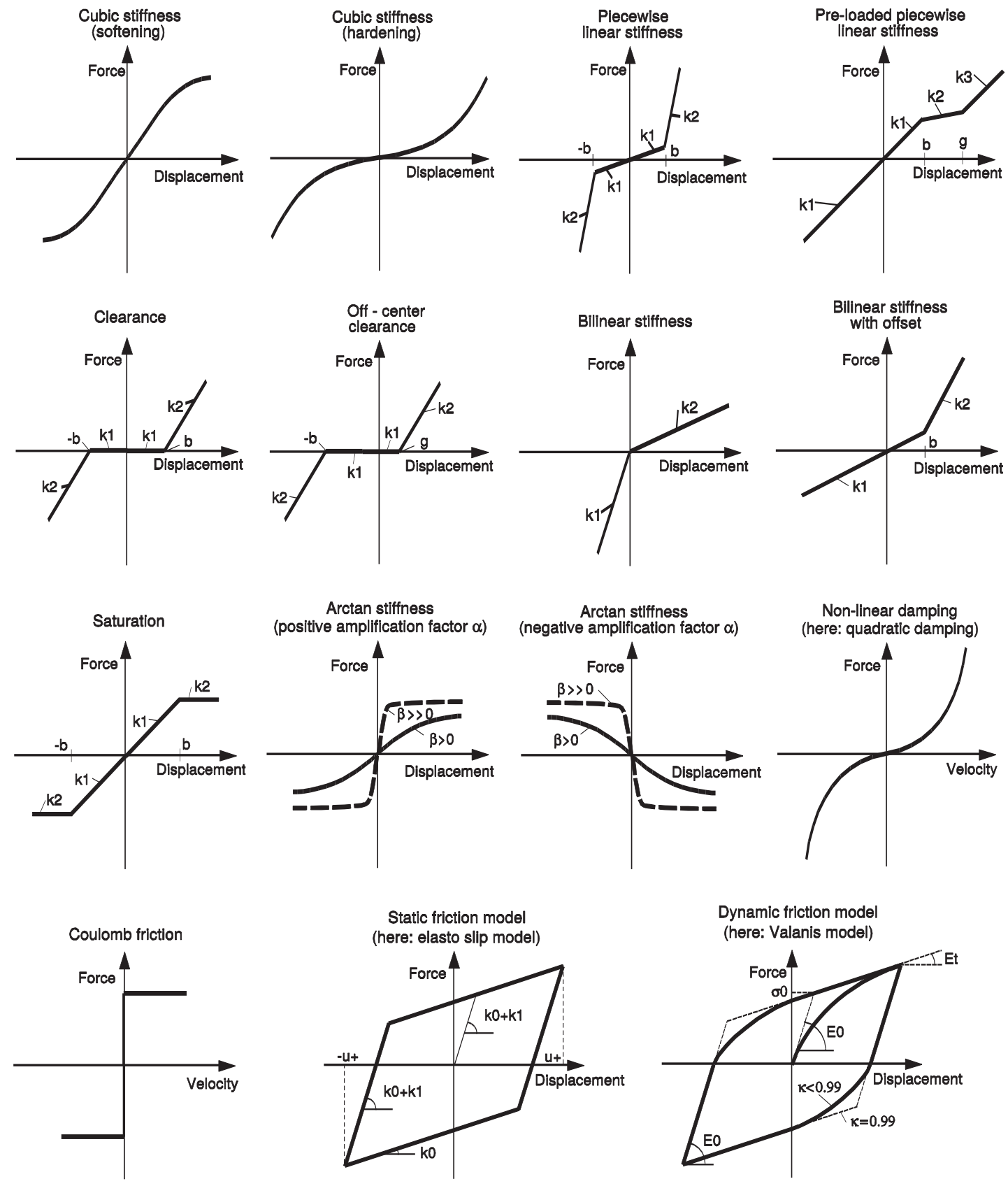

Figure 1 Idealized forms of various types of nonlinearities [1] 


\subsection{Literature Survey}

The first attempts to determine response of nonlinear structures were all time-domain methods, in which the data is taken in the form of time series. Although such methods give reliable results and are relatively straightforward to apply for the dynamic response analysis of nonlinear multi degree of freedom (MDOF) systems [2-4], their application is restricted to small scale problems due to the significant amount of computational time required. Thus, the major effort has been spent to make time-domain methods for MDOF nonlinear systems computationally more efficient $[5,6]$. Yet, time domain methods are still restricted to small scale problems. For large ordered nonlinear systems frequency domain methods were developed starting from 1980s, and still the major studies on the determination of steady state response of large ordered nonlinear systems to periodic excitation are the ones using different forms of harmonic balance method (HBM) which had been successfully applied to single degree of freedom systems long before [7].

In literature, various frequency domain solution methods, particularly to periodic external forcing, have been proposed in order to have accurate steady-state response with reduced computational effort. Earliest studies in harmonic response analysis of MDOF systems have been conducted by Menq et al. [8, 9], Setio et al. [10] and Budak and Özgüven [11, 12]. Menq et al. [8] developed receptance method, in which the number of nonlinear equations to be solved is reduced to a factor of the number of nonlinear elements present in the system by partitioning system degrees of freedom (DOFs) into linear and nonlinear DOFs. In [10], Setio et al. worked on the nonlinear mode superposition approach aiming to obtain a simple and rapid stationary solution which can be applied to real cases of large structures having nonlinear stiffness. Authors showed that truncation of infinite modal coordinates to only few lower modal coordinates can considerably reduce computational time. Budak and Özgüven $[11,12]$ proposed an approach in which different types of nonlinearities are represented by the same general formulation that enables one to express internal nonlinear force vector to write in a multiplication form. Tanrıkulu et al. [13] later generalized the approach presented in [12] by using describing functions 
for the harmonic vibration analysis of MDOF nonlinear systems. Kuran and Özgüven [14] proposed a modal superposition method for nonlinear systems and they showed that using even one mode at the resonance region gives satisfactory results when modes are well separated and nonlinearity does not excite the higher modes of the linear system. Chen and Menq [15] also worked on prediction of the resonant response of frictionally constrained blade systems by using receptance method. Authors used free and constrained mode shapes in the determination of nonlinear system response in order to decrease the computational time further. Cigeroglu et al. $[16,17]$ proposed a modal superposition method for nonlinear forced response analysis of bladed disk systems, which decreases the number of nonlinear equations to be solved significantly compared to receptance method. Petrov [18] studied the effect of number of modes retained in the receptance method, and proposed a model reduction technique that allows the calculation of the high-accuracy FRF matrix and provides accurate forced response results over a wide frequency range. The nonlinear reduced order models presented in $[19,20]$ make the qualitative and quantitative analysis of nonlinear dynamical systems computationally faster and capture response amplitudes quite accurately. Jung et al. [21] and Tien et al. [22] presented bilinear amplitude approximation method for forced response prediction of nonlinear analysis.

Recent studies on the use of HBM for MDOF nonlinear systems in different areas include the application for joints [23, 24], rotor/stator contacts [25], bladed disks [26], geometrically nonlinear beams [27] and plates [28]. In order to improve usability, performance and robustness, researchers tried to develop several types of HBM, including incremental HBM [29], multi-dimensional HBM [30], and the adaptive HBM [31]. Apart from HBM, the describing function method (DFM) proposed as one of the earliest studies on the harmonic vibration analysis of large ordered nonlinear systems [13], also provides a formulation which allows the nonlinear internal force vector to be expressed as a multiplication of the so-called nonlinearity matrix (which is a function of unknown response amplitude vector) with displacement vector. This representation makes it possible to handle nonlinear multi degree of freedom systems more easily in several dynamic analysis problems, such as in structural modification and dynamic coupling applications. 
Moreover, Nonlinear Normal Mode (NNM) concept first proposed by Rosenberg [32] has received attention in further years [33-42], and recently quite a number of new studies have been carried out for the dynamic analysis of nonlinear MDOF systems by using NNM approach [43-48]. NNMs can provide effective bases for constructing reduced-order models of the dynamics of nonlinear oscillators. Touzé [47] showed that using just one NNM in the vicinity of the resonance region captures the dynamic behavior accurately. However, calculation of NNM of a MDOF requires a tedious work and is very expensive in terms of computational effort. Therefore, studies available in the literature that utilize NNM concept focus mostly on the analysis of systems with relatively small number of DOFs.

\subsection{Objective and Scope of Thesis}

Obtaining accurate response by spending less computational effort is a challenging issue for dynamic analysis of nonlinear systems having especially high number of degree of freedoms. In this thesis, a new modal superposition method is presented to improve the performance of capturing dynamic response for nonlinear structures. The method is developed specifically for the systems having nonlinearities where the stiffness of the system may take different limiting values.

Hybrid mode shape concept is utilized to obtain system response. In this way, less number of modes in nonlinear response calculations is used, which enables us to reduce the number of nonlinear equations to be solved, and hence computational time. The proposed method is demonstrated on a lumped parameter model and on a representative finite element model by performing several case studies.

For accuracy considerations, proposed modal superposition method with hybrid mode shapes is compared with the classical modal superposition method which utilizes the mode shapes of the original linear system. 


\subsection{Outline of the Thesis}

Chapter 2 reviews the dynamic response analysis of nonlinear systems under harmonic excitation. It explains mathematical formulation of nonlinear elements based on the describing function method. Classical modal superposition approach, which is used to obtain the nonlinear algebraic equations, is given. Lastly, Newton's method with Arc-length continuation is introduced to solve the equations.

Chapter 3 introduces a new concept for the determination of nonlinear system dynamic response. Firstly, limiting cases, which are the different linear systems for certain type of nonlinearities, is explained. These limiting cases provide different natural frequency and mode shape data. Hybrid mode shape concept is developed and explained using modal information for limiting cases. Lastly, a new modal superposition approach by using hybrid mode shapes is given.

Chapter 4 deals with the validation of the proposed method. It is demonstrated on two different nonlinear systems. Firstly, it is applied on a lumped parameter model having different nonlinear elements. Secondly, dynamic response analysis of a realistic finite element model with the proposed method is given. Different case studies are performed for both models. Results obtained by using the proposed method are compared with those of the classical approach. It is observed from the case studies presented that hybrid mode shapes composed of proper combination of the modes of limiting linear systems provide satisfactory results by keeping the number of modes used in the solution at a minimum.

Chapter 5 concludes the results obtained in this thesis, emphasis being on the contributions and improvements made. It also gives the suggestions for future work in order to enhance the method developed in this study. 


\section{CHAPTER 2}

\section{DYNAMIC RESPONSE ANALYSIS OF NONLINEAR SYSTEMS}

\subsection{Nonlinear Vibration Analysis Under Harmonic Excitation}

Equation of motion of a nonlinear structure under the action of a periodic external forcing can be given as follows

$$
\mathbf{M} \cdot \ddot{\mathbf{x}}+\mathbf{C} \cdot \dot{\mathbf{x}}+i \mathbf{H} \cdot \mathbf{x}+\mathbf{K} \cdot \mathbf{x}+\mathbf{f}_{N}(\mathbf{x})=\mathbf{f}(t)
$$

where $\mathbf{M}, \mathbf{C}, \mathbf{H}$ and $\mathbf{K}$ represent the mass, viscous damping, structural damping, and stiffness matrices of the linear system, respectively. $\mathbf{f}_{N}(\mathbf{x})$ and $\mathbf{f}(t)$ are vectors of the internal nonlinear forcing and external excitation, respectively. Here, $\mathbf{x}$ is the vector of displacements and dot denotes differentiation with respect to time and $i$ is the unit imaginary number.

Response of a nonlinear system to periodic excitation in general can be periodic, quasi-periodic or chaotic [49]. However, most of the time response of a nonlinear system to periodic excitation can be assumed periodic, some examples of which can be seen in $[21,22,50]$. Since the focus of this study is to find the steady-state solutions of the nonlinear system, only periodic solutions which are of importance in the design of several mechanical systems are considered. If one is interested in the stability of the periodic solutions obtained, any method [51], such as Hill's method [25], available in the literature can be used for this purpose. Therefore, external forcing and response vectors can be written as follows

$$
\mathbf{f}=\mathbf{f}_{0}+\sum_{m=1}^{N_{h}} \mathbf{f}_{m}^{*} e^{i m \omega t}
$$




$$
\mathbf{x}=\mathbf{x}_{0}+\sum_{m=1}^{N_{h}} \mathbf{x}_{m}^{*} e^{i m \omega t}
$$

where $\mathbf{f}_{m}^{*}$ and $\mathbf{x}_{m}^{*}$ are the $m^{\text {th }}$ harmonic complex amplitude vectors of the external forcing and response, respectively. $\mathbf{f}_{0}$ and $\mathbf{x}_{0}$ are the bias components of the external forcing and nonlinear response vectors, which are real. $N_{h}$ represents the total number of harmonics in the above expressions which is considered to be the same for both external forcing and response.

Similarly, for periodic motion the internal nonlinear forcing vector can be written as

$$
\mathbf{f}_{N}=\mathbf{f}_{n l, 0}+\sum_{m=1}^{N_{p}} \mathbf{f}_{n l, m}^{*} e^{i m \omega t},
$$

where, $\mathbf{f}_{n l, 0}$ is the real bias amplitude vector and $\mathbf{f}_{n l, m}^{*}$ is the $m^{\text {th }}$ harmonic complex amplitude vector of the internal nonlinear forcing.

\subsection{Expression of Nonlinear Harmonics by Using Describing Function Method}

The nonlinear internal forcing vector, $\mathbf{f}_{N}(\mathbf{x})$, can be written as a matrix multiplied by displacement vector as

$$
\mathbf{f}_{N}(\mathbf{x})=\boldsymbol{\Delta}(\mathbf{x}) \cdot \mathbf{x}=\left(\boldsymbol{\Delta}_{r e}(\mathbf{x})+i \boldsymbol{\Delta}_{i m}(\mathbf{x})\right) \cdot \mathbf{x},
$$

if only a single harmonic is used. Here, $\Delta(\mathbf{x})$ is the displacement or velocity dependent complex nonlinearity matrix, $\boldsymbol{\Delta}_{r e}(\mathbf{x})$ and $\boldsymbol{\Delta}_{i m}(\mathbf{x})$ are the real and imaginary parts, respectively. Elements of the complex nonlinearity matrix can be obtained as follows [13]

$$
\boldsymbol{\Delta}_{k k}=v_{k k}+\sum_{\substack{j=1 \\ j \neq k}}^{n} v_{k j} \quad \text { and } \quad \boldsymbol{\Delta}_{k j}=-v_{k j},
$$


where $v_{k j}$ is the harmonic input describing function of a nonlinear element in the system and can be described as equivalent complex stiffness for the internal nonlinear force, $f_{N}^{k j}$ acting between the $k^{\text {th }}$ and the $j^{\text {th }}$ coordinates. Single harmonic describing function, $v_{k j}$ is given as follows [13]

$$
v_{k j}=\frac{i}{\pi Y_{k j}} \int_{0}^{2 \pi} f_{N}^{k j}\left(Y_{k j}, \psi\right) e^{-i \psi} d \psi, \quad \psi=\omega \mathrm{t}
$$

where

$$
Y_{k j}= \begin{cases}X_{k}-X_{j} & \text { for } k \neq j \\ X_{k} & \text { for } k=j\end{cases}
$$

$X_{k}$ is the complex displacement amplitude of the $k^{\text {th }}$ degree of freedom.

Substituting Eq.(2.5) into Eq.(2.1)

$$
\mathbf{M} \cdot \ddot{\mathbf{x}}+\mathbf{C} \cdot \dot{\mathbf{x}}+i\left(\mathbf{H}+\boldsymbol{\Delta}_{i m}\right) \cdot \mathbf{x}+\left(\mathbf{K}+\boldsymbol{\Delta}_{r e}\right) \cdot \mathbf{x}=\mathbf{f}(t)
$$

Considering a single harmonic in the representation of the external forcing and response vectors given by Eqs. (2.2) and (2.3), the following set of nonlinear equations is obtained

$$
\left[\left(\mathbf{K}+\boldsymbol{\Delta}_{r e}\right)-\omega^{2} \mathbf{M}+i\left(\mathbf{H}+\boldsymbol{\Delta}_{i m}\right)+i \omega \mathbf{C}\right] \cdot \mathbf{x}^{*}=\mathbf{f}^{*}
$$

Since only a single harmonic representation is used, the subscript $m$ is dropped in Eq. (2.10). It can be seen from Eq. (2.9) that real part of the nonlinearity matrix changes the overall stiffness matrix of the system; whereas, the imaginary part modifies the overall structural damping matrix. 


\subsection{Modal Superposition Approach to Nonlinear Systems}

Using expansion theorem, response of the nonlinear system can be written in terms of its linear mode shapes as follows $[10,14]$

$$
\mathbf{x}^{*}=\sum_{r=1}^{N} a_{r} \phi^{r}=\boldsymbol{\Phi} \cdot \mathbf{a},
$$

where $\boldsymbol{\Phi}$ is the mass normalized modal matrix of the linear system excluding the nonlinearities, $\mathbf{a}$ is the complex vector of modal coefficients and $N$ is the number of modes used in the expansion. Substituting this equation in Eq. (2.10) and multiplying both sides by $\boldsymbol{\Phi}^{T}$ from the left, the following set of nonlinear algebraic equation in terms of unknown modal coefficient vector is obtained

$$
\left[\left(\boldsymbol{\Omega}+\boldsymbol{\Phi}^{T} \boldsymbol{\Delta}_{r e} \boldsymbol{\Phi}\right)-\omega^{2} \mathbf{I}+i \boldsymbol{\Phi}^{T}\left(\mathbf{H}+\boldsymbol{\Delta}_{i m}\right) \boldsymbol{\Phi}+i \omega \boldsymbol{\Phi}^{T} \mathbf{C} \boldsymbol{\Phi}\right] \cdot \mathbf{a}=\boldsymbol{\Phi}^{T} \mathbf{f}^{*}
$$

where $\boldsymbol{\Omega}$ is the matrix of squares of natural frequencies. In the expansion process, the number of modes of the linear system used is much less than the total DOFs of the system; therefore, the number of nonlinear equations defined by Eq. (2.12) is significantly reduced. Being different from the modal analysis of linear systems, here the solution of Eq. (2.12) requires iteration since nonlinearity matrix is response level dependent. It should be noted that multiple harmonics can be easily used in the modal superposition method where Eq. (2.12) is repeated for each harmonic by replacing $\omega$ with $p \omega$, where $p$ corresponds to the harmonic included in the solution. 


\subsection{Solution of Nonlinear Algeabric Equations}

A set of $n$ nonlinear ordinary differential equations, Eq. (2.1), is firstly converted to a set of $n$ nonlinear complex algebraic equations, Eq. (2.12), for the nonlinear analysis explained above. The fundamental harmonic response of the structure can be determined by using Newton's Method with Arc-length Continuation.

The nonlinear algebraic equation set given in Eq. (2.12) can be written as a residual vector function as

$$
\mathbf{R}(\mathbf{a}, \omega)=\left[\left(\boldsymbol{\Omega}+\boldsymbol{\Phi}^{T} \boldsymbol{\Delta}_{r e} \boldsymbol{\Phi}\right)-\omega^{2} \mathbf{I}+i \boldsymbol{\Phi}^{T}\left(\mathbf{H}+\boldsymbol{\Delta}_{i m}\right) \boldsymbol{\Phi}+i \omega \boldsymbol{\Phi}^{T} \mathbf{C} \boldsymbol{\Phi}\right] \cdot \mathbf{a}-\boldsymbol{\Phi}^{T} \mathbf{f}=\mathbf{0}
$$

Eq. (2.13) can be expanded in Taylor Series around $\mathbf{a}$ as

$$
\mathbf{R}(\mathbf{a}+\Delta \mathbf{a}, \omega)=\mathbf{R}(\mathbf{a}, \omega)+\mathbf{J}(\mathbf{a}, \omega) \cdot \Delta \mathbf{a}+\mathbf{O}\left(\Delta \mathbf{a}^{2}\right),
$$

where $\mathbf{J}$ is the Jacobian Matrix, and it can be calculated as

$$
\mathbf{J}(\mathbf{a}, \omega)=\frac{\partial \mathbf{R}(\mathbf{a}, \omega)}{\partial \mathbf{a}}
$$

Neglecting higher order terms and taking $\mathbf{R}(\mathbf{a}+\Delta \mathbf{a})=\mathbf{0}$, at each frequency, $\omega_{k}$, an iterative solution is obtained by using

$$
\mathbf{a}_{k}^{i+1}=\mathbf{a}_{k}^{i}-\left(\mathbf{J}\left(\mathbf{a}_{k}^{i}, \omega_{k}\right)\right)^{-1} \cdot \mathbf{R}\left(\mathbf{a}_{k}^{i}, \omega_{k}\right) .
$$

where $\mathbf{a}_{k}^{i}$ is the complex coefficient vector at $k^{\text {th }}$ frequency $\omega_{k}$ and at $i^{\text {th }}$ iteration, $\mathbf{J}\left(\mathbf{a}_{k}^{i}, \omega_{k}\right)$ and $\mathbf{R}\left(\mathbf{a}_{k}^{i}, \omega_{k}\right)$ are the Jacobian Matrix and the residual function evaluated at $\mathbf{a}_{k}^{i}$ and $\omega_{k}$, respectively. 
Convergence to correct solution in Newton's Method is obtained if the given initial guess is sufficiently close to the actual solution. However, in nonlinear systems, there may be jump phenomena where the Jacobian becomes singular. Then, a new parameter, Arc-length parameter, may be added to the unknown vector in order to trace the solution in unstable region. This new path following parameter can be defined as the radius of a hypothetical $n$-dimensional sphere in which the next solution is searched. Since the number of unknowns increases by one with the addition of a new parameter, one more equation is needed to solve the system. This equation comes from the equation of the $n$-dimensional sphere centered at the previous converged solution point which can be expressed as

$$
\left(\Delta \mathbf{q}_{k}^{i}\right)^{T} \cdot \Delta \mathbf{q}_{k}^{i}=\mathrm{s}^{2}
$$

where $\mathrm{s}$ is the radius of the arc length. Here, $\mathbf{q}_{k}^{i}$ is the new vector of unknowns at the $i^{\text {th }}$ solution point which is given as

$$
\mathbf{q}_{k}^{i}=\left\{\begin{array}{c}
\mathbf{a}_{k}^{i} \\
\omega_{k}^{i}
\end{array}\right\} .
$$

and

$$
\Delta \mathbf{q}_{k}^{i}=\mathbf{q}_{k}^{i}-\mathbf{q}_{k}^{i-1}
$$

Therefore the new equation added to the system can be written as

$$
\mathbf{h}\left(\mathbf{a}_{k}^{i}, \omega_{k}^{i}\right)=\left(\Delta \mathbf{q}_{k}^{i}\right)^{T} \cdot \Delta \mathbf{q}_{k}^{i}-\mathrm{s}^{2}=0,
$$

Therefore, Newton's iteration for the new system of equations becomes

$$
\mathbf{q}_{k}^{i+1}=\mathbf{q}_{k}^{i}-\left[\left.\begin{array}{cc}
\frac{\partial \mathbf{R}(\mathbf{a}, \omega)}{\partial \mathbf{a}} & \frac{\partial \mathbf{R}(\mathbf{a}, \omega)}{\partial \omega} \\
\frac{\partial \mathbf{h}(\mathbf{a}, \omega)}{\partial \mathbf{a}} & \frac{\partial \mathbf{h}(\mathbf{a}, \omega)}{\partial \omega}
\end{array}\right|_{\mathbf{a}_{k}^{i}, \omega_{k}^{i}} \times\left\{\begin{array}{c}
\mathbf{R}\left(\mathbf{a}_{k}^{i}, \omega_{k}^{i}\right) \\
\mathbf{h}\left(\mathbf{a}_{k}^{i}, \omega_{k}^{i}\right)
\end{array}\right\} .\right.
$$


where the last row of the new Jacobian matrix can be obtained as follows

$$
\left[\left.\begin{array}{ll}
\frac{\partial \mathbf{h}(\mathbf{a}, \omega)}{\partial \mathbf{a}} & \frac{\partial \mathbf{h}(\mathbf{a}, \omega)}{\partial \omega}
\end{array}\right|_{\mathbf{a}_{k}^{i}, \omega_{k}^{i}}=\left[2 \Delta \mathbf{q}_{k}^{i}\right]^{T} .\right.
$$

During the solution procedure, first order estimators, which are calculated by using the Jacobian inverse found at the previously converged solution, are used. Detailed information on Newton's Method with Arc-length Continuation can be found in [25, $52,53]$. 


\section{CHAPTER 3}

\section{THEORY OF A NEW MODAL TECHNIQUE FOR DYNAMIC ANALYSIS OF NONLINEAR SYSTEMS}

\subsection{Limiting Cases}

For certain type of nonlinear elements, the nonlinearity matrix may become constant at the limiting cases where the displacement amplitudes are smaller or greater than a certain value. This occurs if the nonlinearity is piecewise linear as in the case of gap nonlinearity or piecewise linear stiffness nonlinearity etc., or if the nonlinearity saturates as in the case of dry friction nonlinearity. In such cases, since the nonlinearity matrices do not depend on the displacement amplitude, new linear systems can be defined as follows

$$
\begin{array}{ll}
\mathbf{M} \cdot \ddot{\mathbf{x}}+\mathbf{C} \cdot \dot{\mathbf{x}}+i\left(\mathbf{H}+\boldsymbol{\Delta}_{i m_{1}}\right) \cdot \mathbf{x}+\mathbf{K}_{1} \cdot \mathbf{x}=\mathbf{f}(t) & \text { Condition } 1 \\
\vdots & \vdots \\
\mathbf{M} \cdot \ddot{\mathbf{x}}+\mathbf{C} \cdot \dot{\mathbf{x}}+i\left(\mathbf{H}+\boldsymbol{\Delta}_{i m_{l}}\right) \cdot \mathbf{x}+\mathbf{K}_{l} \cdot \mathbf{x}=\mathbf{f}(t) & \text { Condition } l \\
& \\
\mathbf{K}_{l}=\mathbf{K}+\boldsymbol{\Delta}_{r e l l}, &
\end{array}
$$

where $\mathbf{K}_{l}$ is the stiffness matrix of the $l^{\text {th }}$ limiting case. In these equations, $\Delta_{r e, l}$ and $\boldsymbol{\Delta}_{i m, 1}$ are the real and imaginary parts of the constant nonlinearity matrix for the $l^{t h}$ limiting case. For the sake of simplicity, the number of limiting cases considered in the rest of the thesis is taken as two. However, proposed method is applicable to systems with limiting cases more than two. Utilizing these new stiffness matrices, a new eigenvalue problem can be defined for each case as follows 


$$
\left(\mathbf{K}_{l}-\lambda_{l} \mathbf{M}\right) \cdot \mathbf{x}_{l}=\mathbf{0}, \quad l=1,2 .
$$

Solution of this eigenvalue problem gives eigenvalues $\lambda_{l_{i}}, i=1,2, \ldots, n$, which are the squares of the natural frequencies, and mass normalized modal matrix $\boldsymbol{\Phi}_{l}$ of the $l^{\text {th }}$ limiting case.

For better illustration of limiting cases, consider a two degree of freedom (DOF) nonlinear system with a gap element as shown Figure 2(a). When the nonlinear element is never in contact with the mass as shown in Figure 2(b) the first limiting case is obtained. In this case, the total stiffness between the ground and the first mass becomes $k$.Solution of the eigenvalue problem for this case gives the eigenvalues $\left(\begin{array}{ll}\lambda_{1} & \lambda_{1_{2}}\end{array}\right)^{T}$ and modal vectors $\boldsymbol{\Phi}_{1}$ for the first limiting case, respectively. Similarly, when the nonlinear element is always in contact with the mass as shown in Figure 2(c), in the second limiting case, the total stiffness between the ground and the first mass becomes $k+k_{g}$. Eigenvalues and modal vectors obtained for the second case $\operatorname{are}\left(\begin{array}{ll}\lambda_{2_{1}} & \lambda_{2_{2}}\end{array}\right)^{T}$ and $\boldsymbol{\Phi}_{2}$, respectively.
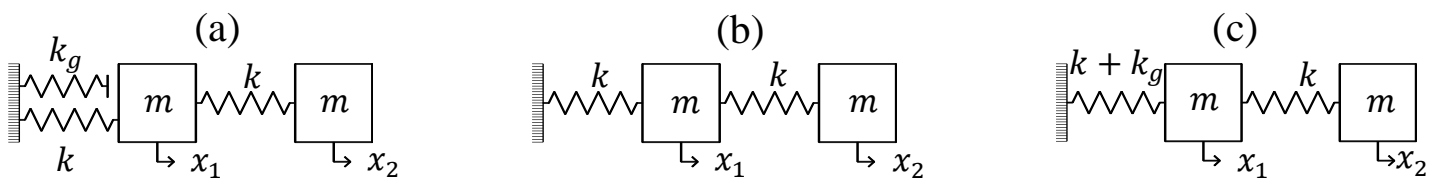

Figure 2 A Nonlinear System with Gap Nonlinearity

\subsection{Hybrid Mode Shape Concept}

The number of linear system modes required in modal superposition method depends on how good the linear modes span the nonlinear response space. If the deviation of the nonlinear system from the linearized system is small, the number of mode shapes 
required can be minimized. For systems with piecewise nonlinear elements such as gap nonlinearity, piecewise linear stiffness, etc. and/or saturating nonlinear elements such as dry friction nonlinearity, the nonlinearity matrix obtained by DFM approaches to a limiting case. Therefore, for such cases, depending on the response amplitude it is possible to define different linear systems, mode shapes of which span the nonlinear response space better than the mode shapes of the linear system obtained by disregarding nonlinear elements. In this thesis, these linear systems are referred to as limiting cases or limiting linear cases. It should be noted that, when the mode shapes of the linear system used in the modal superposition approach deviate less from the nonlinear system modes, i.e. when the mode shape vectors span the nonlinear response space better, less number of modes is required to obtain an accurate representation of the response of the nonlinear system. This is in agreement with the approach used by Cigeroglu and Özgüven [50]. In [50], authors decompose the nonlinear microslip friction element into two parts: a linear stiffness and a nonlinear macroslip element. Then they include the linear stiffness part into the linear system, which improves the convergence property of the nonlinear solution. For the sake of simplicity, only two limiting cases are considered in the rest of the thesis. However, the method proposed here is applicable to cases with more than two limiting cases as well.

For a nonlinear system with two limiting cases, the nonlinear equation of motion defined by Eq. (2.9) can be written in the following forms

$$
\begin{gathered}
\mathbf{M} \cdot \ddot{\mathbf{x}}+\mathbf{C} \cdot \dot{\mathbf{x}}+i \mathbf{H}_{1} \cdot \mathbf{x}+\mathbf{K}_{1} \cdot \mathbf{x}+\Delta_{1} \cdot \mathbf{x}=\mathbf{f}(t), \\
\mathbf{M} \cdot \ddot{\mathbf{x}}+\mathbf{C} \cdot \dot{\mathbf{x}}+i \mathbf{H}_{2} \cdot \mathbf{x}+\mathbf{K}_{2} \cdot \mathbf{x}+\boldsymbol{\Delta}_{2} \cdot \mathbf{x}=\mathbf{f}(t),
\end{gathered}
$$

where

$$
\begin{gathered}
\mathbf{K}_{1}=\mathbf{K}+\boldsymbol{\Delta}_{r e, l 1}, \quad \mathbf{H}_{1}=\mathbf{H}+\boldsymbol{\Delta}_{i m, l 1}, \quad \mathbf{K}_{2}=\mathbf{K}+\boldsymbol{\Delta}_{r e, l 2}, \quad \mathbf{H}_{2}=\mathbf{H}+\boldsymbol{\Delta}_{i m, l 2}, \\
\boldsymbol{\Delta}_{l 1}=\boldsymbol{\Delta}_{r e, l 1}+i \boldsymbol{\Delta}_{i m, l 1}, \quad \boldsymbol{\Delta}_{l 2}=\boldsymbol{\Delta}_{r e, l 2}+i \boldsymbol{\Delta}_{i m, l 2}, \quad \boldsymbol{\Delta}_{1}=\boldsymbol{\Delta}-\boldsymbol{\Delta}_{l 1}, \quad \boldsymbol{\Delta}_{2}=\boldsymbol{\Delta}-\boldsymbol{\Delta}_{l 2} .
\end{gathered}
$$


$\Delta_{l j}=\Delta_{r e, l j}+i \Delta_{i m, l j}$ is the complex nonlinearity matrix for the $j^{\text {th }}$ limiting case, which is constant and does not change with the response. It should be noted that since $i \mathbf{H}_{1}+\mathbf{K}_{1}+\boldsymbol{\Delta}_{1}=i \mathbf{H}_{2}+\mathbf{K}_{2}+\boldsymbol{\Delta}_{2}=i \mathbf{H}+\mathbf{K}+\boldsymbol{\Delta}$, Eq. (3.4) and Eq.(3.5) are identical to each other. If $\Delta_{1}$ is small, less number of mode shapes of limiting case 1 is required to approximate the nonlinear dynamics compared to the same accuracy of dynamic response obtained by using mode shapes of limiting case 2 . It should be noted that at the limit where $\boldsymbol{\Delta}_{1}=\mathbf{0}$, a linear system is obtained and the lowest possible number of modes of limiting case 1 can be used to approximate the system response. Similarly, if $\Delta_{2}$ is small, less number of modes of limiting case 2 is required to represent the nonlinear response with the same accuracy compared to limiting case 1 which is in agreement with the findings of Chen and Menq [15]. However, if the complex nonlinearity matrix is not close to any of the limiting cases, the number of modes used in the process can be decreased by using a linear combination of the mode shapes of the limiting cases and, in this work, it is referred to as hybrid mode shape and defined as follows

$$
\boldsymbol{\Phi}_{h}=\alpha \boldsymbol{\Phi}_{2}+(1-\alpha) \boldsymbol{\Phi}_{1}
$$

Here $\boldsymbol{\Phi}_{h}$ is the hybrid modal matrix, $\boldsymbol{\Phi}_{1}$ and $\boldsymbol{\Phi}_{2}$ are the mass normalized modal matrices of the limiting case 1 and 2, respectively and $\alpha$ is a weighting factor changing between 0 and 1 . If $\alpha=0$, only mode shapes of limiting case 1 are used and if $\alpha=1$, only the mode shapes of limiting case 2 are used. Proper selection of $\alpha$ is the key to decrease the number of hybrid modes required in the solution of the nonlinear system. It can be seen from Eq. (2.7) that describing function, $v$, is a complex quantity and can be decomposed into real and imaginary parts as

$$
v=v_{r e}+i v_{i m}
$$

During the solution process, the numerical value of describing function for each nonlinearity is recalculated at every iteration step. Comparing the real part of the 
describing function, i.e. equivalent stiffness, with respect to its limiting value, this weighting factor can be defined as follows

$$
\alpha=\sum_{i=1}^{N l} \frac{v_{r e_{i}}}{k_{i}^{*}},
$$

where $0 \leq \alpha \leq 1, k^{*}{ }_{i}$ is the maximum limiting value of the equivalent stiffness of the $i^{\text {th }}$ nonlinear element and $N_{l}$ is the total number of nonlinear elements attached to the interested DOF. Here, it is assumed that the maximum limiting value of the equivalent stiffness occurs for limiting case 2 , and the minimum value occurs for limiting case 1 . It is important to note that even though hybrid mode shape concept is proposed for piecewise linear or saturated nonlinearities for which equivalent stiffness converges to a constant value, depending on the vibration amplitude, it can as well be defined for any nonlinearity by considering a maximum vibration amplitude that may occur in the analysis as the limiting case. For instance, nonlinearities showing exponential behavior with respect to displacement or cubic stiffness may be given as examples for such cases. Regarding these types of nonlinearities, maximum vibration amplitude can be roughly anticipated by monitoring linear response of the system before starting nonlinear analysis, and then a limiting linear case can be defined by addition of the approximated equivalent stiffness of the nonlinearities, i.e. describing functions, for the anticipated response of the system. After the construction of limiting cases, hybrid mode shapes are determined and proposed approach can be applied for the solution of the nonlinear system. 


\subsection{New Modal Superposition Method Using Hybrid Mode Shapes}

Response of a nonlinear system can be written in terms of hybrid mode shapes as

$$
\mathbf{x}(t)=\boldsymbol{\Phi}_{h} \cdot \mathbf{a} e^{i \omega t}
$$

Substituting Eq. (3.11) into Eq. (2.9) and pre-multiply by both sides by $\boldsymbol{\Phi}_{h}{ }^{T}$ the following equation is obtained

$$
\begin{aligned}
& {\left[-\omega^{2} \cdot \boldsymbol{\Phi}_{h}{ }^{T} \mathbf{M} \boldsymbol{\Phi}_{h}+i \omega \cdot \boldsymbol{\Phi}_{h}{ }^{T} \mathbf{C} \boldsymbol{\Phi}_{h}+\right.} \\
& \left.\boldsymbol{\Phi}_{h}{ }^{T}(\mathbf{K}+i \mathbf{H}) \boldsymbol{\Phi}_{h}+\boldsymbol{\Phi}_{h}{ }^{T} \boldsymbol{\Delta}(\mathbf{a}) \boldsymbol{\Phi}_{h}\right] \cdot \mathbf{a}=\boldsymbol{\Phi}_{h}{ }^{T} \cdot \mathbf{f}^{\prime}
\end{aligned}
$$

where $\mathbf{a}$ is the complex vector of modal coefficients. In this nonlinear equation set, the unknowns are the modal coefficients given by vector $\mathbf{a}$. In case multiple harmonics are used in HBM, Eq. (3.12) is repeated for each harmonic by simply replacing $\omega$ with $p \omega$ as described in Section 2.3. It should be noted that hybrid mode shapes are not orthogonal with respect to mass and stiffness matrices of the original linear system; hence, Eq. (3.12) contains system matrices which do not appear in Eq. (2.12). If we expand the first term in Eq. (3.12), the following equation is obtained

$$
\begin{aligned}
\boldsymbol{\Phi}_{h}{ }^{T} \mathbf{M} \boldsymbol{\Phi}_{h}= & (1-\alpha)^{2} \cdot \boldsymbol{\Phi}_{1}^{T} \mathbf{M} \boldsymbol{\Phi}_{1}+\alpha^{2} \cdot \boldsymbol{\Phi}_{2}{ }^{T} \mathbf{M} \boldsymbol{\Phi}_{2}+ \\
& (1-\alpha) \alpha \cdot \boldsymbol{\Phi}_{1}^{T} \mathbf{M} \boldsymbol{\Phi}_{2}+(1-\alpha) \alpha \cdot \boldsymbol{\Phi}_{2}{ }^{T} \mathbf{M} \boldsymbol{\Phi}_{1}
\end{aligned}
$$

Since both limiting linear system modal matrices, i.e. $\boldsymbol{\Phi}_{1}$ and $\boldsymbol{\Phi}_{2}$, are orthogonal with respect to the mass matrix, $\boldsymbol{\Phi}_{1}^{T} \mathbf{M} \boldsymbol{\Phi}_{1}$ and $\boldsymbol{\Phi}_{2}{ }^{T} \mathbf{M} \boldsymbol{\Phi}_{2}$ are equal to identity matrix. Moreover, it should be noted that for a self adjoint system, mass matrix is symmetric and therefore, $\boldsymbol{\Phi}_{2}{ }^{T} \mathbf{M} \boldsymbol{\Phi}_{1}$ is equal to the transpose of $\boldsymbol{\Phi}_{1}^{T} \mathbf{M} \boldsymbol{\Phi}_{2}$. Therefore, final form of Eq. (3.13) is obtained as follows 


$$
\boldsymbol{\Phi}_{h}{ }^{T} \mathbf{M} \boldsymbol{\Phi}_{h}=\left[(1-\alpha)^{2}+\alpha^{2}\right] \cdot \mathbf{I}+(1-\alpha) \alpha \cdot\left[\boldsymbol{\Phi}_{1}^{T} \mathbf{M} \boldsymbol{\Phi}_{2}+\left(\boldsymbol{\Phi}_{1}^{T} \mathbf{M} \boldsymbol{\Phi}_{2}\right)^{T}\right] .
$$

The same procedure can also be applied to the term that contains the stiffness matrix in Eq. (3.13) which gives the following result as

$$
\begin{aligned}
\boldsymbol{\Phi}_{h}{ }^{T} \mathbf{K} \boldsymbol{\Phi}_{h}= & (1-\alpha)^{2} \cdot \boldsymbol{\Omega}_{1}+\alpha^{2} \cdot\left(\boldsymbol{\Omega}_{2}-\boldsymbol{\Phi}_{2}{ }^{T} \Delta \mathbf{K} \boldsymbol{\Phi}_{2}\right)+ \\
& (1-\alpha) \alpha \cdot\left[\boldsymbol{\Phi}_{1}{ }^{T} \mathbf{K} \boldsymbol{\Phi}_{2}+\left(\boldsymbol{\Phi}_{1}{ }^{T} \mathbf{K} \boldsymbol{\Phi}_{2}\right)^{T}\right],
\end{aligned}
$$

where $\Delta \mathbf{K}=\mathbf{K}_{2}-\mathbf{K}_{1}, \boldsymbol{\Omega}_{1}$ and $\boldsymbol{\Omega}_{2}$ are diagonal matrices composed of squares of natural frequencies of the first and the second limiting linear cases, respectively.

It can be seen from Eqs. (3.14) and (3.15) that system matrices still appear in the equation. This might be a problem for realistic finite element models, since very large matrices need to be stored and used in the calculations. In order to overcome this problem, we define a square matrix $\mathbf{Q}$ such that the following equation is satisfied

$$
\boldsymbol{\Phi}_{2}=\boldsymbol{\Phi}_{1} \cdot \mathbf{Q}
$$

Pre-multiplying both sides of the Eq. (3.16) with the pseudo-inverse of $\boldsymbol{\Phi}_{1}$, the following result is obtained

$$
\boldsymbol{\Phi}_{1}^{+} \boldsymbol{\Phi}_{2}=\boldsymbol{\Phi}_{1}^{+} \boldsymbol{\Phi}_{1} \cdot \mathbf{Q}
$$

If all modes of the first limiting linear system are used, $\boldsymbol{\Phi}_{1}^{+} \boldsymbol{\Phi}_{1}$ results in identity matrix and hence, $\mathbf{Q}$ is obtained as follows

$$
\mathbf{Q}=\boldsymbol{\Phi}_{1}^{+} \boldsymbol{\Phi}_{2}
$$


It should be noted that contribution of higher modes to system response at lower frequencies is negligible and in practical problems only a limited number of mode shapes are used in modal superposition approach. This results in a significant decrease in the number of nonlinear equations to be solved by omitting the effect of higher modes. Therefore, Eq. (3.18) can still be used for the systems having large number of DOFs. Substituting Eq. (3.18) into Eq. (3.16) the following result is obtained

$$
\boldsymbol{\Phi}_{2}=\boldsymbol{\Phi}_{1} \boldsymbol{\Phi}_{1}^{+} \boldsymbol{\Phi}_{2}
$$

By substituting Eq. (3.19) and knowing that $\boldsymbol{\Phi}_{1}$ is orthogonal with respect to mass and stiffness matrices, terms that contain mass and stiffness matrix in Eq. (3.12) can be eliminated as follows

$$
\begin{gathered}
\boldsymbol{\Phi}_{1}^{T} \mathbf{M} \Phi_{2}=\boldsymbol{\Phi}_{1}^{T} \mathbf{M} \Phi_{1} \Phi_{1}^{+} \boldsymbol{\Phi}_{2}=\boldsymbol{\Phi}_{1}^{+} \boldsymbol{\Phi}_{2} \\
\boldsymbol{\Phi}_{1}^{T} \mathbf{K} \Phi_{2}=\boldsymbol{\Phi}_{1}^{T} \mathbf{K} \Phi_{1} \Phi_{1}^{+} \boldsymbol{\Phi}_{2}=\boldsymbol{\Omega}_{1} \Phi_{1}^{+} \boldsymbol{\Phi}_{2}
\end{gathered}
$$

Substituting Eqs. (3.20) and (3.21) into Eqs. (3.14) and (3.15), mass and stiffness matrices in the set of nonlinear algebraic equations given by Eq. (3.12) are eliminated and the following final form is obtained

$$
-\omega^{2} \overline{\mathbf{M}} \cdot \mathbf{a}+i \omega \overline{\mathbf{C}} \cdot \mathbf{a}+(\overline{\mathbf{K}}+i \overline{\mathbf{H}}) \cdot \mathbf{a}+\boldsymbol{\Phi}_{h}{ }^{T} \Delta(\mathbf{a}) \boldsymbol{\Phi}_{h} \cdot \mathbf{a}=\boldsymbol{\Phi}_{h}{ }^{T} \cdot \mathbf{f}
$$

where

$$
\begin{gathered}
\overline{\mathbf{M}}=\boldsymbol{\Phi}_{h}{ }^{T} \mathbf{M} \boldsymbol{\Phi}_{h}=\left[(1-\alpha)^{2}+\alpha^{2}\right] \cdot \mathbf{I}+(1-\alpha) \alpha \cdot\left[\boldsymbol{\Phi}_{1}{ }^{+} \boldsymbol{\Phi}_{2}+\left(\boldsymbol{\Phi}_{1}{ }^{+} \boldsymbol{\Phi}_{2}\right)^{T}\right] \\
\overline{\mathbf{K}}=\boldsymbol{\Phi}_{h}{ }^{T} \mathbf{K} \boldsymbol{\Phi}_{h}=(1-\alpha)^{2} \cdot \mathbf{\Omega}_{1}+\alpha^{2} \cdot\left(\boldsymbol{\Omega}_{2}-\boldsymbol{\Phi}_{2}{ }^{T} \Delta \mathbf{K} \boldsymbol{\Phi}_{2}\right)+ \\
(1-\alpha) \alpha \cdot\left[\mathbf{\Omega}_{1} \boldsymbol{\Phi}_{1}{ }^{+} \boldsymbol{\Phi}_{2}+\left(\mathbf{\Omega}_{1} \boldsymbol{\Phi}_{1}{ }^{+} \boldsymbol{\Phi}_{2}\right)^{T}\right]
\end{gathered}
$$




$$
\begin{gathered}
\overline{\mathbf{C}}=\boldsymbol{\Phi}_{h}{ }^{T} \mathbf{C} \Phi_{h}=\kappa \cdot \boldsymbol{\Phi}_{h}{ }^{T} \mathbf{M} \boldsymbol{\Phi}_{h}+\tau \cdot \boldsymbol{\Phi}_{h}{ }^{T} \mathbf{K} \boldsymbol{\Phi}_{h} \\
\overline{\mathbf{H}}=\boldsymbol{\Phi}_{h}{ }^{T} \mathbf{H} \boldsymbol{\Phi}_{h}=\gamma \cdot \boldsymbol{\Phi}_{h}{ }^{T} \mathbf{K} \boldsymbol{\Phi}_{h}
\end{gathered}
$$

Proportional damping is assumed in this study, where $\kappa$ and $\tau$ are constants of proportionality of mass and stiffness matrices, respectively, and $\gamma$ is the loss factor.

Set of nonlinear algebraic equations obtained in Eq. (3.22) is going to be solved for the complex vector of modal coefficients a by using Newton's method with arclength continuation as explained in Section 2.4. The number of nonlinear algebraic equation is determined by the number of mode shape used in the expansion theorem for the single harmonic solution as shown in Eq. (3.11). Hence, the total number of nonlinear algebraic equations to be solved can be decreased further by using hybrid mode shapes, compared to using modal vectors of the corresponding linear system. Then, response amplitude of nonlinear system is obtained with multiplication of hybrid mode shapes and modal coefficients.

It should be noted that proposed method is applicable to any system, being independent from whether there exist weak or strong modal interactions. Similar to standard modal superposition approach, for strong modal interaction the number of mode shapes used increases. However, since the hybrid mode shapes span the nonlinear response space better than the linear mode shapes, the number of hybrid mode shapes used is always smaller than the number of linear mode shapes used. 


\section{CHAPTER 4}

\section{CASE STUDIES}

In this section, the application of the method proposed is presented using several case studies with different nonlinearities. In the case studies presented, piecewise linear stiffness, gap and dry friction nonlinearities (Figure 3) are considered which show limiting behaviors. However, in order to show that the method can be easily applied to other types of nonlinearities as described in the previous section, a case with cubic stiffness is presented as well. Moreover, direct time integration of the nonlinear equations by employing equivalent viscous damping in the system for the first case study is performed which validates the use of single harmonic term in the harmonic balance method. Describing function expressions for nonlinearities considered in the thesis are given in the Appendix.

Two different systems are used in the case studies presented. The first system is a 20DOF lumped parameter model; whereas, the second system is a finite element model of a realistic structure with 5400 DOFs.

(a)

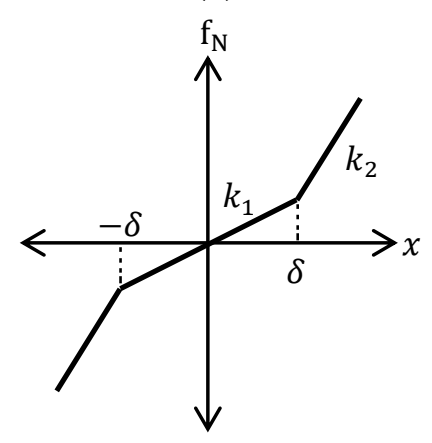

(b)

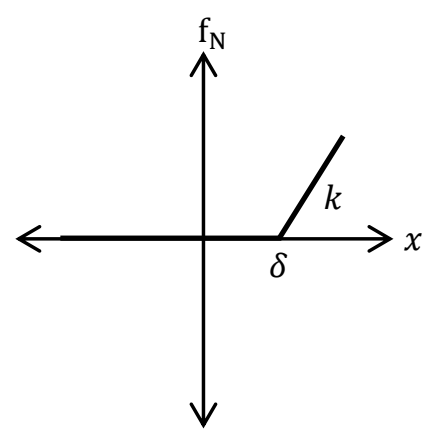

(c)

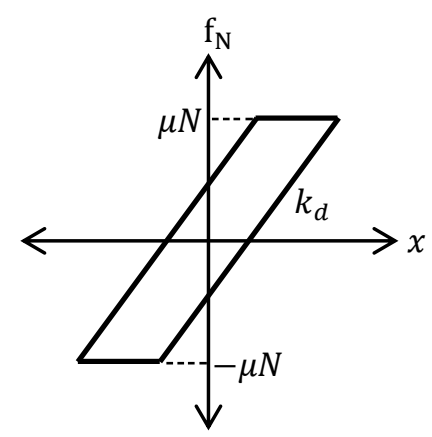

Figure 3 Internal Nonlinear Force of Nonlinearities with respect to Displacement 


\subsection{Lumped Parameter Model}

The 20-DOF linear lumped parameter system used in the following case studies is shown in Figure 4. Parameters used in the model are $k=30000 \mathrm{~N} / \mathrm{m}, m=$ $0.1 \mathrm{~kg}, \mathrm{~h}=1500 \mathrm{~N} / \mathrm{m}$.

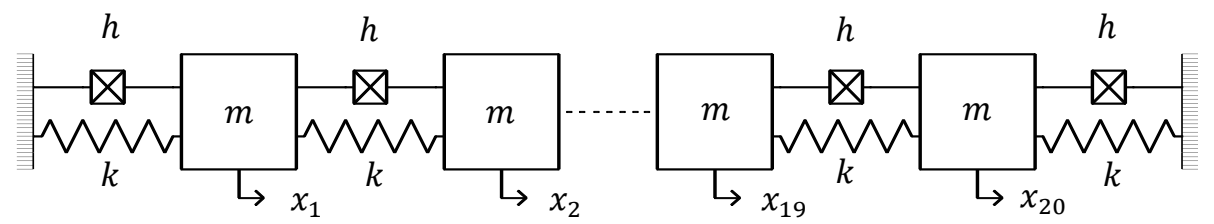

Figure 4 20-DOF Linear System

The system is excited by two different external forces applied to the $6^{\text {th }}$ DOF and the $12^{\text {th }}$ DOF which are defined as $15 \sin (\omega t) \mathrm{N}$ and $5 \sin (\omega t+\pi / 2) \mathrm{N}$, respectively.

Four case studies are presented by using this lumped parameter system. Two nonlinear elements are inserted into the linear system in the first three case studies and one nonlinear element is attached for the last case study. The nonlinearity types and their locations are given in Table 1.

Table 1 Nonlinear Element Types Used in the Case Studies

\begin{tabular}{|c|c|c|c|}
\hline Nonlinearity Type & Quantity & $\begin{array}{c}\text { Insertion } \\
\text { DOFs }\end{array}$ & Properties \\
\hline $\begin{array}{l}\text { Piecewise Linear } \\
\text { Stiffness }\end{array}$ & 2 & $\begin{array}{l}\text { 7-ground, } \\
\text { 11-ground }\end{array}$ & $\begin{array}{c}k_{1}=2000 \mathrm{~N} / \mathrm{m}, k_{2}=10000 \mathrm{~N} / \mathrm{m} \\
\delta=0.002 \mathrm{~m}\end{array}$ \\
\hline Dry Friction & 2 & $\begin{array}{l}\text { 5-10, } \\
\text { 10-ground }\end{array}$ & $\begin{array}{c}k_{d}=5000 \mathrm{~N} / \mathrm{m}, k_{d}=10000 \mathrm{~N} / \mathrm{m} \\
\mu N_{1}=5 \mathrm{~N}, \mu N_{2}=10 \mathrm{~N} \\
\mu N_{1}=10 \mathrm{~N}, \mu N_{2}=15 \mathrm{~N} \\
\mu N_{1}=20 \mathrm{~N}, \mu N_{2}=25 \mathrm{~N}\end{array}$ \\
\hline $\begin{array}{l}\text { Gap and Dry } \\
\text { Friction }\end{array}$ & 1,1 & $\begin{array}{l}\text { 11-ground, } \\
\text { 1-ground }\end{array}$ & $\begin{array}{l}k=10000 \mathrm{~N} / \mathrm{m}, \delta=0.005 \mathrm{~m} \\
k_{d}=10000 \mathrm{~N} / \mathrm{m}, \mu N=35 \mathrm{~N}\end{array}$ \\
\hline Cubic Stiffness & 1 & 12-ground & $k_{c}=10^{7} \mathrm{~N} / \mathrm{m}^{3}$ \\
\hline
\end{tabular}




\subsubsection{Case Study 1: Piecewise Linear Stiffness Element}

For piecewise nonlinear element, two limiting equivalent stiffness values can be defined. The first one occurs when the vibration amplitude is smaller than the breakaway amplitude (limiting case 1) resulting to an equivalent stiffness of $k_{1}$ and the second one occurs when the vibration amplitude is very large (limiting case 2) such that the region with stiffness $k_{1}$ is relatively very small; hence, the nonlinear element acts almost as a linear element of stiffness $k_{2}$ (see Figure 3). Therefore, adding these equivalent stiffness values to the original system, it is possible to define two additional linear systems. In order to obtain mode shapes of the limiting cases, mathematical expression of describing function is also needed which is given in the Appendix. After solving the eigenvalue problems, hybrid mode shapes can be calculated by using Eq. (3.8).

Figure 5 shows the response of the $9^{\text {th }}$ DOF of the linear system (i.e. system with no nonlinear element is connected) and that of the nonlinear system using all modal information (i.e. without applying a reduction). It is clearly seen that nonlinearity strongly affects the response at the first and the second resonance regions where hardening effects and jump phenomena are observed around the resonance frequency values.

In Figure 6a, Figure $6 \mathrm{~b}$ and Figure $6 c$, responses of the $9^{\text {th }}$ DOF around the first resonance region are given by using modes of the linear system corresponding to limiting case 1 , limiting case 2 , and hybrid mode shapes, respectively. It is observed from the results obtained that using even a single hybrid mode shape gives very accurate results throughout the frequency range considered. Similar accuracy can be obtained by using 12 modes of limiting case 1 and 4 modes of limiting case 2 . It can be seen from the results that, for this particular case, using the modes of limiting case 2 performs much better than using the modes of limiting case 1 ; however, modal superposition method utilizing hybrid mode shapes significantly outperforms both approaches. 


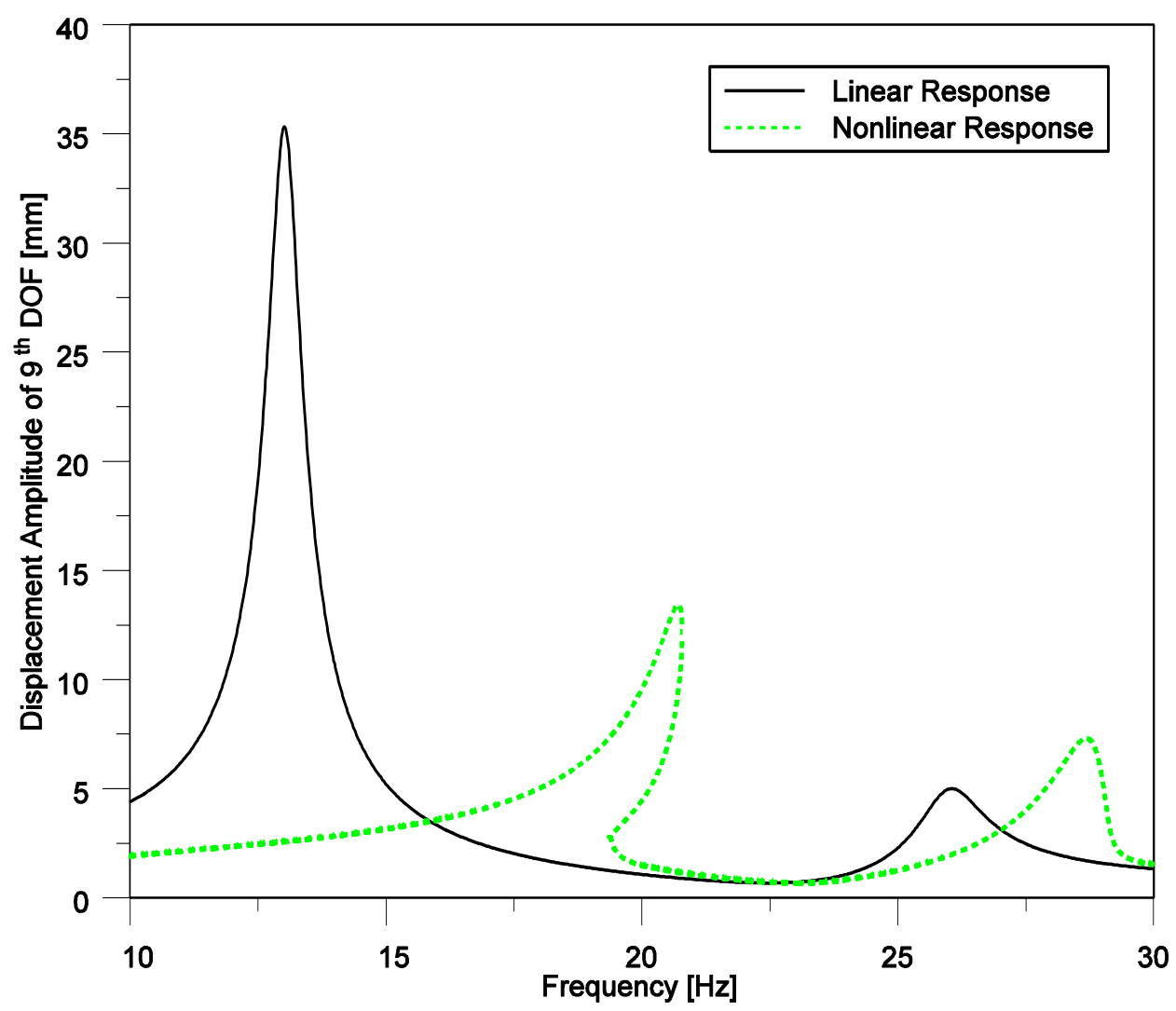

Figure 5 Displacement amplitude of the $9^{\text {th }}$ DOF with respect to frequency

(a)

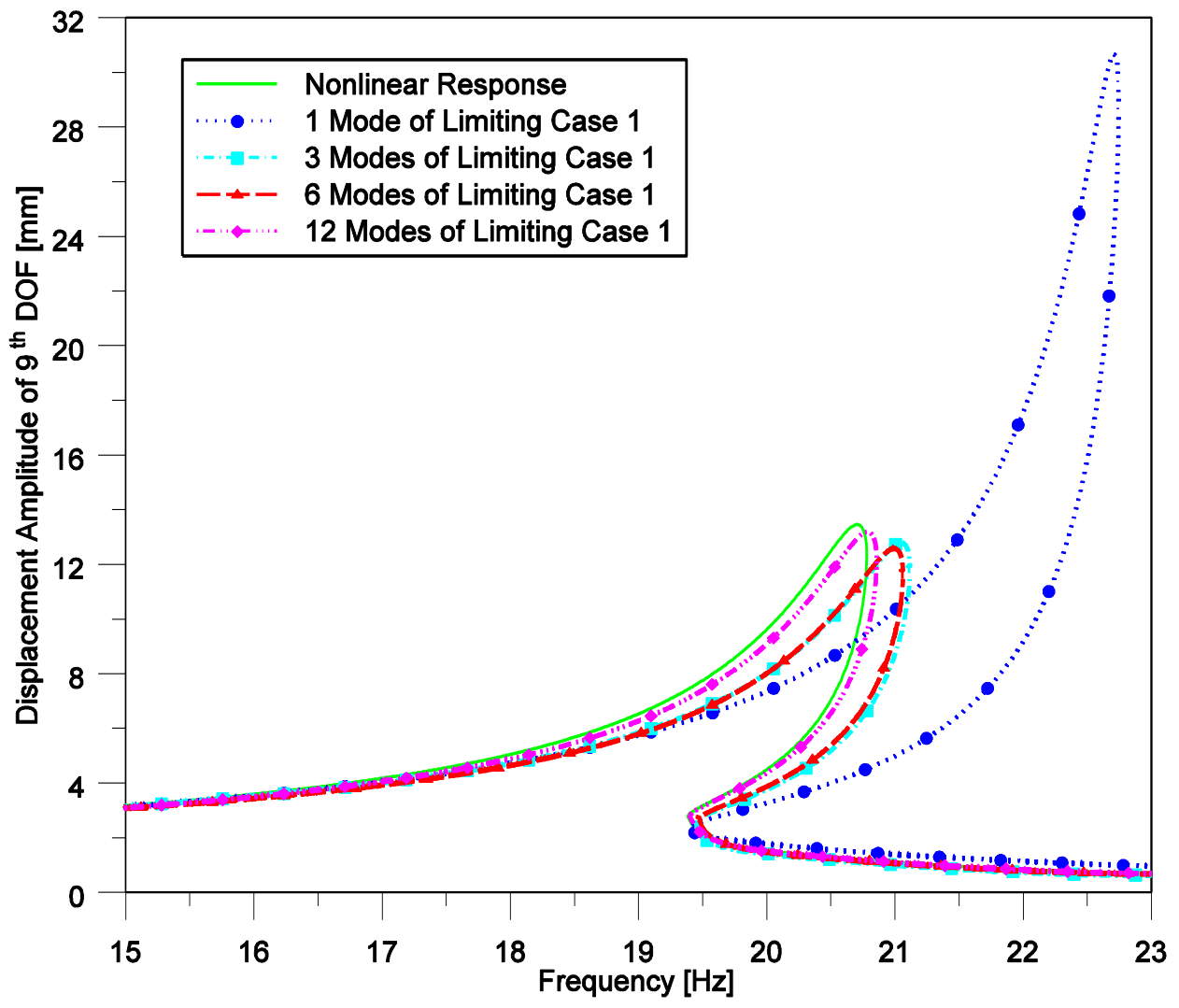


(b)

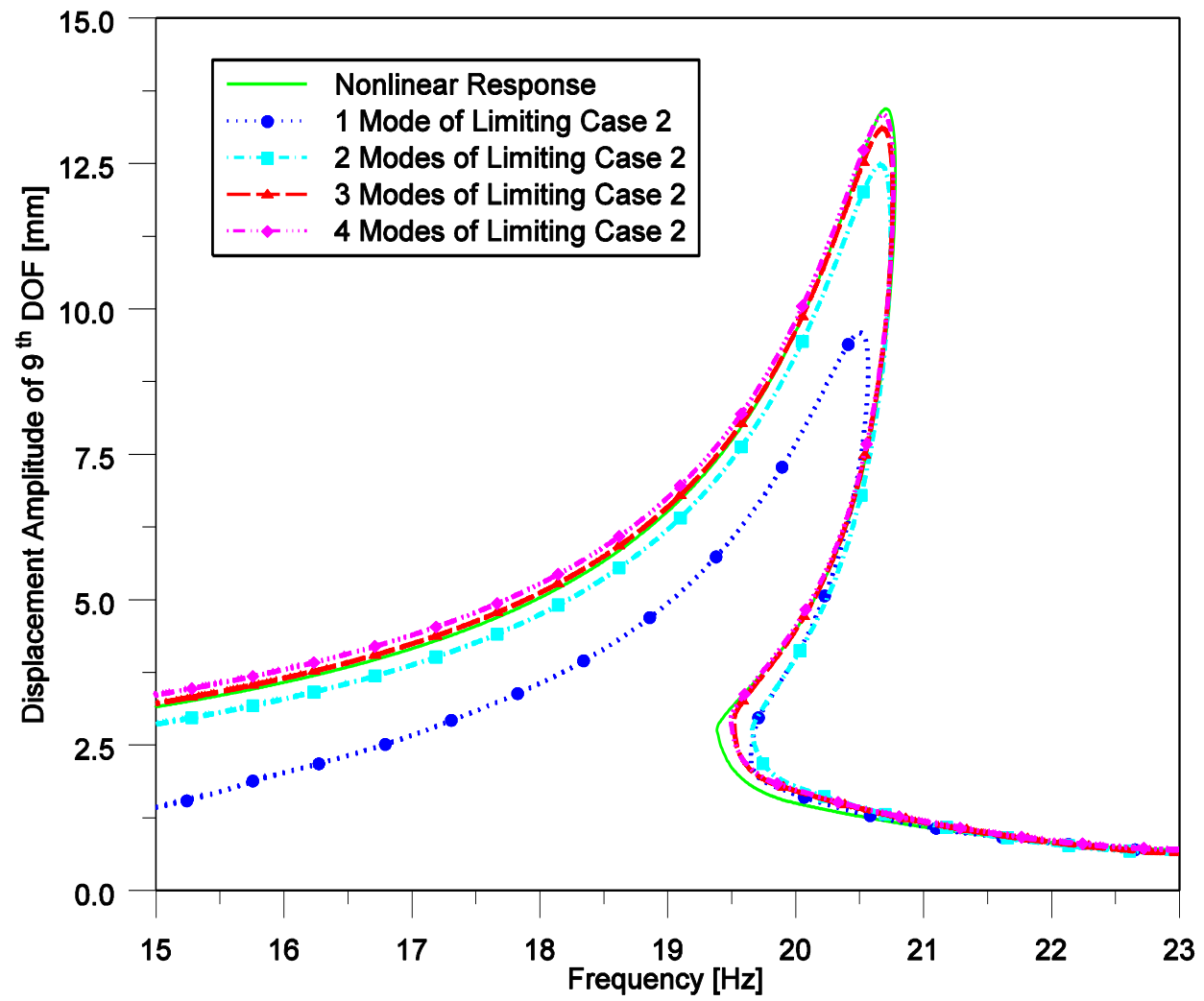

(c)

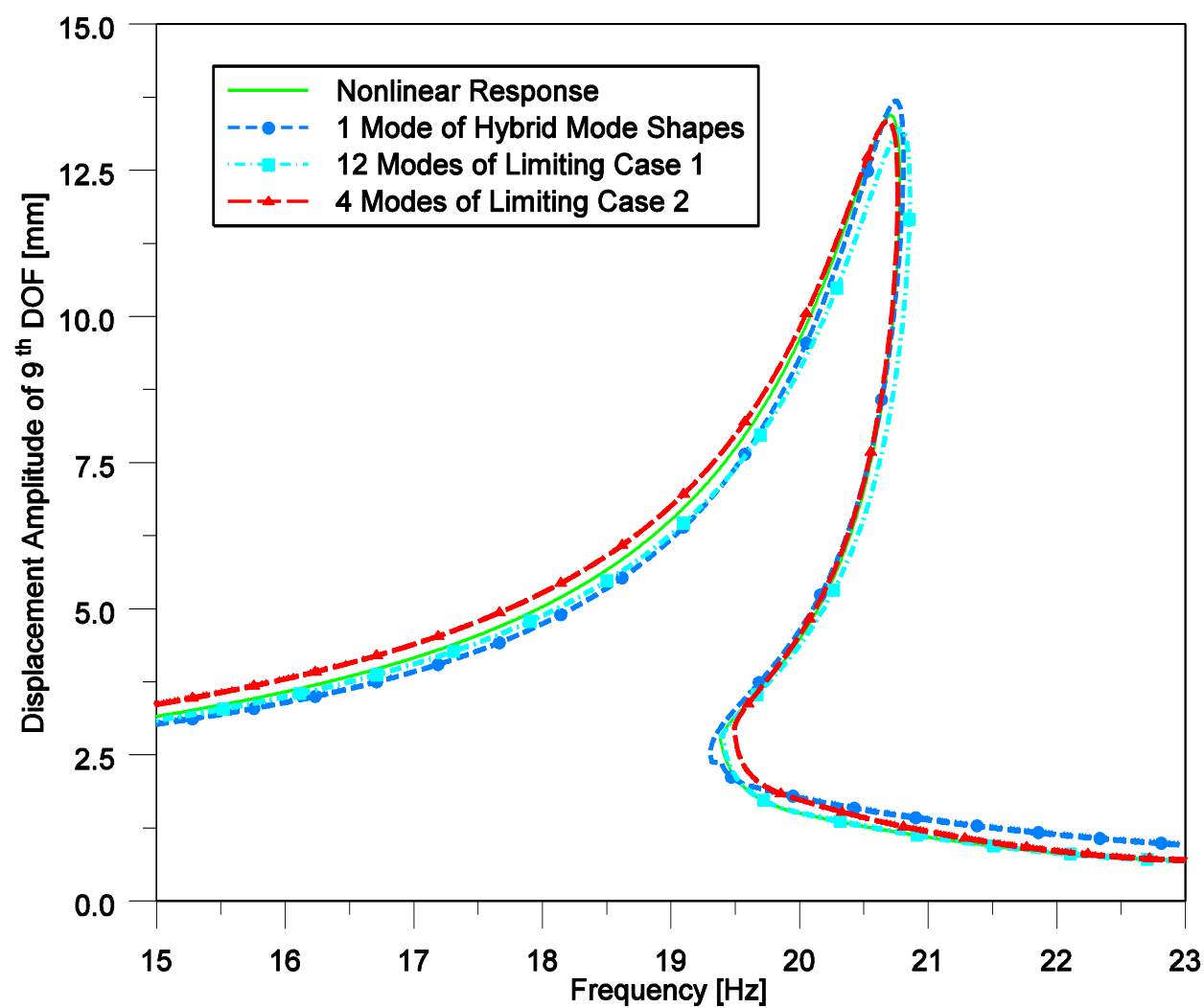

Figure 6 Effect of modes used on the displacement amplitude of the $9^{\text {th }}$ DOF around the first resonance 
The second resonance region is also shown in Figure 7a, Figure $7 \mathrm{~b}$ and Figure 7c. Using a single hybrid mode shape again gives very accurate results compared to traditional modal superposition approach. It should be noted that, since similar results are also obtained for other DOFs, only the response of the $9^{\text {th }}$ DOF is presented here.

In order to quantify errors for the comparison of the results, three different error criteria are defined. The first one is integral error, which is defined as follows

$$
\text { Integral Error }=\left(\int_{\omega_{i}}^{\omega_{f}}\left(x_{o b t}-x_{e x c}\right)^{2} d \omega\right)^{1 / 2},
$$

where $x_{o b t}, x_{e x c}, \omega_{i}$ and $\omega_{f}$ represent the displacement amplitude by using limited number of mode shapes, exact nonlinear displacement amplitude, initial and final frequencies of the frequency range of interest. Secondly, amplitude error, which is the error between the maximum displacement amplitude obtained by using limited number of mode shapes and the exact maximum displacement amplitude in the frequency range of interest is defined. Mathematically it is given as

$$
\text { Amplitude Error }=\left|\frac{x_{\max }^{e x c}-x_{\max }^{o b t}}{x_{\max }^{e x c}}\right| \times 100 .
$$

The last one is frequency error, which is the error between the resonance frequency values corresponding to the maximum displacement amplitude obtained in each approach. It is expressed as follows

$$
\text { Frequency Error }=\left|\frac{\omega_{\max }^{e x c}-\omega_{\max }^{o b t}}{\omega_{\max }^{e x c}}\right| \times 100 .
$$

All errors calculated for Case Study 1 are given in Table 2 and Table 3. Performance of hybrid mode shapes observed in Figure 6 and Figure 7 can be quantified from the error values given in Table 2 and Table 3 which show the capability of the modal superposition method with hybrid mode shapes. 
(a)

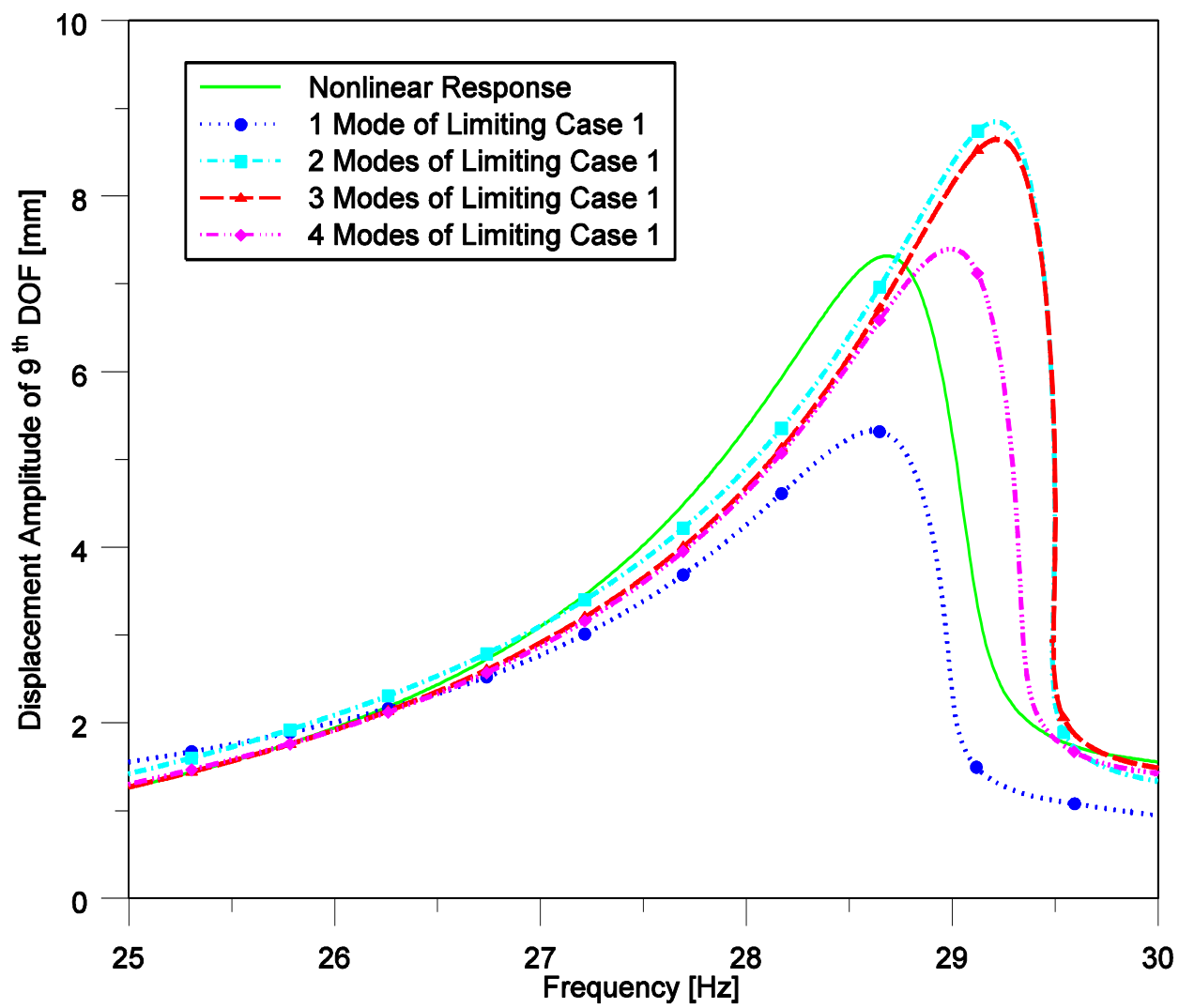

(b)

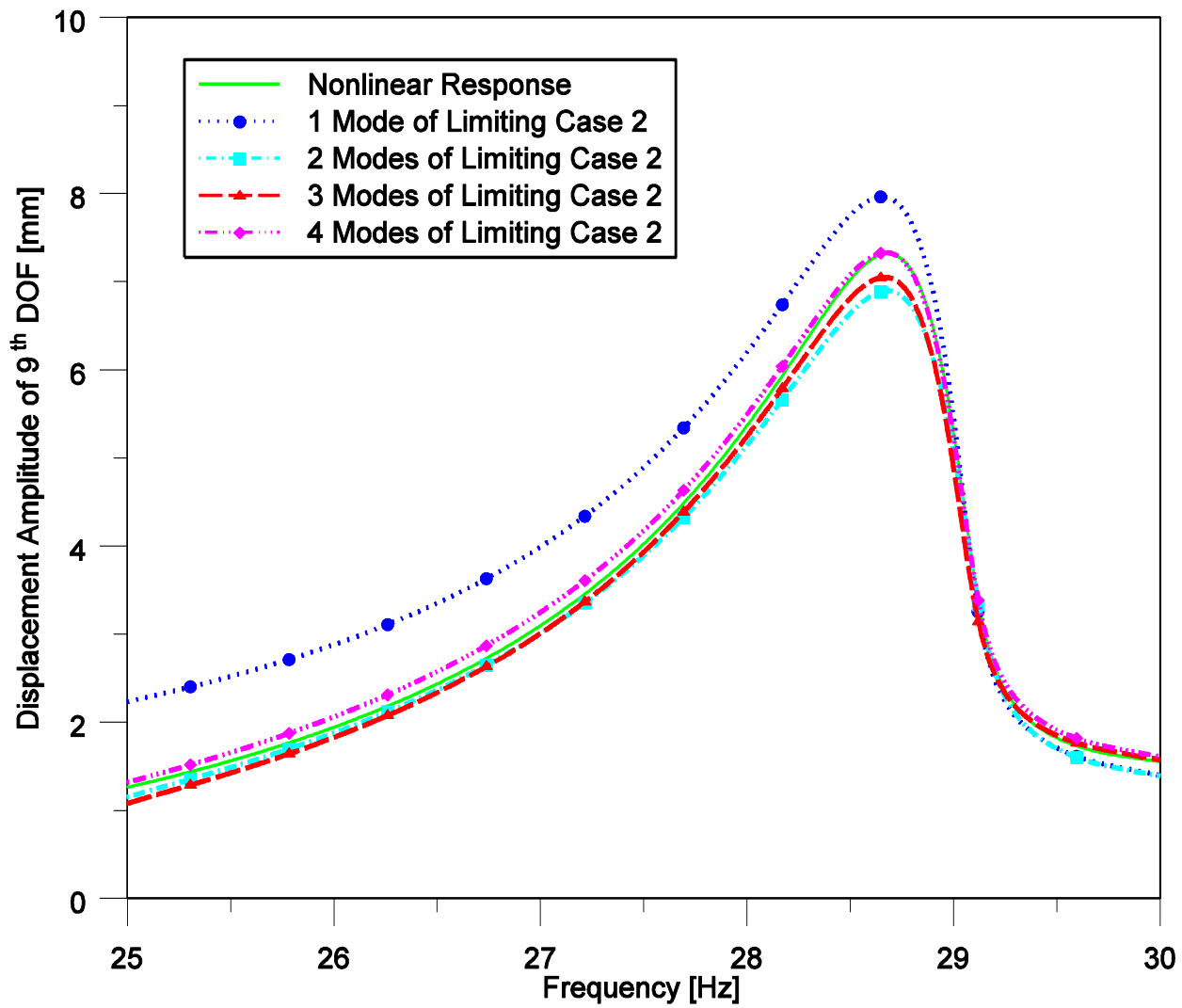


(c)

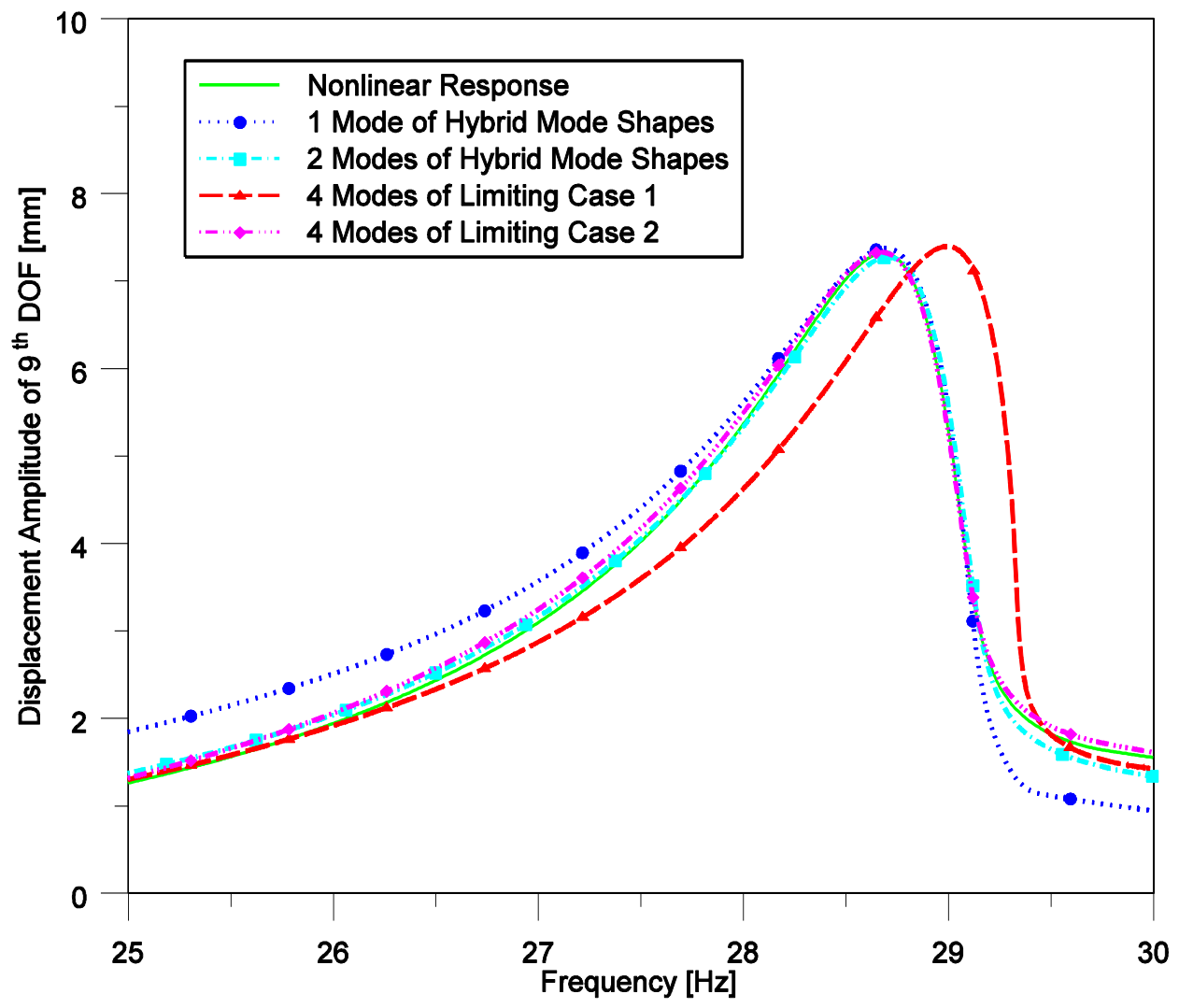

Figure 7 Effect of modes used on the displacement amplitude of the $9^{\text {th }}$ DOF around the second resonance

Table 2 Error analysis for the $9^{\text {th }}$ DOF around the first resonance

\begin{tabular}{cccc} 
Number of Mode Shapes & Integral Error & Amplitude Error (\%) & Frequency Error (\%) \\
\hline LC1 -1 Mode & 61.3 & 128 & 9.7 \\
LC1 - 3 Modes & 17.2 & 4.7 & 1.7 \\
LC1 - 6 Modes & 15.7 & 6.3 & 1.4 \\
LC1 -12 Modes & 8.2 & 1.8 & 0.4 \\
LC2 - Mode & 19.5 & 28.6 & 1.0 \\
LC2 -2 Modes & 7.0 & 7.1 & 0.2 \\
LC2 - 3 Modes & 4.9 & 2.5 & 0.2 \\
LC2 - Modes & 4.7 & 0.7 & 0.1 \\
1 Hybrid Mode & 4.7 & 1.9 & 0.2
\end{tabular}


Table 3 Error analysis for the $9^{\text {th }}$ DOF around the second resonance

\begin{tabular}{cccc} 
Number of Mode Shapes & Integral Error & Amplitude Error $(\%)$ & Frequency Error (\%) \\
\hline LC1 -1 Mode & 6.0 & 27.2 & 0.2 \\
LC1 - 2 Modes & 10.2 & 21.0 & 1.8 \\
LC1 - 3 Modes & 9.9 & 18.3 & 1.9 \\
LC1 - 4 Modes & 5.4 & 1.2 & 1.1 \\
LC2 - 1 Mode & 5.3 & 8.9 & 0.1 \\
LC2 - 2 Modes & 1.1 & 5.7 & 0.03 \\
LC2 - 3 Modes & 1.0 & 3.6 & 0.05 \\
LC2 - 4 Modes & 0.7 & 0.3 & 0.05 \\
1 Hybrid Mode & 3.3 & 0.9 & 0.00009 \\
2 Hybrid Modes & 0.8 & 0.5 & 0.06
\end{tabular}

Apart from frequency domain solutions, a time-domain numerical integration of the equations of motion is performed to demonstrate the validity of the harmonic response assumption. Moreover, amplitude values obtained in frequency domain can also be verified with time-domain solution by calculating dynamic response at several excitation frequency values. It should be noted that in the case studies presented in this thesis proportional structural damping is assumed, and therefore structural damping values need to be converted to equivalent forms of proportional viscous damping to perform direct time integration.

In the lumped parameter model with piecewise linear stiffness nonlinearity, the structural damping in the system is replaced with equivalent viscous damping. The displacement time response of the $9^{\text {th }}$ DOF is given in Figure 8 and Figure 9, which show that the system response is harmonic. The solution is obtained by using all of the modes of the system in order to obtain exact solution. The frequency of the excitation force is $20.5 \mathrm{~Hz}$ corresponding to resonance. Moreover, in Figure 10 the response amplitude obtained by time integration and single-harmonic HBM are compared. It is observed that the response of the system is harmonic and using a single-harmonic term it can be captured accurately for the case study considered. 


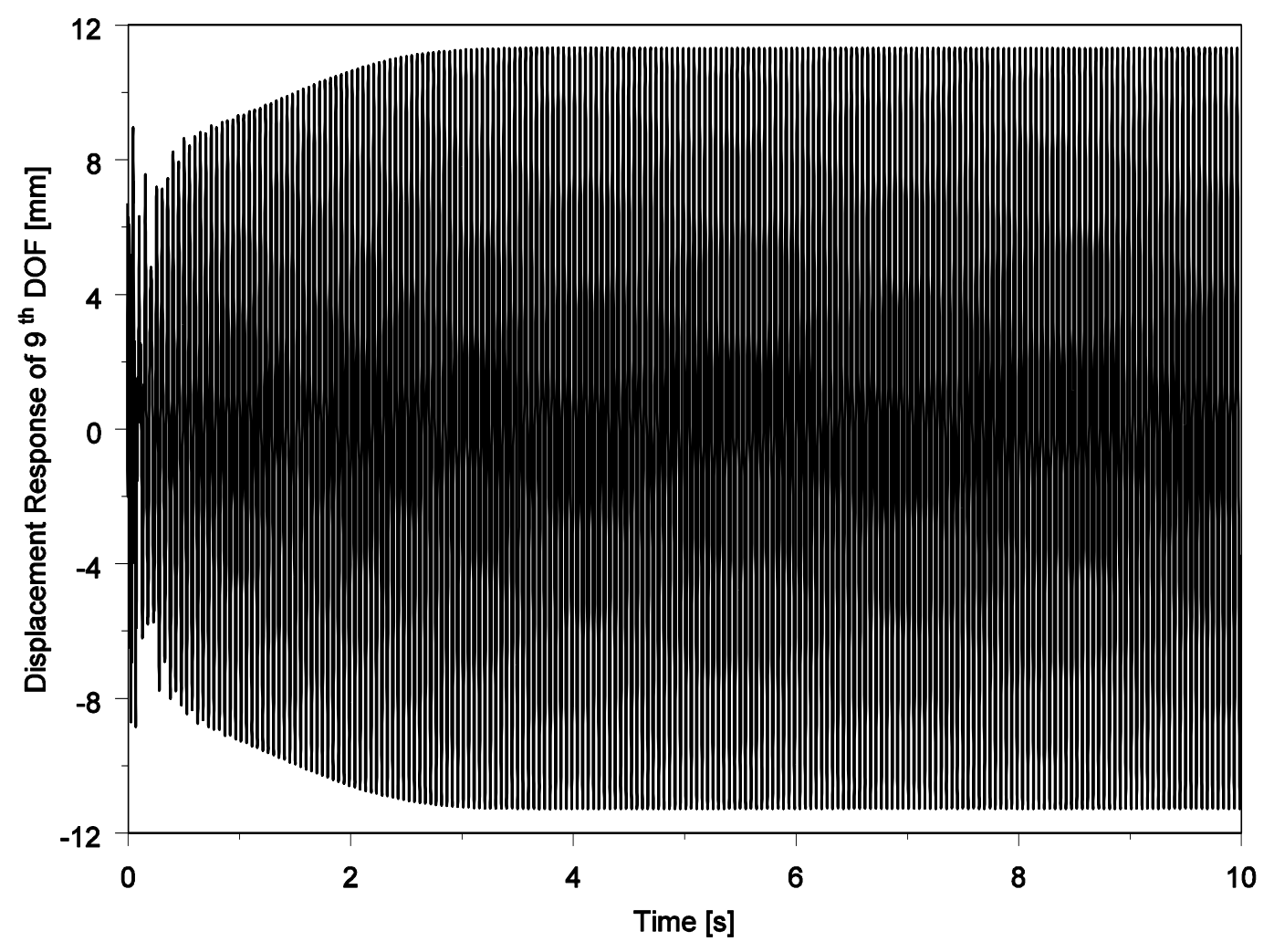

Figure 8 Displacement time response of $9^{\text {th }}$ DOF

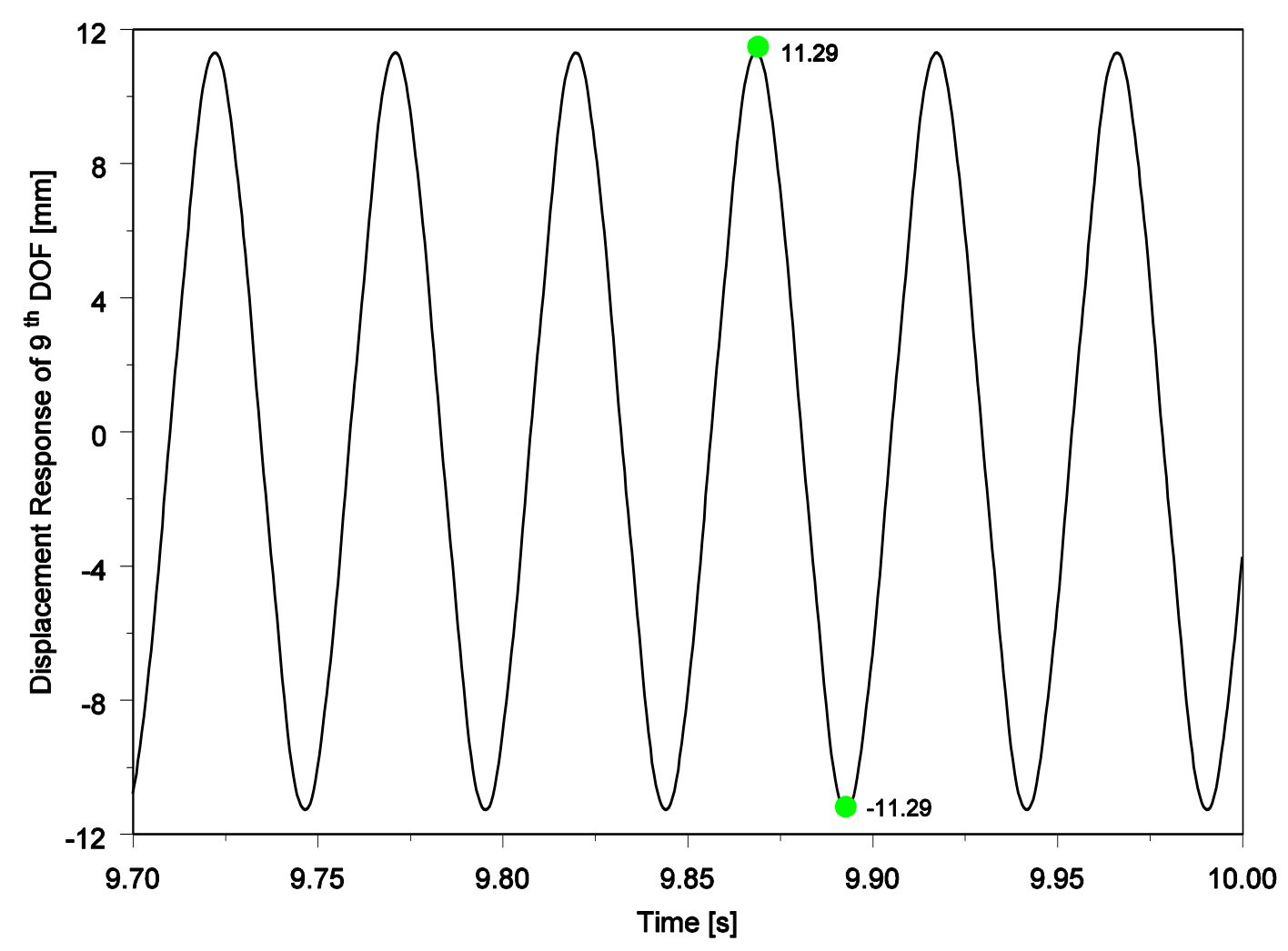

Figure 9 Displacement time response of $9^{\text {th }}$ DOF 


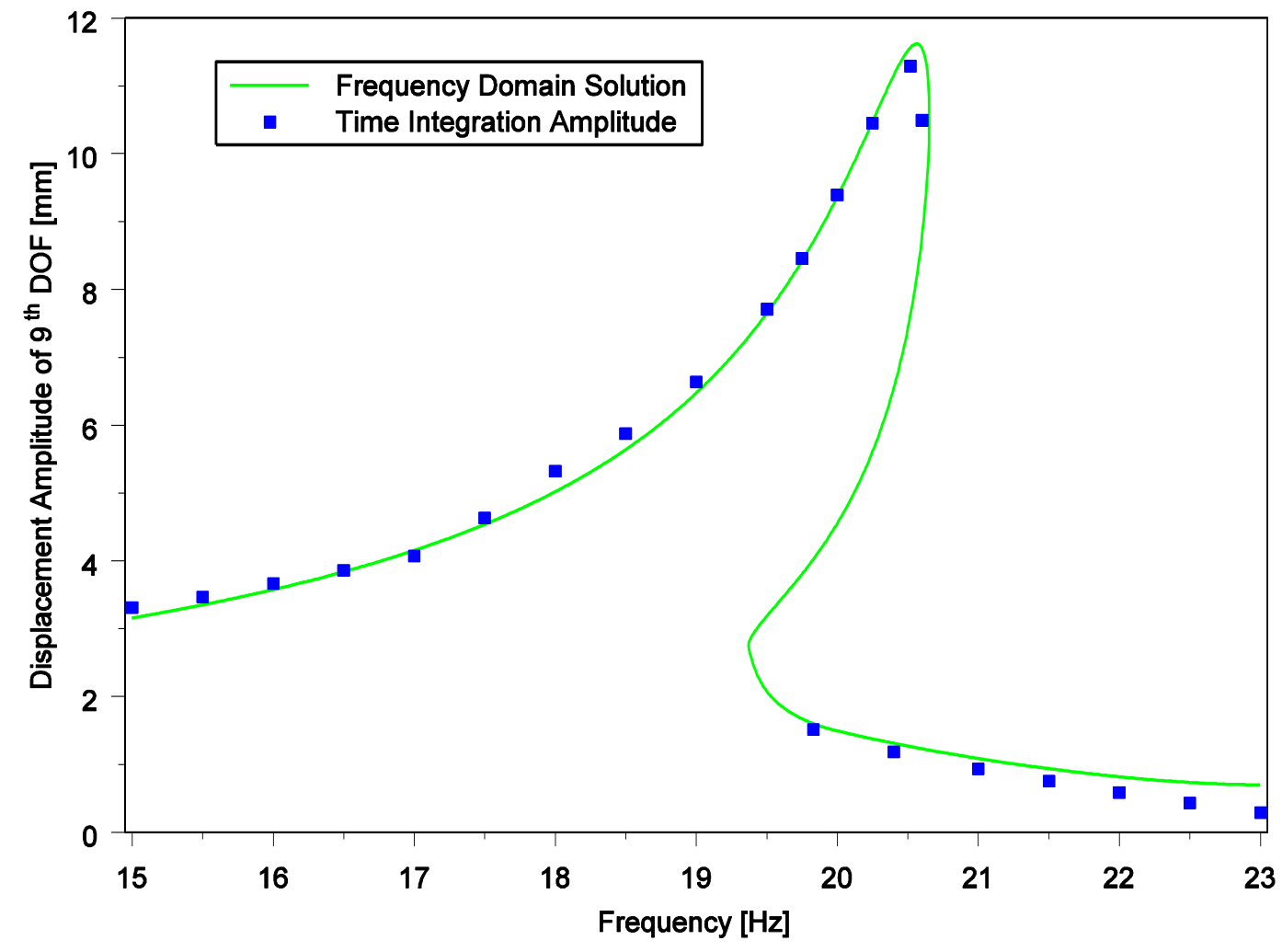

Figure 10 Displacement amplitude of the $9^{\text {th }}$ DOF with respect to frequency

The main aim of this thesis is to develop a method which uses less number of mode shapes than the number of linear mode shapes used in the standard modal superposition approach for the determination of periodic solutions of a nonlinear system. Therefore, it is assumed that the response of the nonlinear system is periodic. In the case studies, single-harmonic HBM is used; however, if single harmonic does not give accurate result multiple harmonics can be used. Either single-harmonic or multi-harmonics are used in the solution; the number of hybrid modes used in the modal superposition method is significantly less than the linear ones. 


\subsubsection{Case Study 2: Dry Friction Element}

For dry friction nonlinearity, two limiting cases can be defined. For very large displacement amplitudes, since majority of a cycle is covered by slip state, limiting equivalent stiffness due to friction is zero which makes the system equivalent to the linear system without any dry friction damper. This is referred to as limiting case 1. On the other hand, if the displacement amplitude is very small, dry friction element is always in stick state which results in a limiting equivalent stiffness of $k_{d}$ and this case is considered as limiting case 2 .

Response of the $10^{\text {th }}$ DOF around the resonance frequency is given in Figure 11. It can be seen from the figure that dry friction element reduces the vibration amplitude of the linear system significantly; hence, it is working effectively where the damper experiences both stick and slip regions in one cycle and its motion cannot be captured by modes of either of the limiting cases alone. In Figure 12a, Figure 12b, and Figure $12 \mathrm{c}$, response of the $10^{\text {th }}$ DOF is calculated by using modes of limiting case 1, limiting case 2 and hybrid mode shapes. It is seen from the displacement results obtained and the error values given in Table 4 that using only 2 hybrid mode shapes, very accurate results are obtained compared to the results obtained by using 4 modes of limiting case 1 and 16 modes of limiting case 2 . It should be also noted that, since only two hybrid mode shapes are used, the number of nonlinear equations solved is reduced significantly which has a drastic effect in the calculation times as well, in addition to improved accuracy. Similar results are also obtained for the other resonance regions and DOFs. 


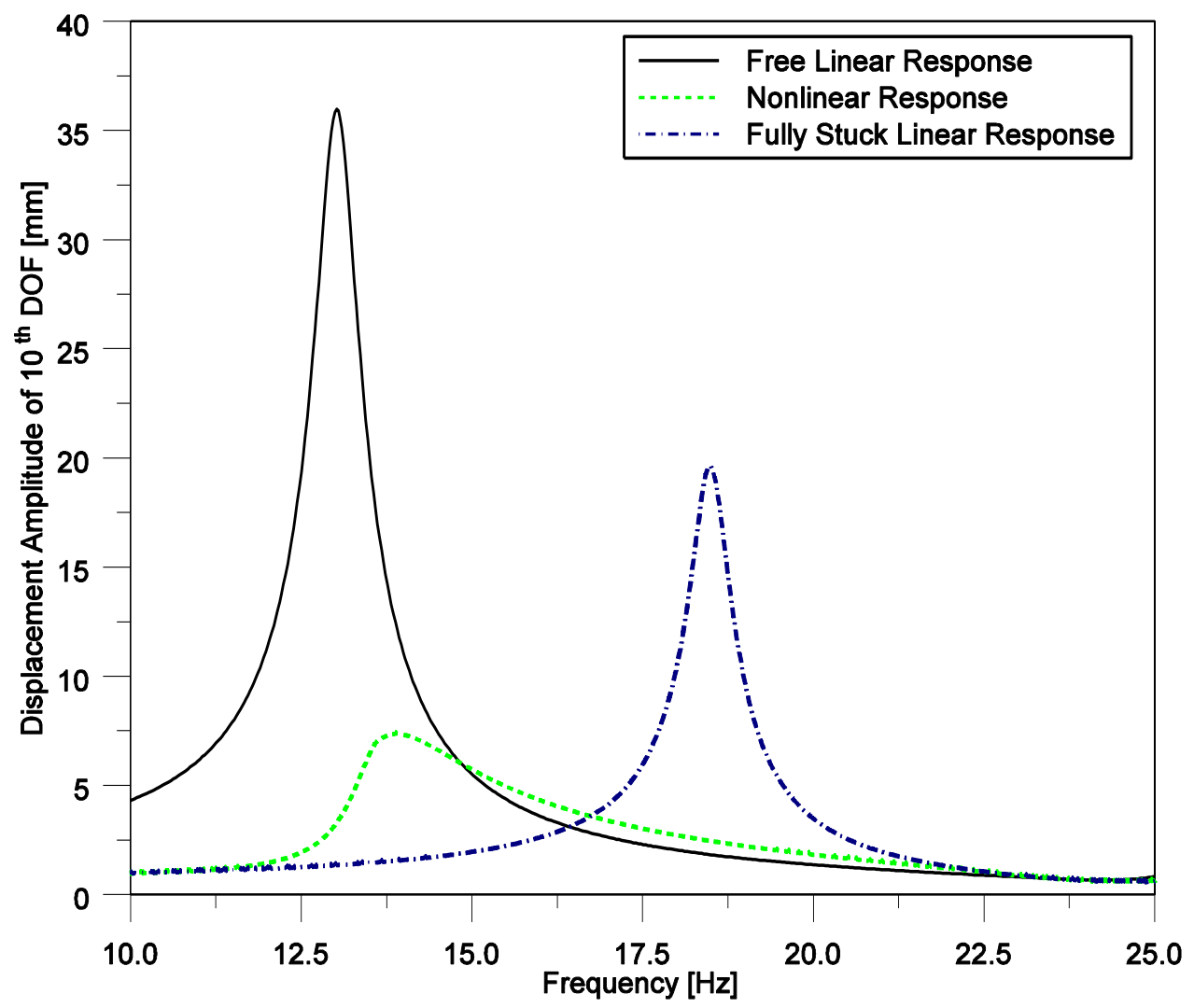

Figure 11 Displacement amplitudes of the $10^{\text {th }}$ DOF vs. frequency

(a)

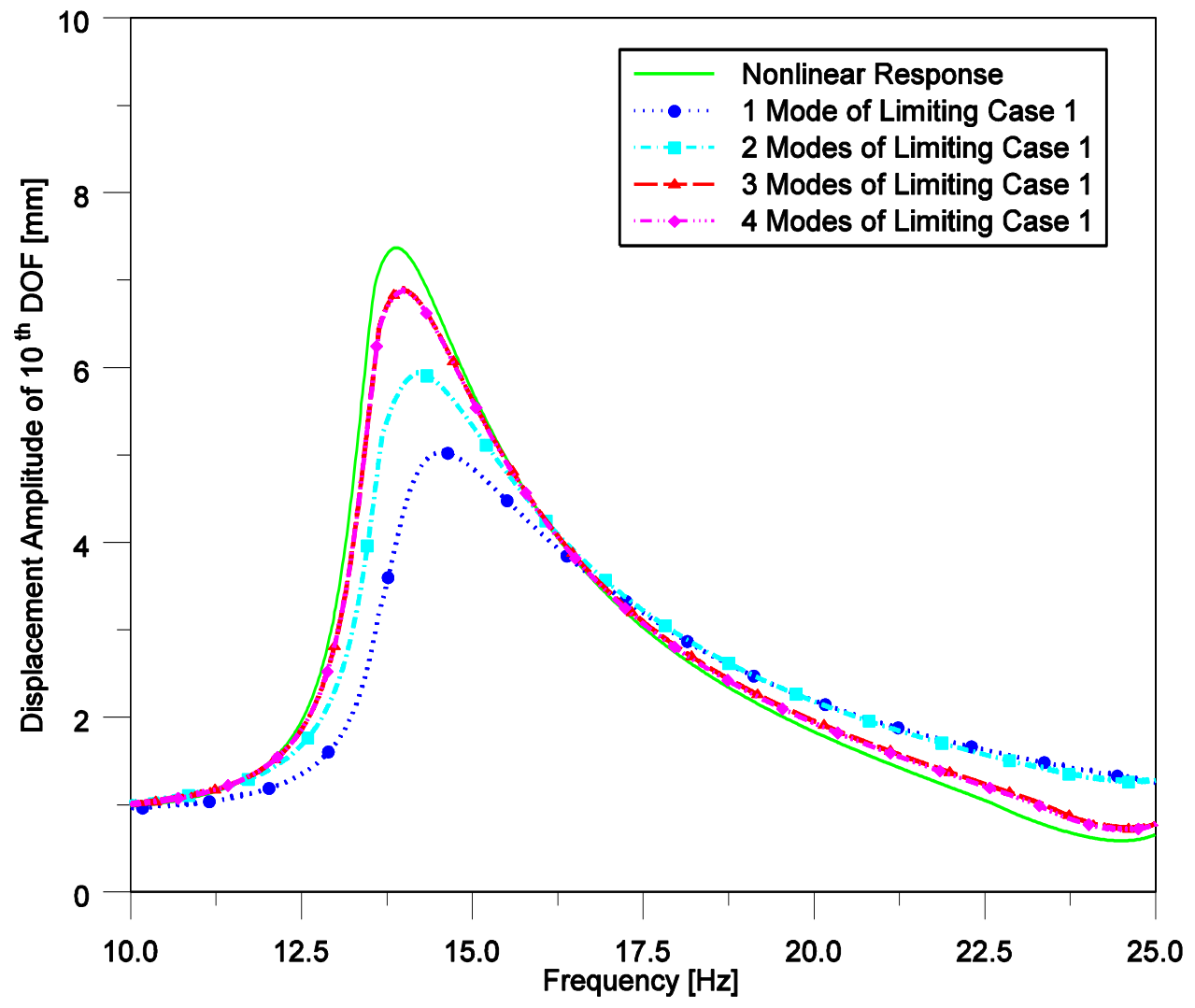


(b)

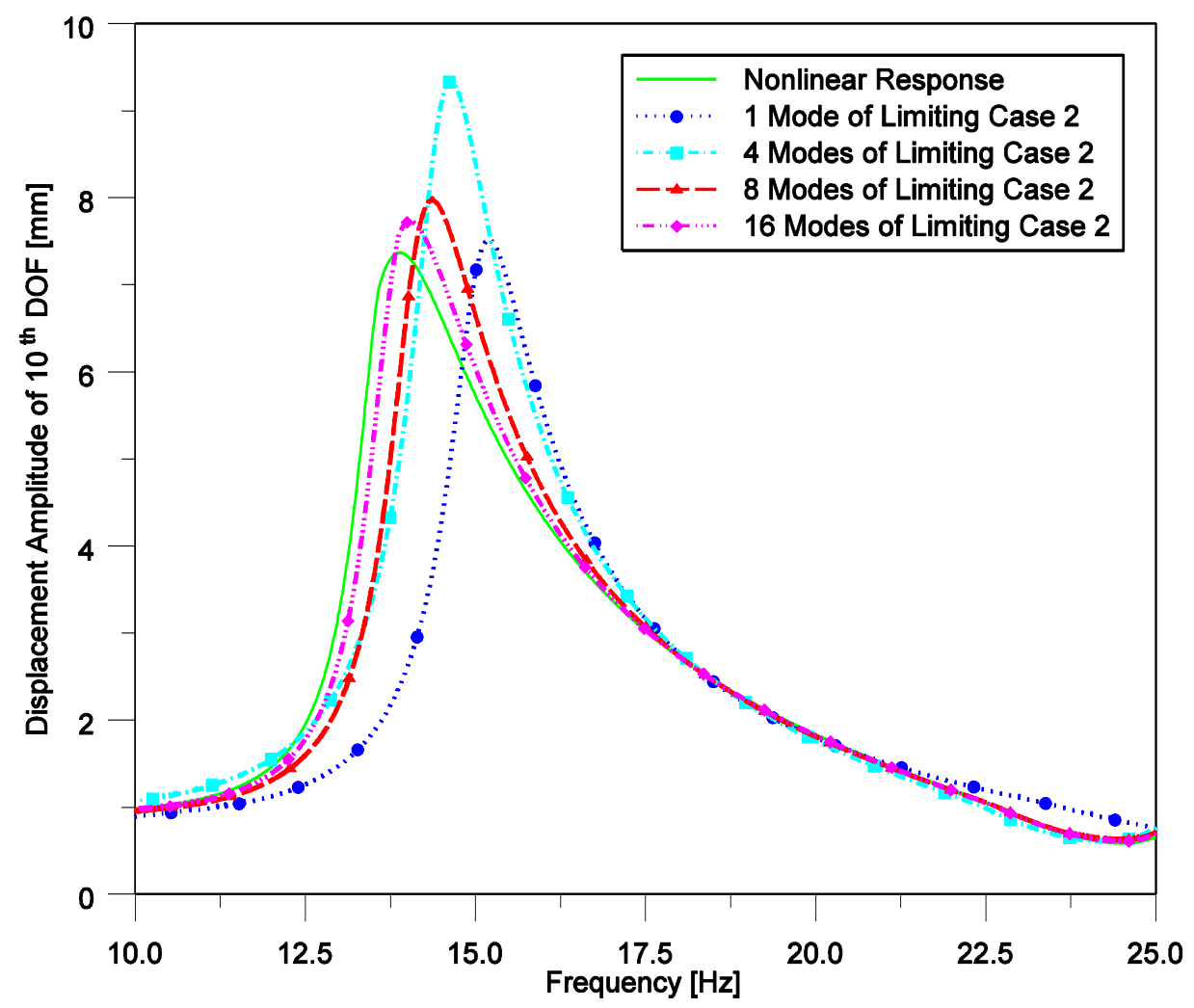

(c)

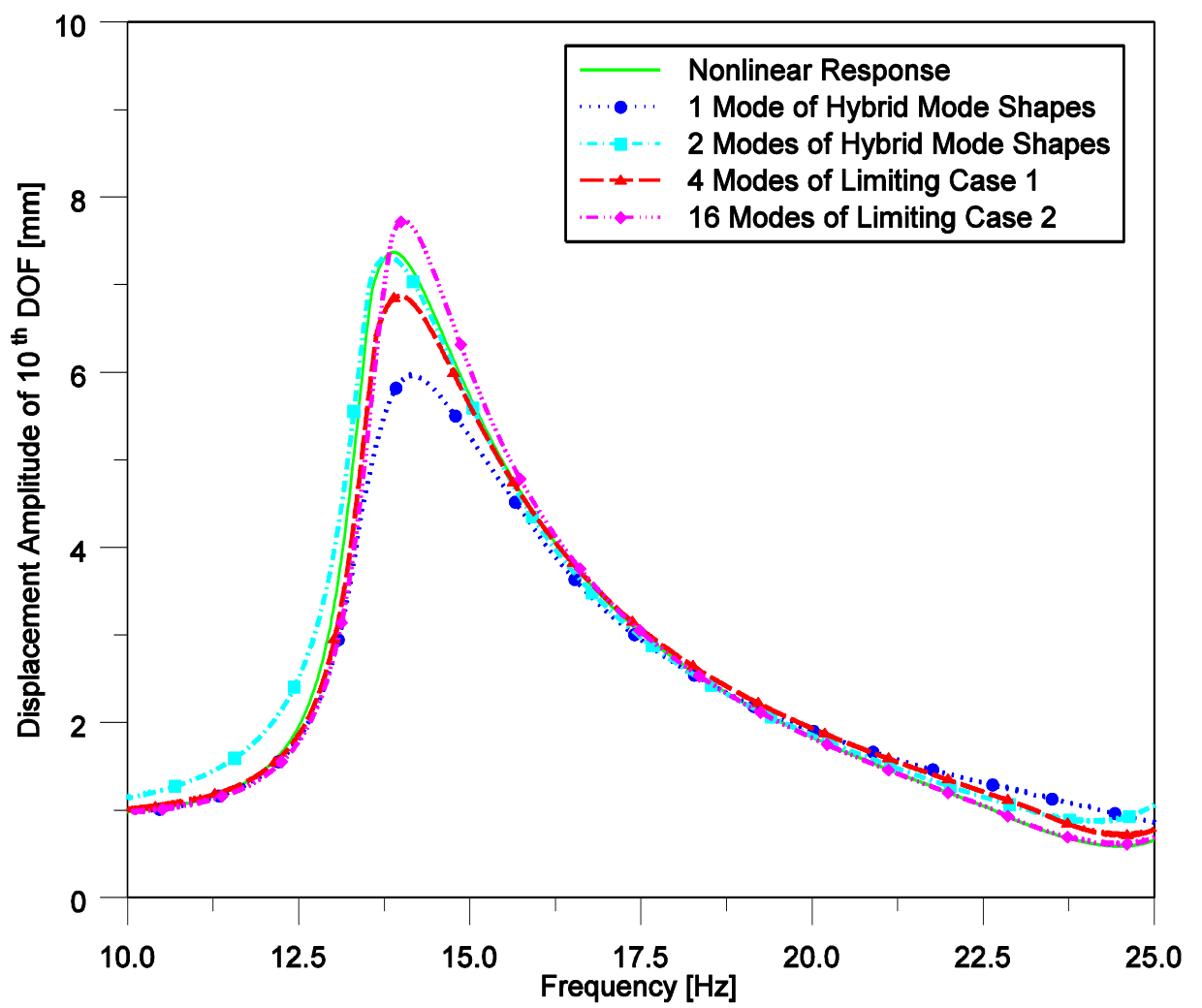

Figure 12 Effect of modes used on the displacement amplitude of the $10^{\text {th }}$ DOF around the first resonance for the first slip force values 
Table 4 Error analysis for the $10^{\text {th }}$ DOF around the first resonance for the first slip force values

\begin{tabular}{cccc} 
Number of Mode Shapes & Integral Error & Amplitude Error $(\%)$ & Frequency Error (\%) \\
\hline LC1 -1 Mode & 9.6 & 31.7 & 4.7 \\
LC1 -2 Modes & 5.4 & 19.5 & 2.4 \\
LC1 -3 Modes & 1.9 & 6.5 & 0.6 \\
LC1 -4 Modes & 1.9 & 6.7 & 0.6 \\
LC2 - 1 Mode & 13.7 & 2.1 & 9.4 \\
LC2 - 4 Modes & 9.5 & 26.8 & 5.4 \\
LC2 - 8 Modes & 6.2 & 8.3 & 3.4 \\
LC2 -16 Modes & 2.4 & 4.9 & 1.0 \\
1 Hybrid Mode & 4.4 & 19.1 & 2.0 \\
2 Hybrid Modes & 1.9 & 0.6 & 0.6
\end{tabular}

Additionally, the previous case study is repeated for two different slip force values in order to show how the number of modes retained in the modal superposition method changes depending on the parameters of the nonlinear elements. The results obtained and the error values calculated for these cases are given in Figure 13 and Table 5, and in Figure 14 and Table 6, respectively. Studying the results presented in the previous and these additional cases, it can be concluded that, as the slip force increases, the solution approaches to the fully stuck linear response, in which the number of mode shapes of the original linear system needs to be increased from 4 to 8. On the other hand, less number of modes of the second limiting case, i.e. linear system including contact stiffness of the friction damper, is required to obtain the same accuracy, where the number of modes retained decreases from 16 to 4 . This is an expected result since the nonlinear response is bounded by the two linear responses corresponding to the two limiting cases. It should be noted that if linear modes are used in the modal superposition method, the number of modes retained changes as the parameters of the nonlinearities vary; whereas for all cases, only 2 hybrid mode shapes are always sufficient to obtain similar accuracy, and this number is significantly less than the number of the linear modes used in the three cases presented. 


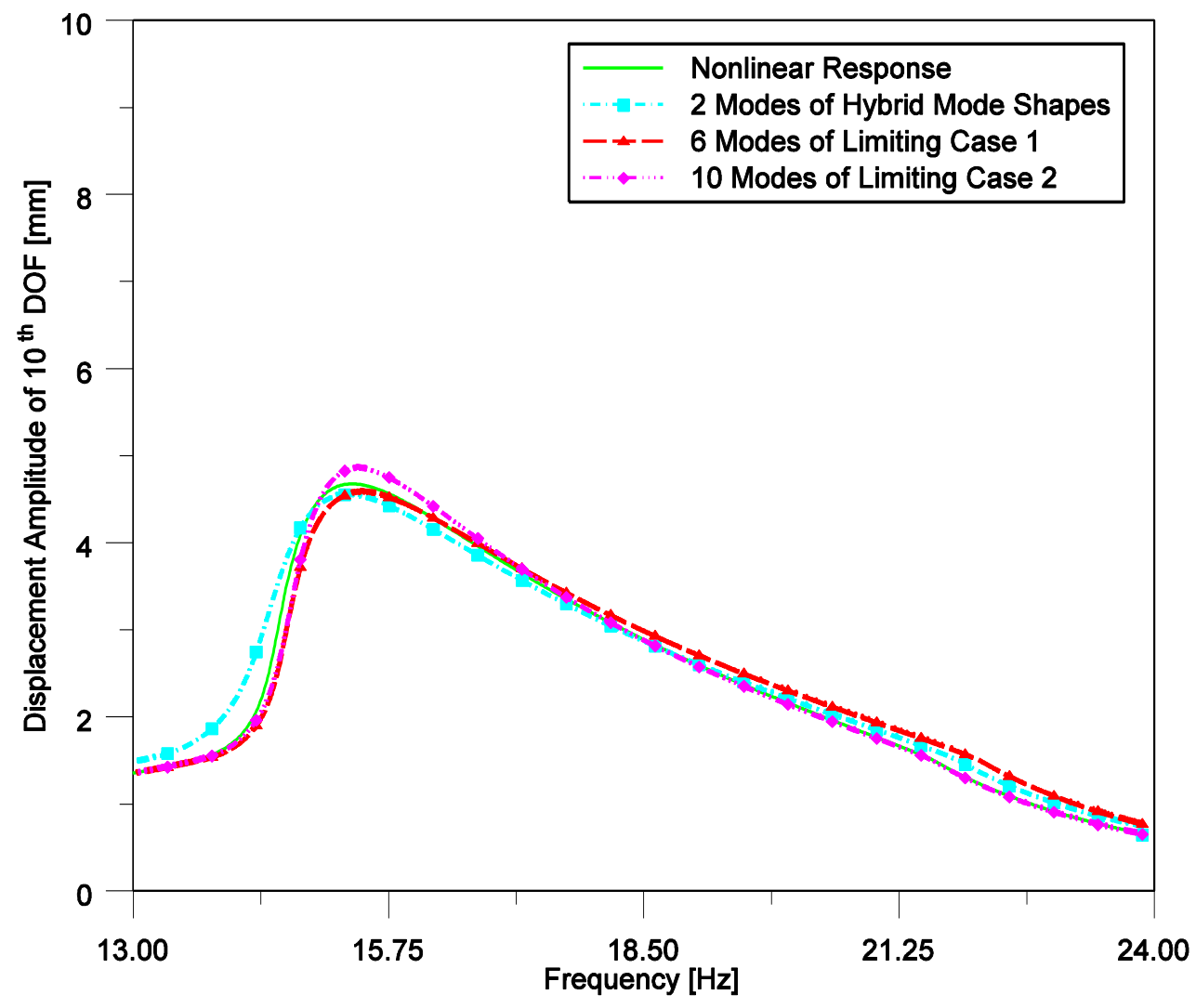

Figure 13 Effect of modes used on the displacement amplitude of the $10^{\text {th }}$ DOF around the first resonance for the second slip force values

Table 5 Error analysis for the $10^{\text {th }}$ DOF around the first resonance for the second slip force values

Number of Mode Shapes Integral Error Amplitude Error (\%) Frequency Error (\%)

$\begin{array}{cccc}\text { LC1 }-6 \text { Modes } & 1.3 & 1.9 & 0.6 \\ \text { LC2 }-10 \text { Modes } & 0.8 & 4.0 & 0.4 \\ \text { 2 Hybrid Modes } & 1.5 & 2.5 & 0.4\end{array}$




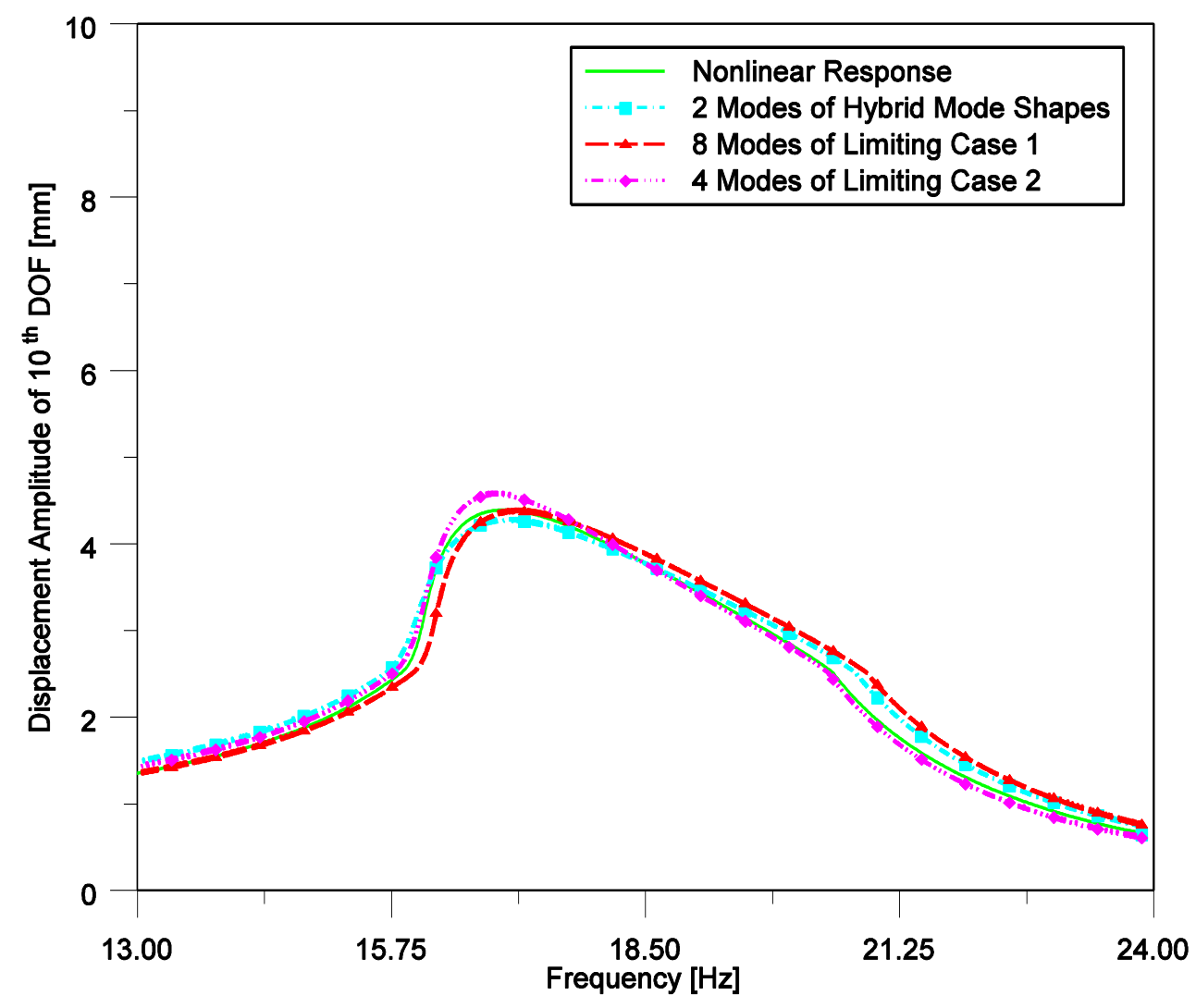

Figure 14 Effect of modes used on the displacement amplitude of the $10^{\text {th }}$ DOF around the first resonance for the third slip force values

Table 6 Error analysis for the $10^{\text {th }}$ DOF around the first resonance for the third slip force values

Number of Mode Shapes Integral Error Amplitude Error (\%) Frequency Error (\%)

$\begin{array}{llll}\text { LC1 }-8 \text { Modes } & 1.5 & 0.3 & 0.9 \\ \text { LC2 }-4 \text { Modes } & 0.8 & 4.2 & 0.5 \\ \text { 2 Hybrid Modes } & 1.2 & 2.6 & 0.2\end{array}$

In order to observe how the weighting factor $\alpha$ changes as a function of frequency, its variation is given in Figure 15 for the three different slip loads used in the case studies. As explained previously, limiting case 1 is equivalent to linear system with no nonlinear element which corresponds to the case where the displacement amplitudes are high and the majority of a cycle is governed by slip state. Therefore, for such cases weighting factor should be equal to zero, since the modes of limiting case 1 are the exact basis for the response. On the other hand, limiting case 2 is the 
case where dry friction element sticks, which occurs at small displacement amplitudes. For such cases, since the modes of limiting case 2 are the exact basis for the response, weighting factor should be equal to 1 . For any other nonlinear case, the weighting factor takes a value in between 0 to 1 . It can be seen from Figure 15 that weighting factor equals to 1 away from the resonance region, since the displacement amplitude is small as a result of which nonlinear element is in fully stuck state. However, when the response amplitude gets larger, slip starts and the weighting factor starts to decrease from 1, and it takes its minimum value at the maximum displacement amplitude value at resonance frequency. Moreover, since percentage of a cycle governed by slip state increases as the slip force decreases, the weighting factor becomes smaller and it deviates from 1 in a wider frequency range.

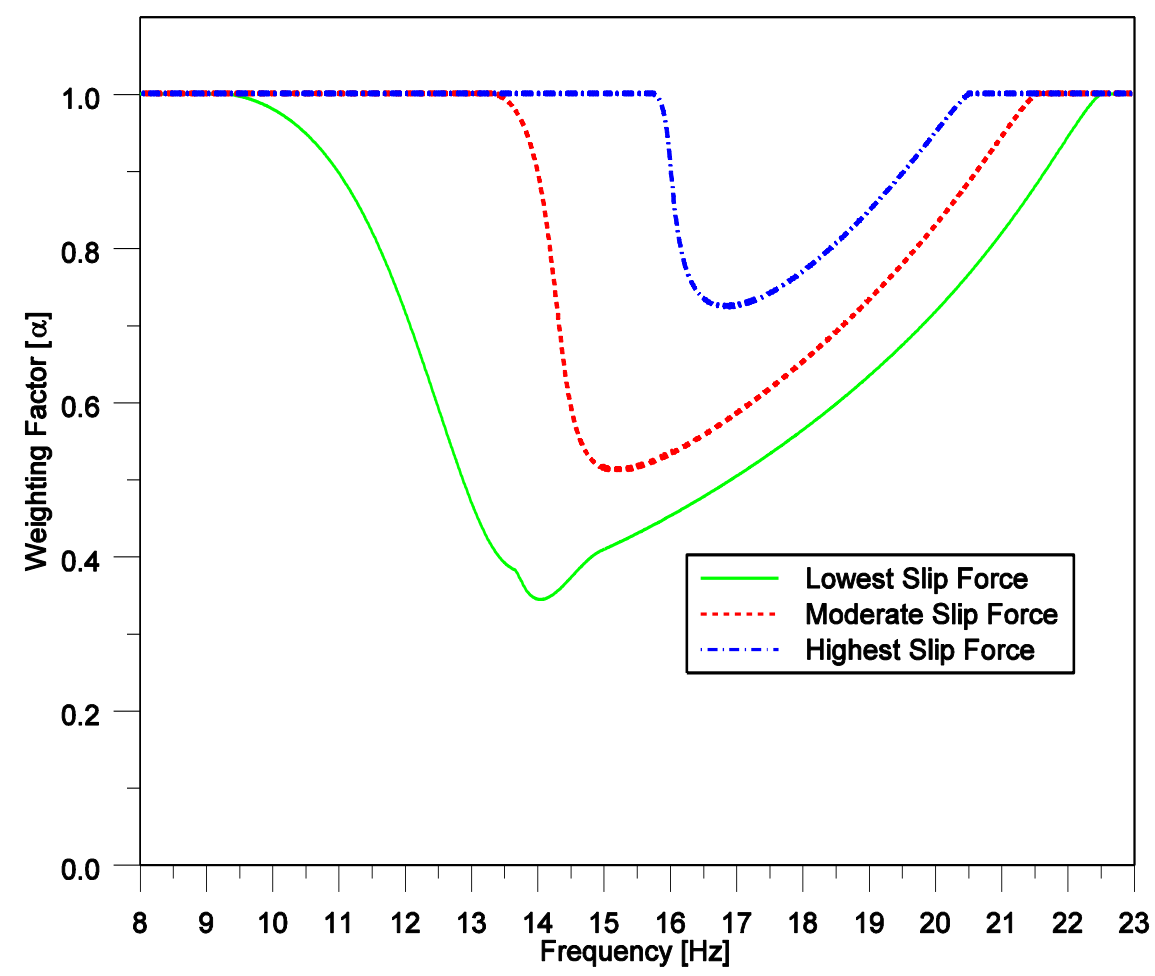

Figure 15 Variation of weighting factor $\alpha$ with respect to frequency

\subsubsection{Case Study 3: Gap and Dry Friction Elements Together}

In this case study, gap and dry friction nonlinear elements are used simultaneously. Here, it is specifically intended to increase the nonlinear effect in the system by coupling different types of nonlinearities. As a result of this, it becomes very hard to 
capture the nonlinear response by using small number of the modes. In this case, there exist two limiting cases. The first one is the original linear system in which the limiting equivalent stiffness is zero, i.e. no nonlinear element exists in the system. On the other hand, limiting case 2 corresponds to the case where the effect of both contact stiffness of the dry friction and stiffness element of gap element are taken into account.

In Figure 16, nonlinear response of the $12^{\text {th }}$ DOF is given. The strong nonlinear effects present in the system can clearly be seen in this figure. Figure 17a, Figure 17b and Figure 17c show the response of the same DOF calculated by using modes of limiting case 1 , modes of limiting case 2 and hybrid mode shapes. It is seen that utilizing only a single hybrid mode shape gives very accurate results. In order to obtain similar accuracy 12 modes of limiting case 2 are required in the modal superposition approach, and the nonlinear dynamics cannot be captured accurately even using 12 modes of limiting case 1. Error values in terms of each error criterion are given in Table 7 which clearly shows that utilizing a single hybrid mode shape outperforms the use of 12 modes of both limiting cases. Moreover, in addition to the error values, computational time required by each method is given in the final column of Table 7. The analyses are performed on a computer with Intel(R) Xeon(R) CPU E5-1620 v2 @3.70 GHz processor, 16GB or RAM and 64-bit operating system. Analyses are repeated five times and average of these five calculations is recorded as the computational time. It can be seen that the computational time increases as the number of mode shapes used in the modal superposition approach increases, as expected. But the increase in the computational time is more than the increase in the number of nonlinear equations, due to the quadratic increase in the memory requirements, Jacobian matrix evaluations and matrix calculations required in the solution process. This increase in computational time becomes more drastic if multiple harmonics are used in the calculations. For this particular case, modal superposition method with hybrid mode shapes decreased the computational time required approximately $85 \%$. 


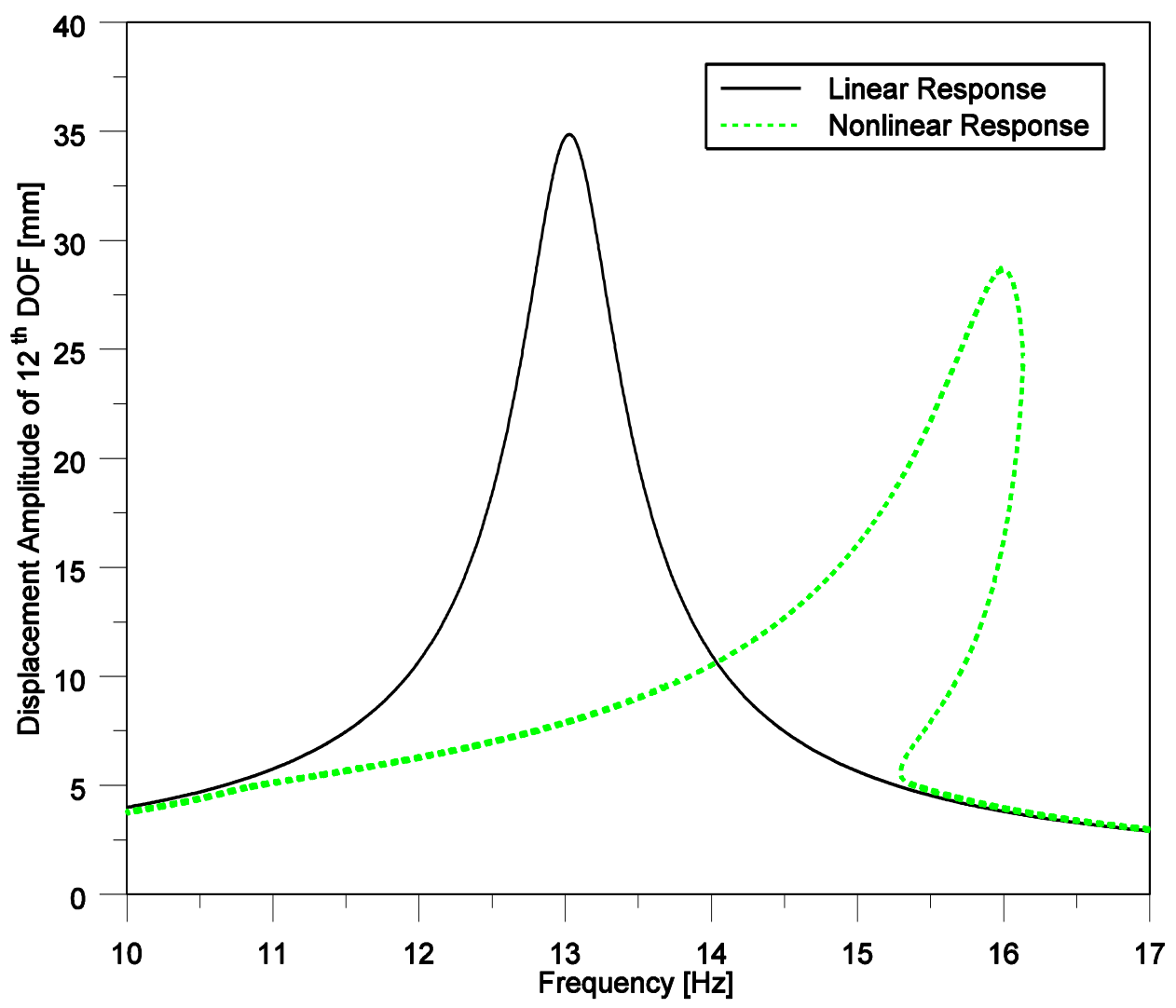

Figure 16 Displacement amplitudes of the $12^{\text {th }}$ DOF vs. frequency

(a)

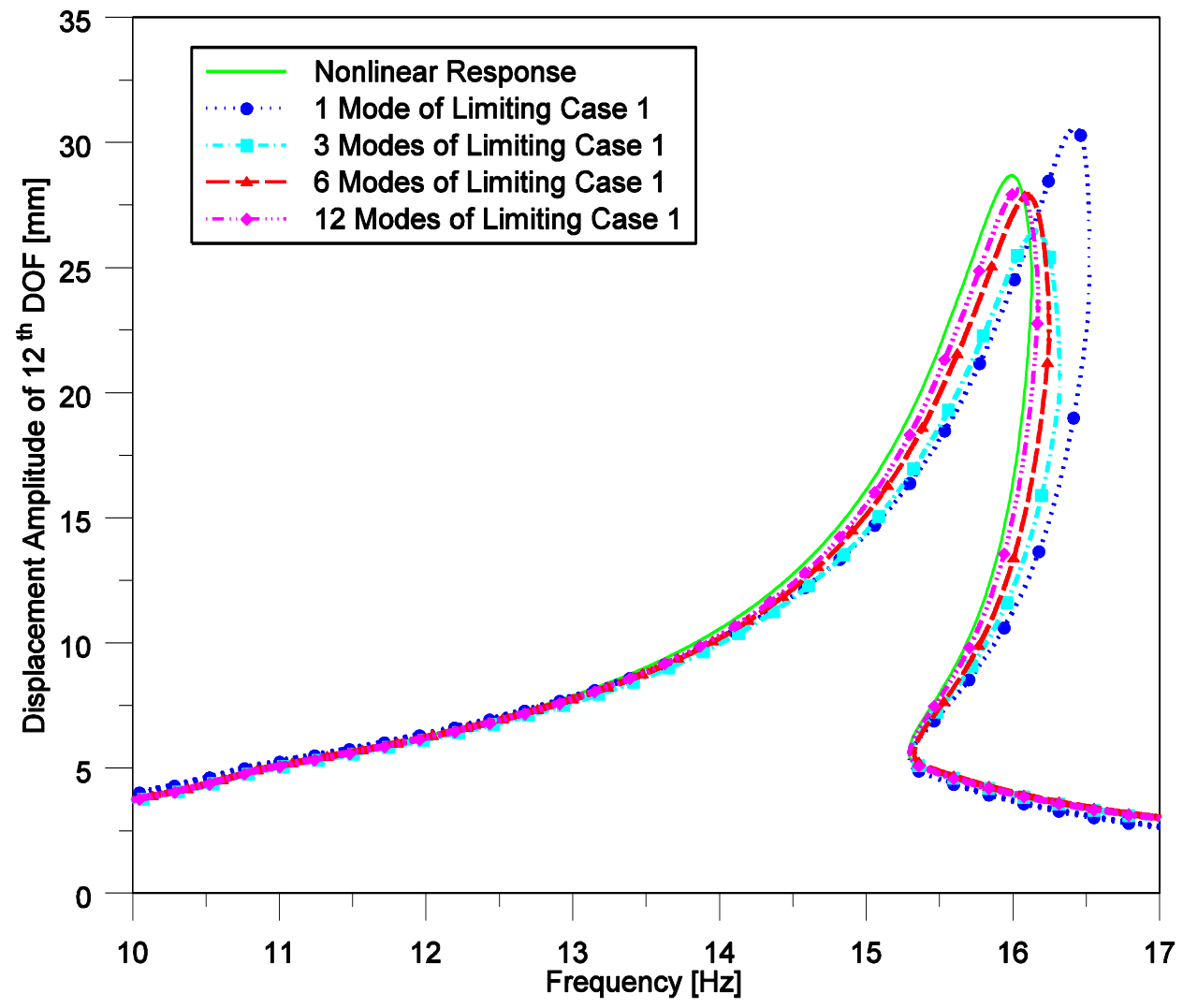


(b)

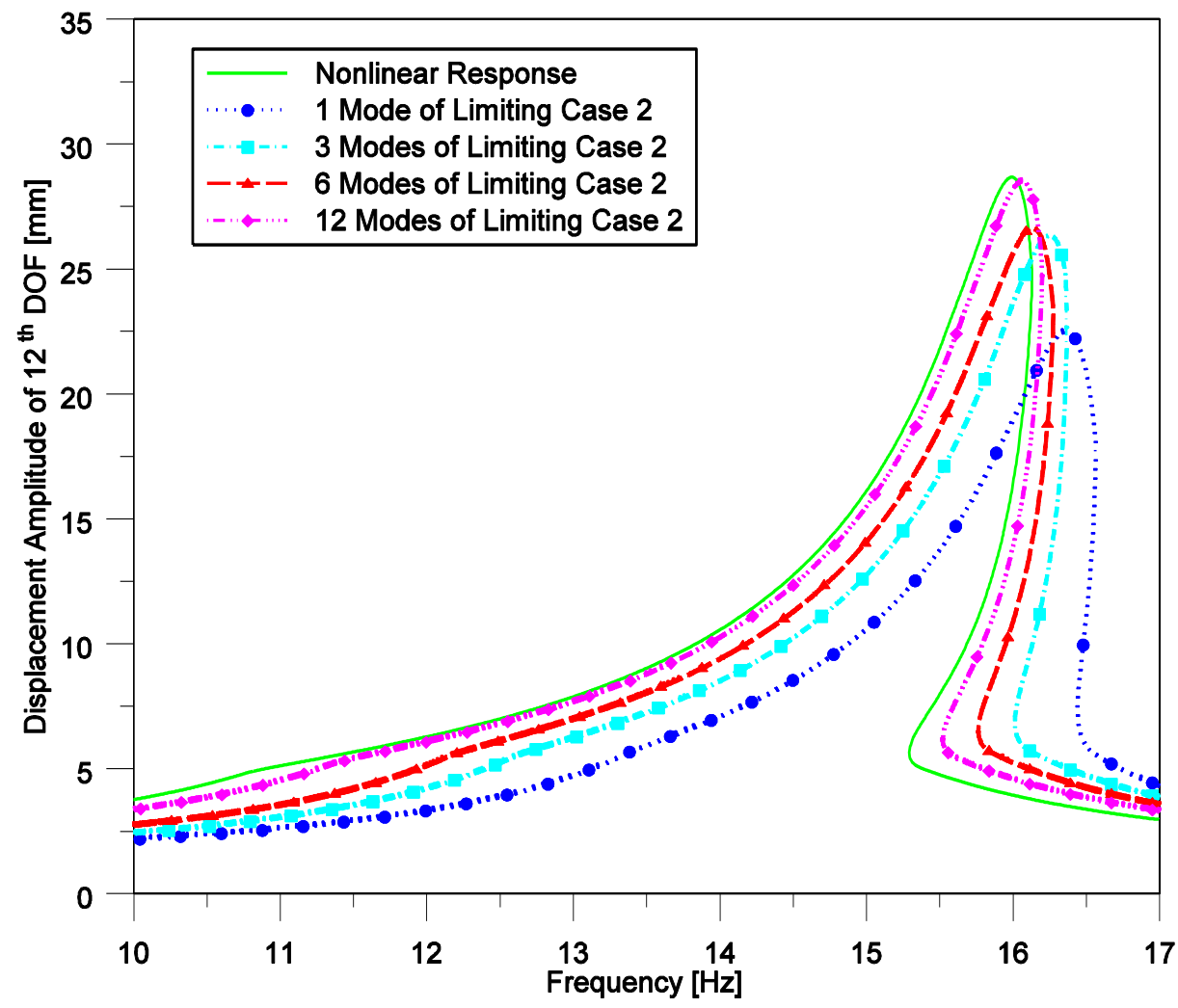

(c)

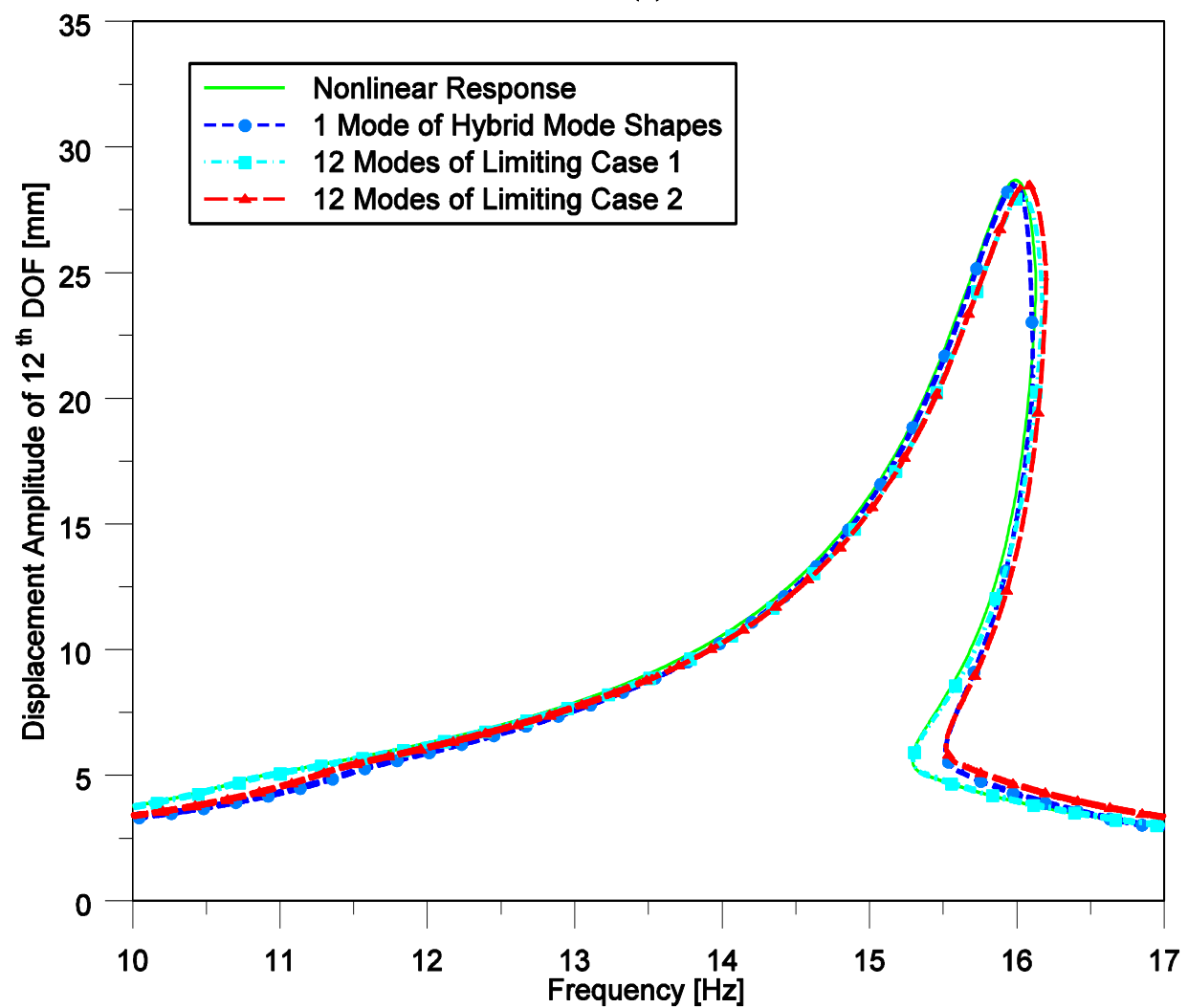

Figure 17 Effect of number of modes used on the displacement amplitude of the $12^{\text {th }}$ DOF around the first resonance 
Table 7 Error analysis for the $12^{\text {th }}$ DOF around the first resonance

\begin{tabular}{ccccc}
$\begin{array}{c}\text { Number of } \\
\text { Mode Shapes }\end{array}$ & $\begin{array}{c}\text { Integral } \\
\text { Error }\end{array}$ & $\begin{array}{c}\text { Amplitude } \\
\text { Error }(\%)\end{array}$ & $\begin{array}{c}\text { Frequency } \\
\text { Error }(\%)\end{array}$ & $\begin{array}{c}\text { Computational } \\
\text { Time [s] }\end{array}$ \\
\hline Exact Solution & - & - & - & 18.6 \\
LC1 -1 Mode & 41.5 & 6.7 & 2.7 & 1.49 \\
LC1 - 3 Modes & 25.4 & 7.8 & 1.0 & 2.55 \\
LC1 -6 Modes & 20.3 & 2.7 & 0.7 & 4.21 \\
LC1 - 12 Modes & 11.8 & 2.1 & 0.2 & 10.26 \\
LC2 - 1 Mode & 40.6 & 21.5 & 2.3 & 1.16 \\
LC2 - 3 Modes & 32.0 & 8.1 & 1.6 & 2.23 \\
LC2 -6 Modes & 23.3 & 7.0 & 0.9 & 4.07 \\
LC2 - 12 Modes & 15.5 & 0.5 & 0.4 & 10.11 \\
1 Hybrid Mode & 8.2 & 0.7 & 0.05 & 1.53
\end{tabular}

\subsubsection{Case Study 4: Cubic Stiffness Element}

In this case study, cubic stiffness nonlinearity, which does not possess limiting or saturating behavior, is used in order to demonstrate the applicability of the proposed method for nonlinearities for which a limiting system cannot be defined physically. It should be noted that as the displacement amplitude increases, the nonlinear stiffness does not show a saturating behavior for cubic stiffness. However, the response of the nonlinear system is limited for a case depending on the forcing amplitude and frequency range of interest. Hence, even though the equivalent stiffness is an unbounded function of displacement amplitude, since the amplitude is bounded so as the equivalent stiffness associated with the nonlinearity. Therefore, if the maximum displacement amplitude can be estimated, the second limiting case can be defined for these types of nonlinearities. For cubic stiffness, the nonlinear internal force and the corresponding describing function for single harmonic input is given as

$$
f_{N}=k_{c} x^{3}, \quad v=\frac{3}{4} k_{c} A^{2}
$$

where $A$ is the amplitude of the single harmonic motion. Describing function given in Eq. (4.4) is the equivalent stiffness of the cubic stiffness nonlinearity and if the maximum displacement amplitude can be estimated roughly, the second limiting case can be obtained by adding this equivalent stiffness to the original linear system. In 
this case study, two different values of maximum displacement amplitude are considered. In one of them the maximum amplitude of the exact nonlinear solution, i.e. $27.5 \mathrm{~mm}$, is used and in the second one the maximum amplitude of the linear system, i.e. $35 \mathrm{~mm}$, is used to determine the mode shapes of limiting case 2 . The results obtained for this case study is given in Figure 18. It can be seen from the results that using limiting case 2 obtained from the exact nonlinear maximum amplitude gives very accurate results. A single hybrid mode is sufficient to obtain better accuracy than using 12 modes of the linear system without any nonlinear element. However, before solving the system it is not possible to know the maximum amplitude of the linear system. The second maximum amplitude estimation has an error of approximately 27\%. By using limiting case 2 corresponding to this maximum displacement amplitude, similar accuracy as in the case of 12 linear modes is obtained by utilizing only 2 hybrid mode shapes. Therefore, it can be concluded that even in the presence of significant error in the estimation of the maximum displacement amplitude, the modal superposition method with hybrid mode shapes outperforms the modal superposition method utilizing the mode shapes of the linear system. The error values and the computational time spent for each case given in Table 8 also verify the conclusions obtained. It should be noted that it is also possible to use a two-step solution methodology for these types of nonlinearities. Firstly, maximum linear displacement amplitude can be used to obtain equivalent stiffness of limiting case 2 in order to get an estimation of the maximum nonlinear displacement amplitude by using a single hybrid mode. Then, this estimated nonlinear displacement amplitude can be used to improve the estimation of limiting case 2 and hence the hybrid mode shapes. The nonlinear system is re-solved by using the improved hybrid mode shapes which gives very accurate results by using the minimum number of hybrid modes. 
(a)

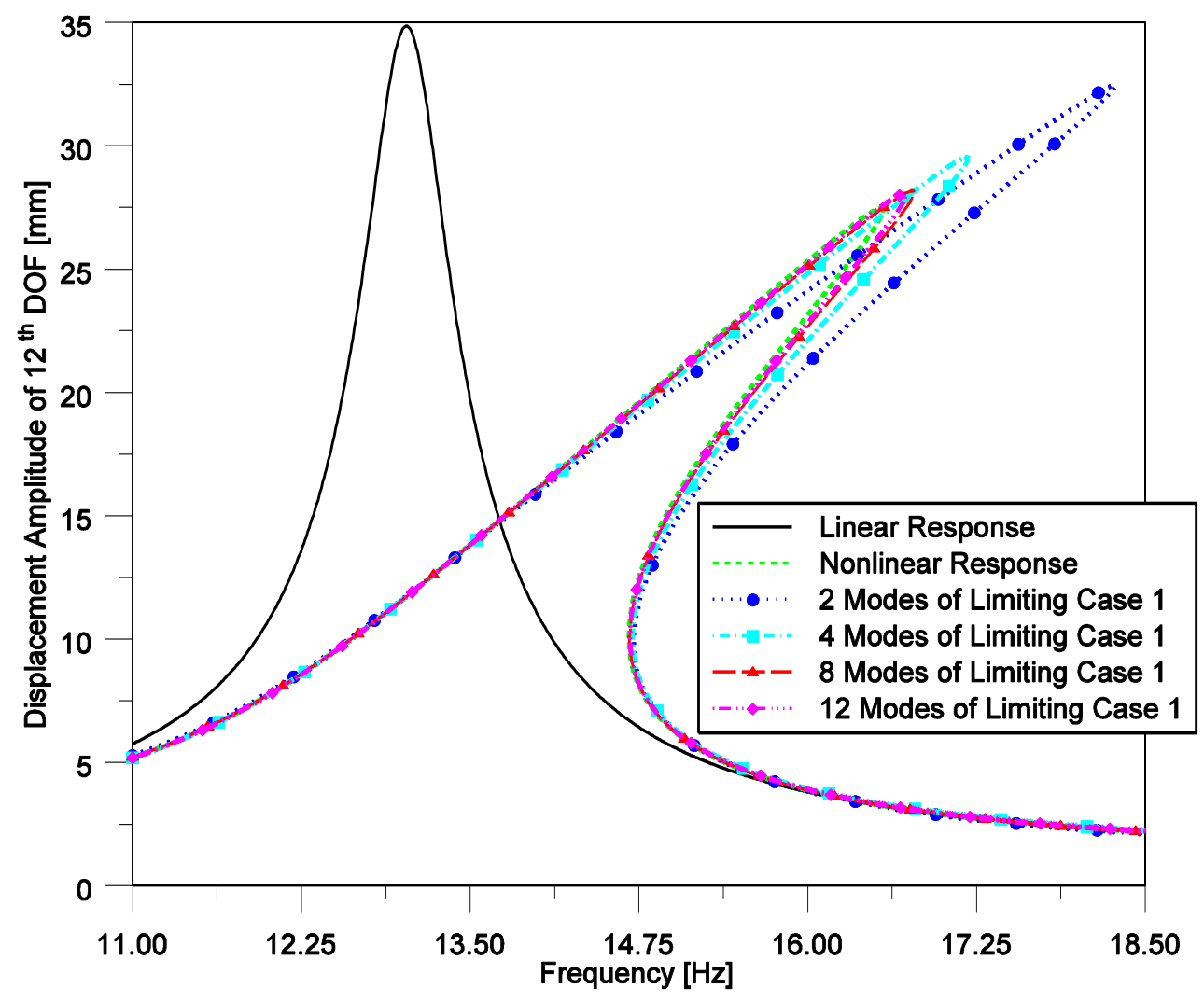

(b)

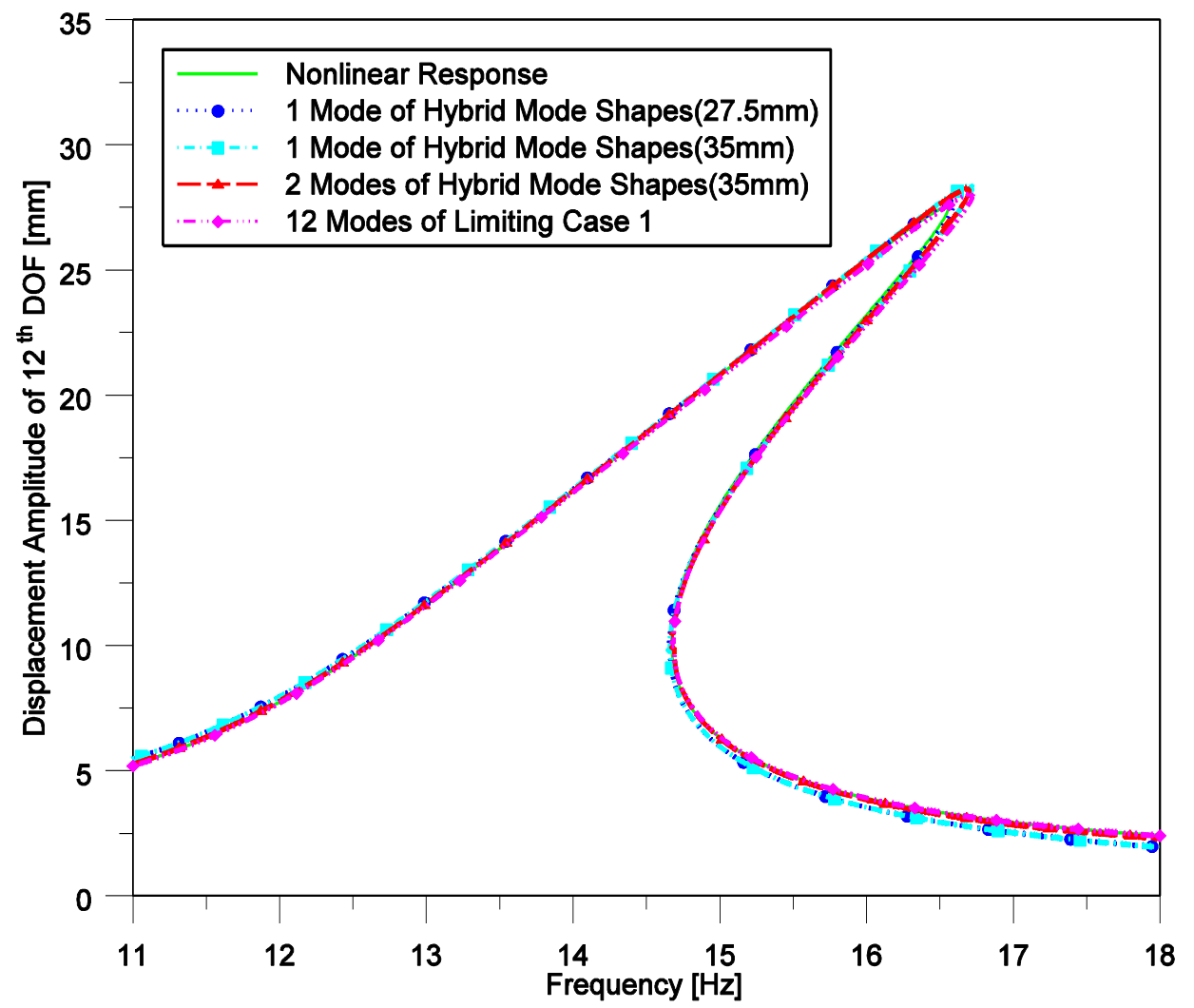

Figure 18 Effect of number of modes used on the displacement amplitude of the $12^{\text {th }}$ DOF around the first resonance 
Table 8 Error analysis for the $12^{\text {th }}$ DOF around the first resonance

\begin{tabular}{ccccc} 
Number of Mode Shapes & $\begin{array}{c}\text { Integral } \\
\text { Error }\end{array}$ & $\begin{array}{c}\text { Amplitude } \\
\text { Error (\%) }\end{array}$ & $\begin{array}{c}\text { Frequency } \\
\text { Error }(\%)\end{array}$ & $\begin{array}{c}\text { Computational } \\
\text { Time [s] }\end{array}$ \\
\hline Exact Solution & - & - & - & 11.4 \\
LC1 - 2 Modes & 88.4 & 18.1 & 10.4 & 1.44 \\
LC1 - 4 Modes & 50.6 & 7.5 & 3.8 & 2.00 \\
LC1 - 8 Modes & 29.6 & 2.6 & 1.4 & 4.15 \\
LC1 - 12 Modes & 25.0 & 2.1 & 1.0 & 6.21 \\
1 Hybrid Mode (35mm) & 24.9 & 3.3 & 1.0 & 1.27 \\
2 Hybrid Modes (35mm) & 22.9 & 2.8 & 0.9 & 1.69 \\
1 Hybrid Mode (27.5mm) & 12.0 & 0.9 & 0.2 & 1.25
\end{tabular}

\subsection{Finite Element Model}

Application of the proposed method is also shown on a large scale finite element model (FEM). A cantilever beam having extensions in all three perpendicular axes is modeled using a commercial finite element software as shown in Figure 19, where the finite element model has 5400 number of degrees of freedom. This structure is considered due to the fact that several modes of the system affect each other. The results obtained for a wide frequency range showed that the nonlinearities considered affect several modes of the system; however, for brevity only the results around specific resonance frequencies are given in the thesis. The first 30 modes of the finite element model are used to calculate the system response in the frequency range of interest for comparison purposes.

Three different harmonic excitation forces are applied to the model at excitation point as shown in Figure 19. The first force is applied in the $X$ direction with $5 \mathrm{~N}$ amplitude, whereas the second and the third ones are applied in the direction of $\mathrm{Y}$ and $\mathrm{Z}$ with $30 \mathrm{~N}$ amplitude. It should be noted that with this type of forcing more modes of the system are expected to be excited which will be a good example to show the performance of the modal superposition approach with hybrid mode shapes. 


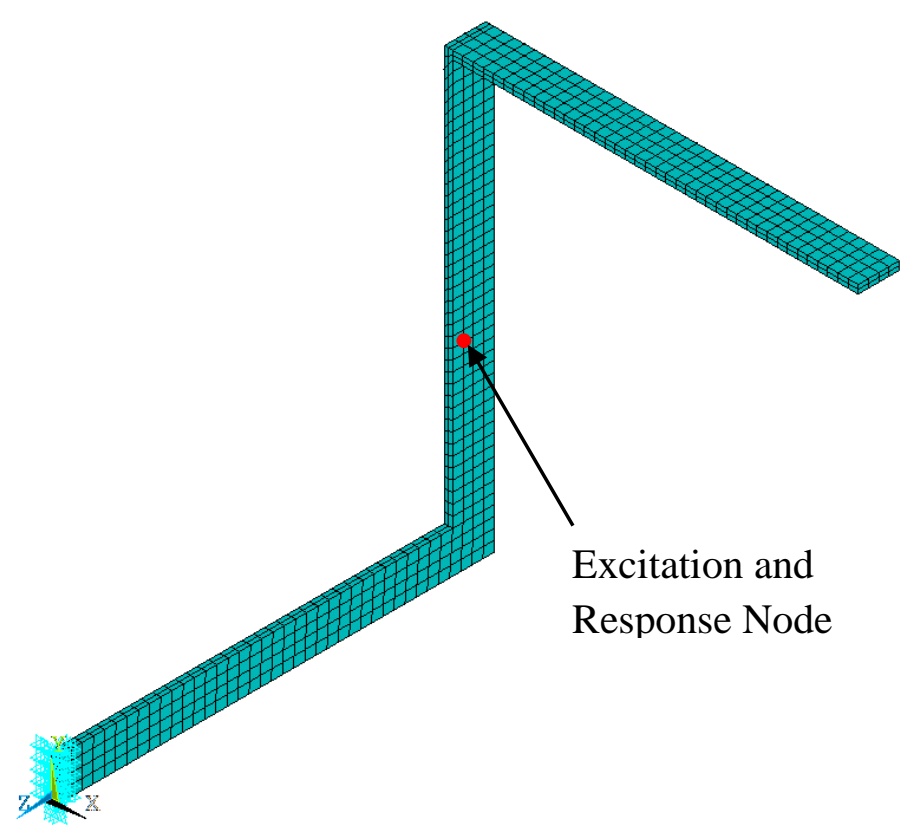

Figure 19 Finite Element Model

Three case studies are presented by using this finite element model. 15 nonlinear elements are inserted into the system. The first two case studies include one of the two nonlinearity types; whereas, the last one has two different types of nonlinear elements simultaneously. These elements are placed to different locations of the finite element model so that capturing the nonlinear dynamics of the system requires high number of modes in the modal superposition approach. The nonlinearity types and their properties are given in Table 9.

Table 9 Nonlinear Element Types Used in the Case Studies

\begin{tabular}{lclc}
$\begin{array}{c}\text { Nonlinearity } \\
\text { Type }\end{array}$ & Quantity & \multicolumn{1}{c}{ Insertion DOFs } & Properties \\
\hline Dry Friction & 15 & $\begin{array}{l}\text { Different locations } \\
\text { of FEM - ground } \\
\text { Different locations } \\
\text { of FEM - ground }\end{array}$ & $\begin{array}{c}k_{d}=500 \mathrm{~N} / \mathrm{m}, \mu \mathrm{N}=0.75 \mathrm{~N}, \\
(\text { same for all) }\end{array}$ \\
Gap & 15 & $\begin{array}{c}\text { De00 } \mathrm{N} / \mathrm{m} \delta=0.004 \mathrm{~m} \\
(\mathrm{same} \text { for all) }\end{array}$ \\
Gap and Dry & 5,10 & $\begin{array}{l}\text { Different locations } \\
\text { of FEM - ground }\end{array}$ & $\begin{array}{c}k=1000 \mathrm{~N} / \mathrm{m} \delta=0.004 \mathrm{~m} \\
k_{d}=500 \mathrm{~N} / \mathrm{m}, \mu \mathrm{N}=0.75 \mathrm{~N}\end{array}$
\end{tabular}




\subsubsection{Case Study 5: Dry Friction Element}

Response of the $\mathrm{X}$ component of interested point around the first resonance frequency is given in Figure 20. It is clearly seen from the figure that response of the point changes significantly due to nonlinear effects of dry friction. In Figure 21a, Figure 21b and Figure 21c, response of the selected point is computed by using modes of limiting case 1 , limiting case 2 and hybrid mode shapes, respectively. It is seen from the obtained results that using even 1 hybrid mode shape gives very accurate results than the 4 mode shapes of limiting case 1 and limiting case 2 . If 2 hybrid mode shapes are used the results become better as can be also seen from the error values given in Table 10. It can also be noted that nonlinear response follows the fully stuck response and around the resonance region it deviates from the fully stuck linear response, i.e. limiting case 2, as shown in Figure 21. Moreover, the nonlinear response is significantly different from the response of the free linear system, i.e. limiting case 1. Therefore, as expected, using four mode shapes of limiting case 2 captures the response of the nonlinear system better than utilizing four mode shapes of limiting case 1 .

Moreover, variation of weighting factor $\alpha$ is also given in Figure 22 for dry friction nonlinearity. It can be seen from Figure 22 that weighting factor equals to 1 away from the resonance region, since the displacement amplitude is small as a result of which nonlinear element is in fully stuck state, as expected. It takes smaller values when slip starts as explained in Section 4.1.2. Increasing the number of hybrid mode shapes also affects the variation of the weighting factor, which improves the accuracy of the solution. 


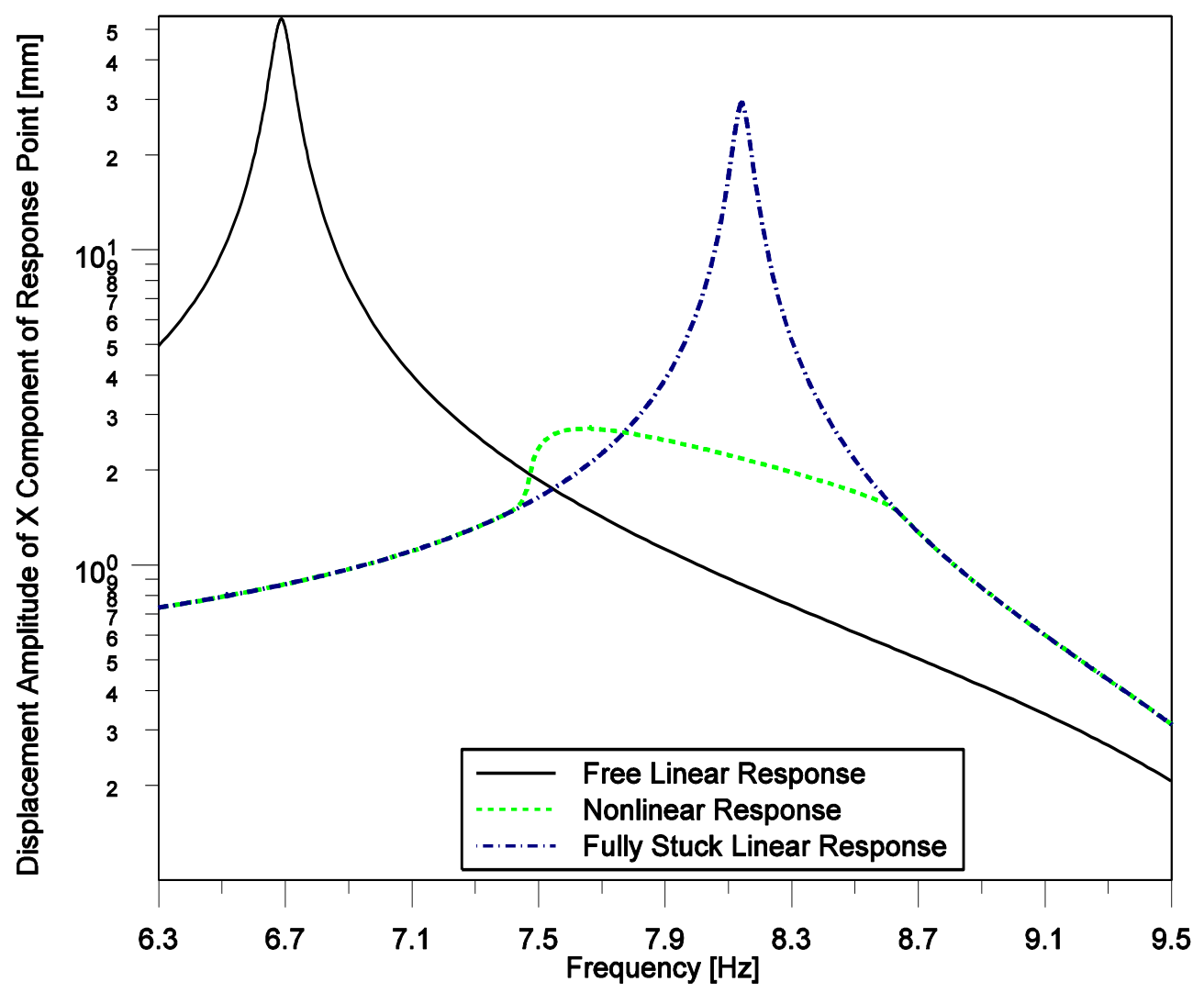

Figure 20 Displacement amplitude of $\mathrm{X}$ component of response node with respect to frequency around the first resonance region

(a)

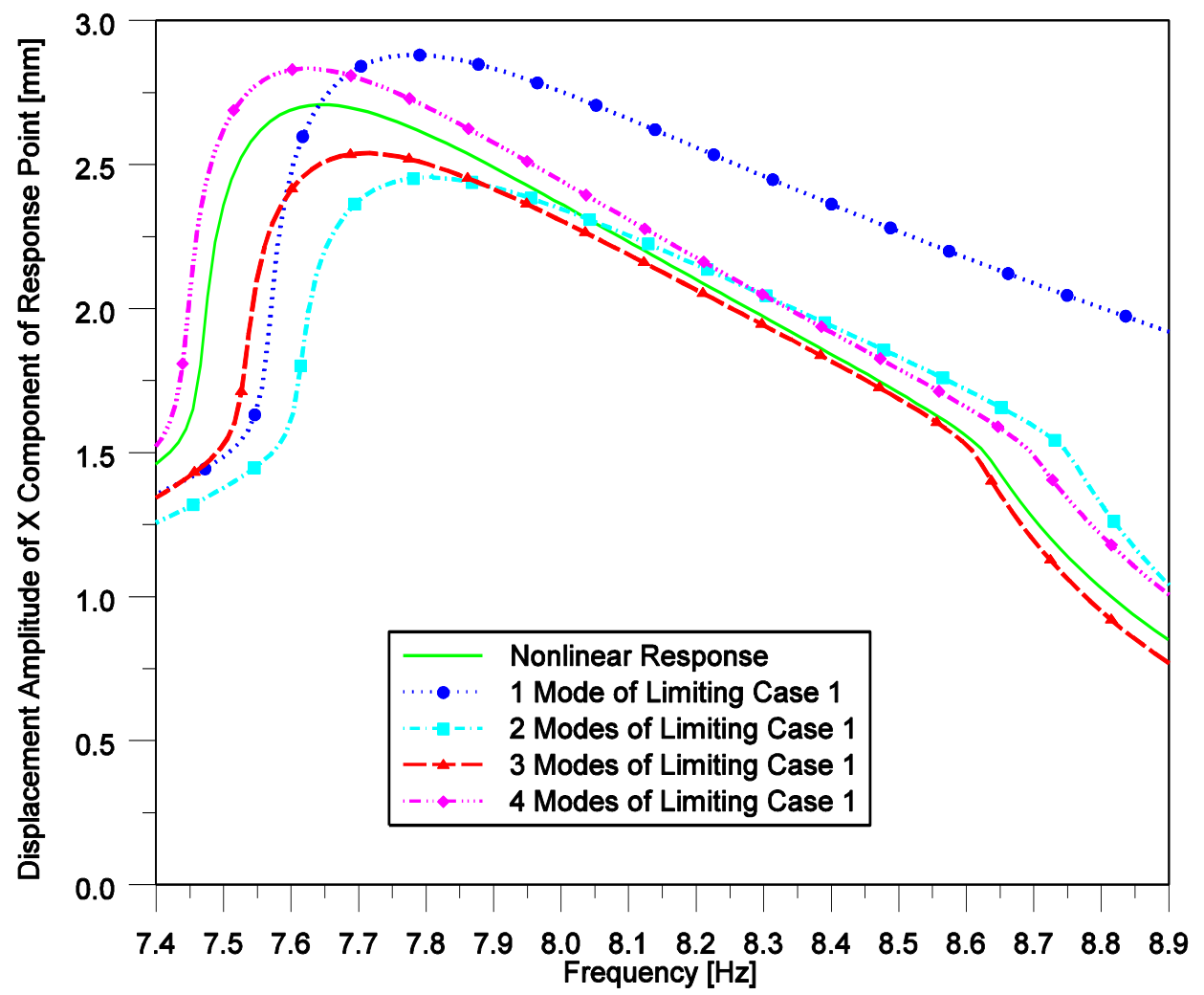


(b)

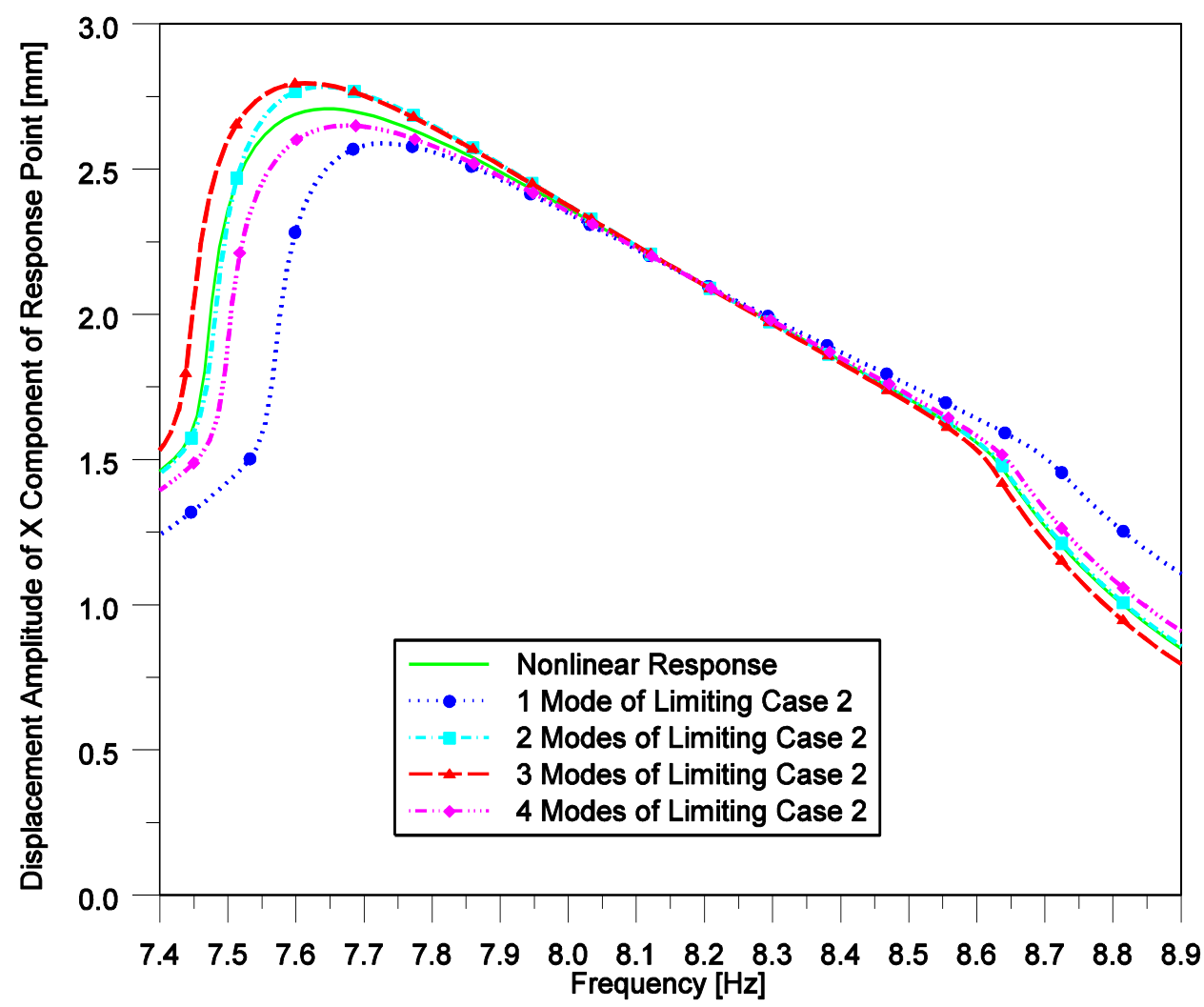

(c)

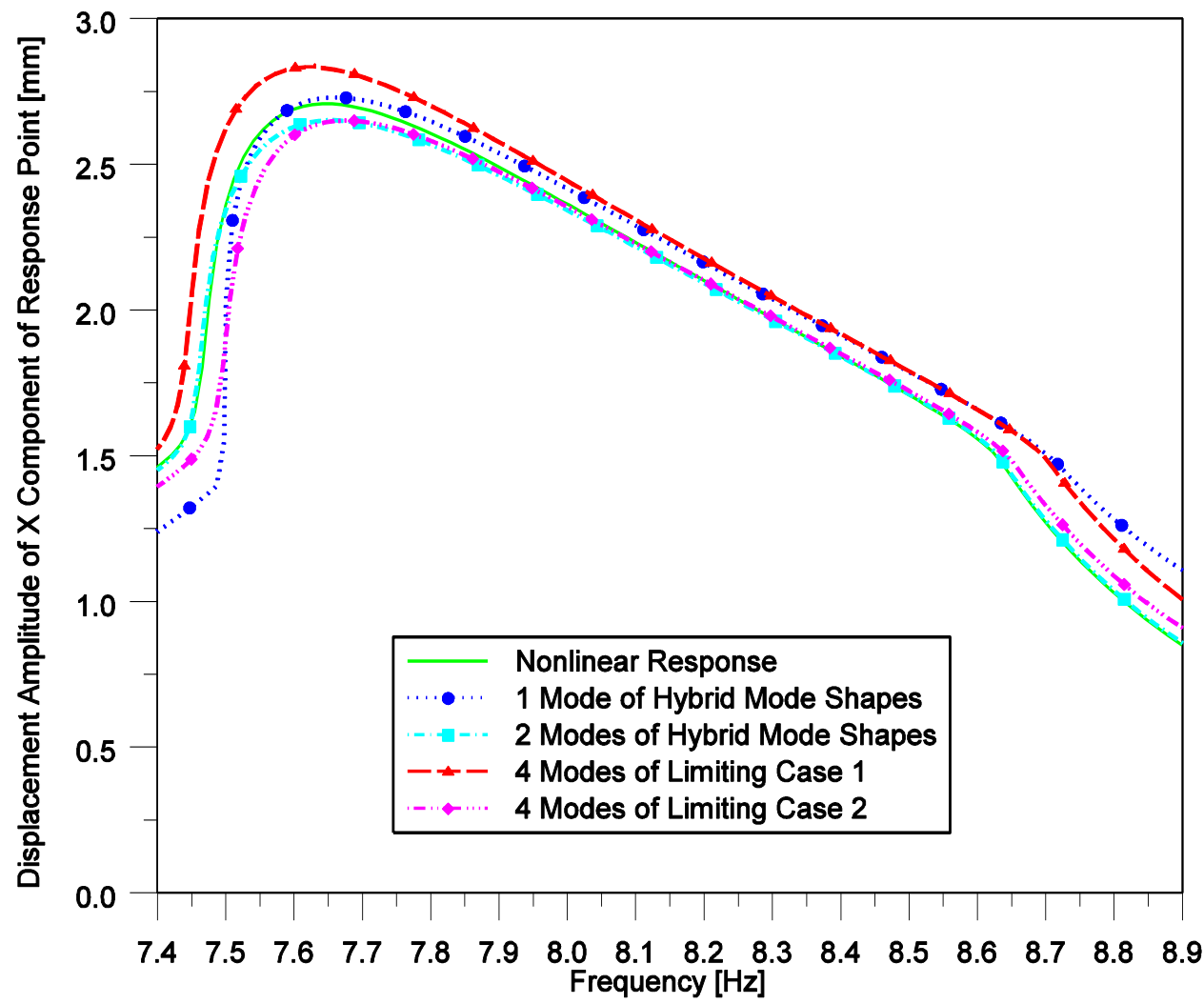

Figure 21 Effect of number of modes used on the displacement amplitude of the response node in $\mathrm{X}$-direction around the first resonance 
Table 10 Error analysis for the response node around the first resonance

Number of Mode Shapes Integral Error Amplitude Error (\%) Frequency Error (\%)

$\begin{array}{cccc}\text { LC1 }-1 \text { Mode } & 1.8 & 6.5 & 1.8 \\ \text { LC1 }-2 \text { Modes } & 1.2 & 9.3 & 2.2 \\ \text { LC1 }-3 \text { Modes } & 0.7 & 6.1 & 1.0 \\ \text { LC1 }-4 \text { Modes } & 0.5 & 4.7 & 0.3 \\ \text { LC2 }-1 \text { Mode } & 0.9 & 4.3 & 1.1 \\ \text { LC2 - 2 Modes } & 0.1 & 2.9 & 0.001 \\ \text { LC2 - 3 Modes } & 0.3 & 3.4 & 0.4 \\ \text { LC2 - 4 Modes } & 0.3 & 2.0 & 0.4 \\ \text { 1 Hybrid Mode } & 0.5 & 0.9 & 0.3 \\ \text { 2 Hybrid Modes } & 0.08 & 2.0 & 0.1\end{array}$

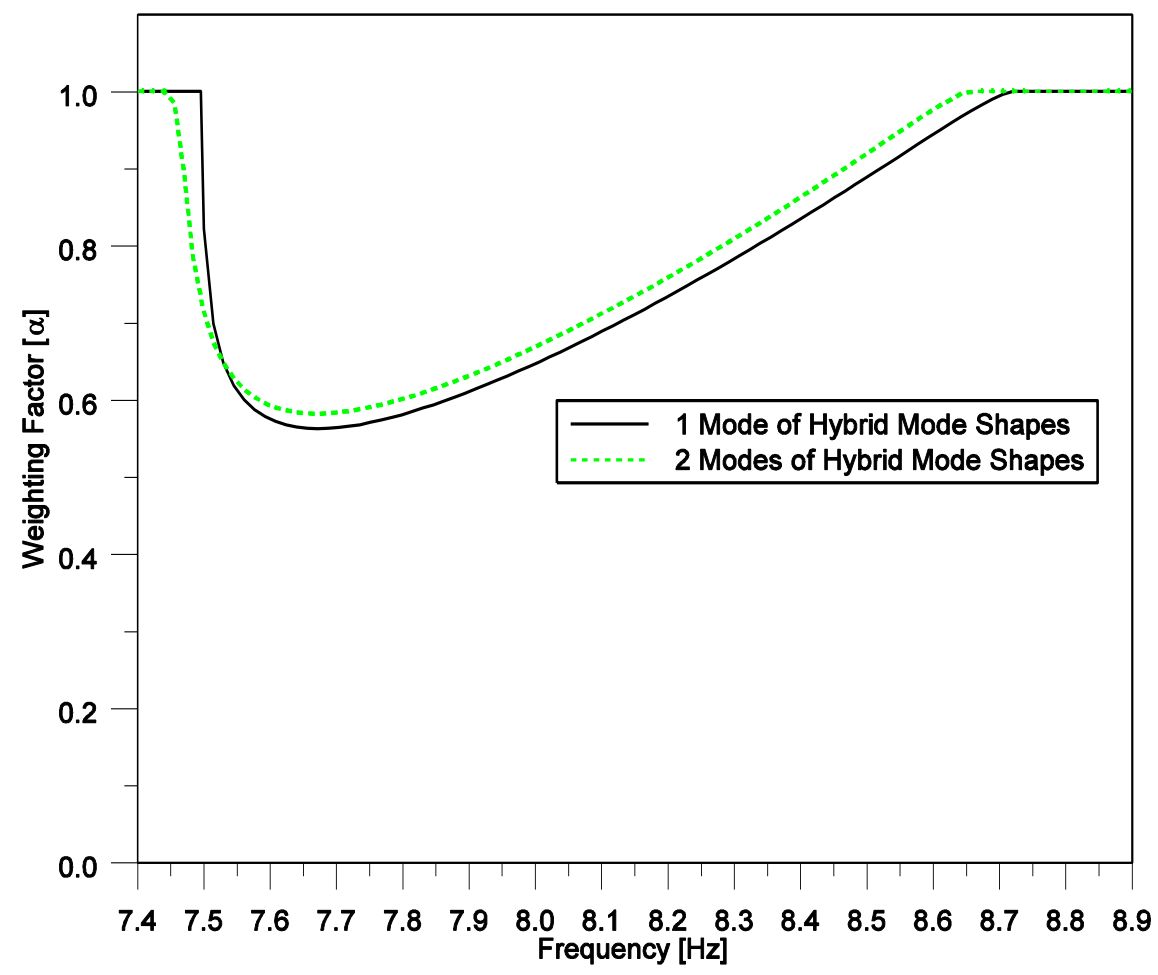

Figure 22 Variation of weighting factor $\alpha$ with respect to frequency

\subsubsection{Case Study 6: Gap Element}

For gap nonlinearity, two limiting cases can be defined as discussed in Section 3.1. The first one corresponds to the case where all the gaps are open (limiting case 1) resulting in zero equivalent stiffness, which corresponds to the linear system without any nonlinear elements, and the second one is obtained when the vibration amplitude 
is large enough (limiting case 2) such that all the gap elements are observed as if they are always in contact (See Figure 2).

Figure 23 shows the displacement amplitude of $\mathrm{X}$ component of response node for the underlying linear system and that of the nonlinear system using 30 modes of the linear system. The effect of the gap element is clearly seen from the Figure 23, which shifts the resonance frequency considerably. It is seen from Figure 24 and the error values given in Table 11 that using even 2 hybrid modes gives more accurate results as the modal superposition method that uses 4 modes of limiting case 1 or 2 . The accuracy of the nonlinear response obtained by using 2 hybrid mode shapes is very similar to the base nonlinear response obtained by using 30 modes of the linear system.

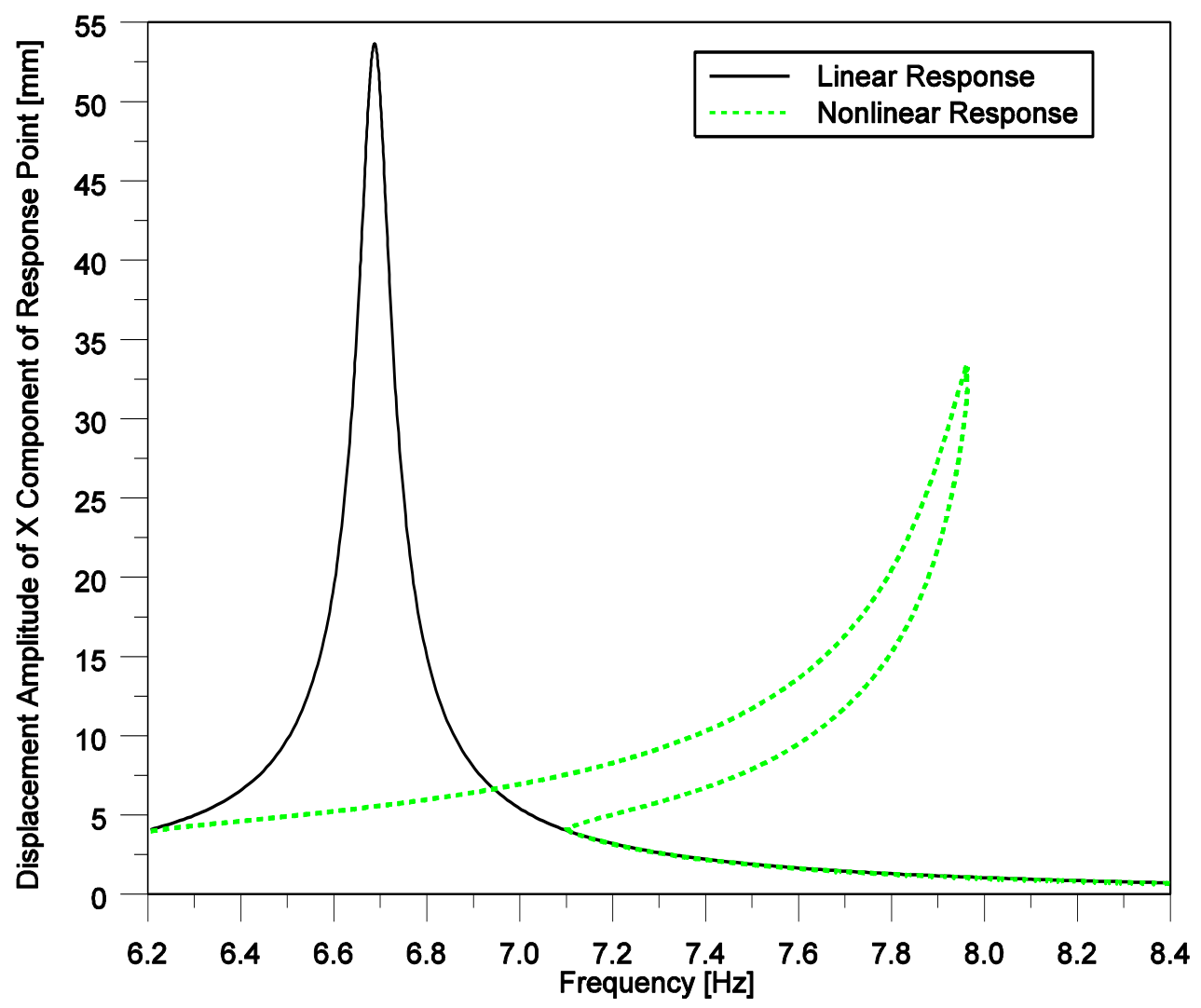

Figure 23 Displacement amplitude of $\mathrm{X}$ component of response node with respect to frequency around the first resonance region 
(a)

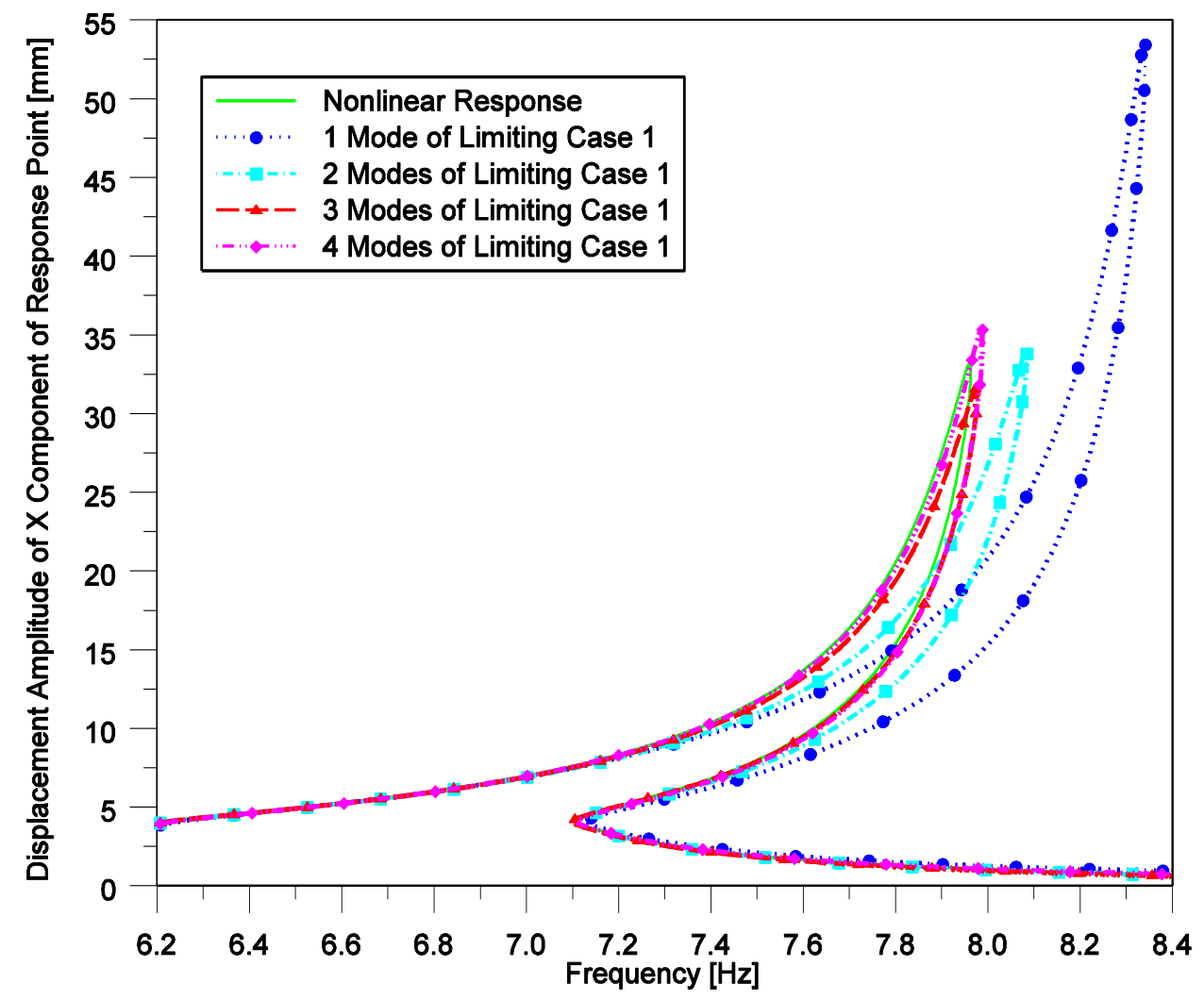

(b)

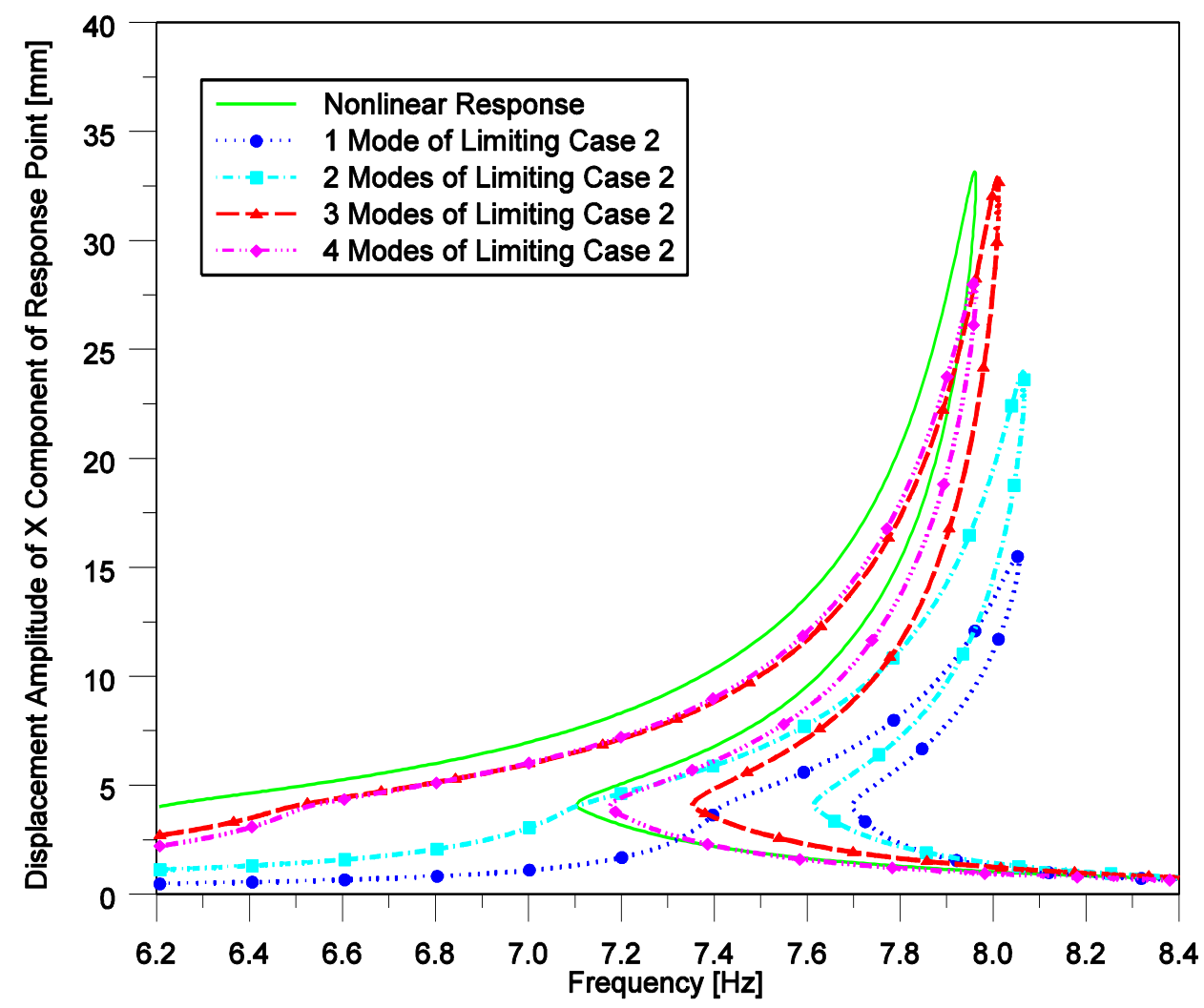


(c)

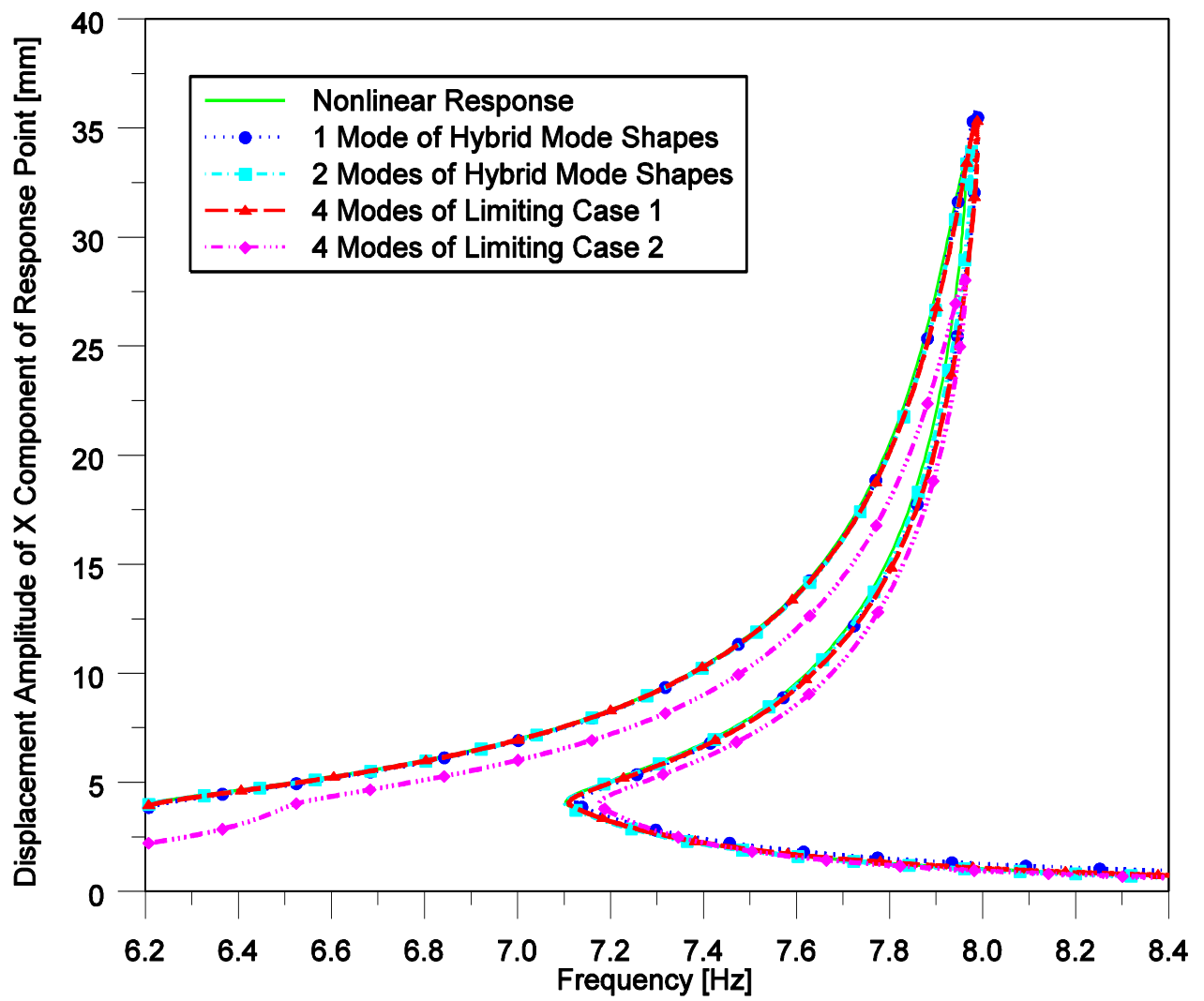

Figure 24 Effect of number of modes used on the displacement amplitude of the response node in $\mathrm{X}$-direction around the first resonance

Table 11 Error analysis for the response node around the first resonance Number of Mode Shapes Integral Error Amplitude Error (\%) Frequency Error (\%)

$\begin{array}{cccc}\text { LC1 }-1 \text { Mode } & 51.1 & 61.9 & 4.8 \\ \text { LC1 }-2 \text { Modes } & 25.5 & 2.4 & 1.5 \\ \text { LC1 }-3 \text { Modes } & 8.8 & 4.7 & 0.2 \\ \text { LC1 }-4 \text { Modes } & 13.4 & 6.8 & 0.3 \\ \text { LC2 }-1 \text { Mode } & 27.9 & 53.2 & 1.1 \\ \text { LC2 }-2 \text { Modes } & 24.9 & 27.8 & 1.3 \\ \text { LC2 }-3 \text { Modes } & 17.6 & 0.9 & 0.6 \\ \text { LC2 }-4 \text { Modes } & 6.2 & 15.0 & 0.01 \\ \text { 1 Hybrid Mode } & 13.6 & 8.3 & 0.3 \\ \text { 2 Hybrid Modes } & 9.3 & 2.6 & 0.2\end{array}$

The results of FE case study with gap nonlinearity at two additional nodes as shown in Figure 25 are also given in Figure 26 and Figure 27. It can be seen that hybrid mode shape approach gives similar results and solution follows the same pattern for 
different response points. Error values given in Table 12 and Table 13 also show the same argument. For other case studies and for different response nodes, similar results can be obtained. However, for brevity, the results for other response nodes are not shown.

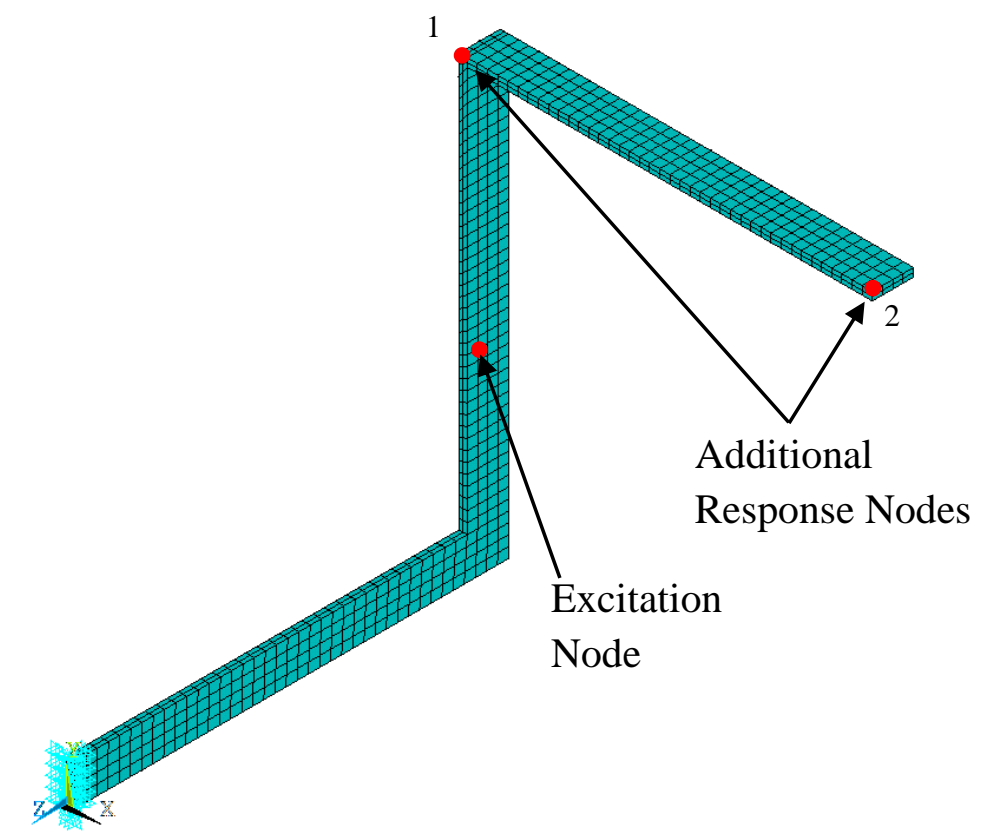

Figure 25 FE Model with additional response nodes

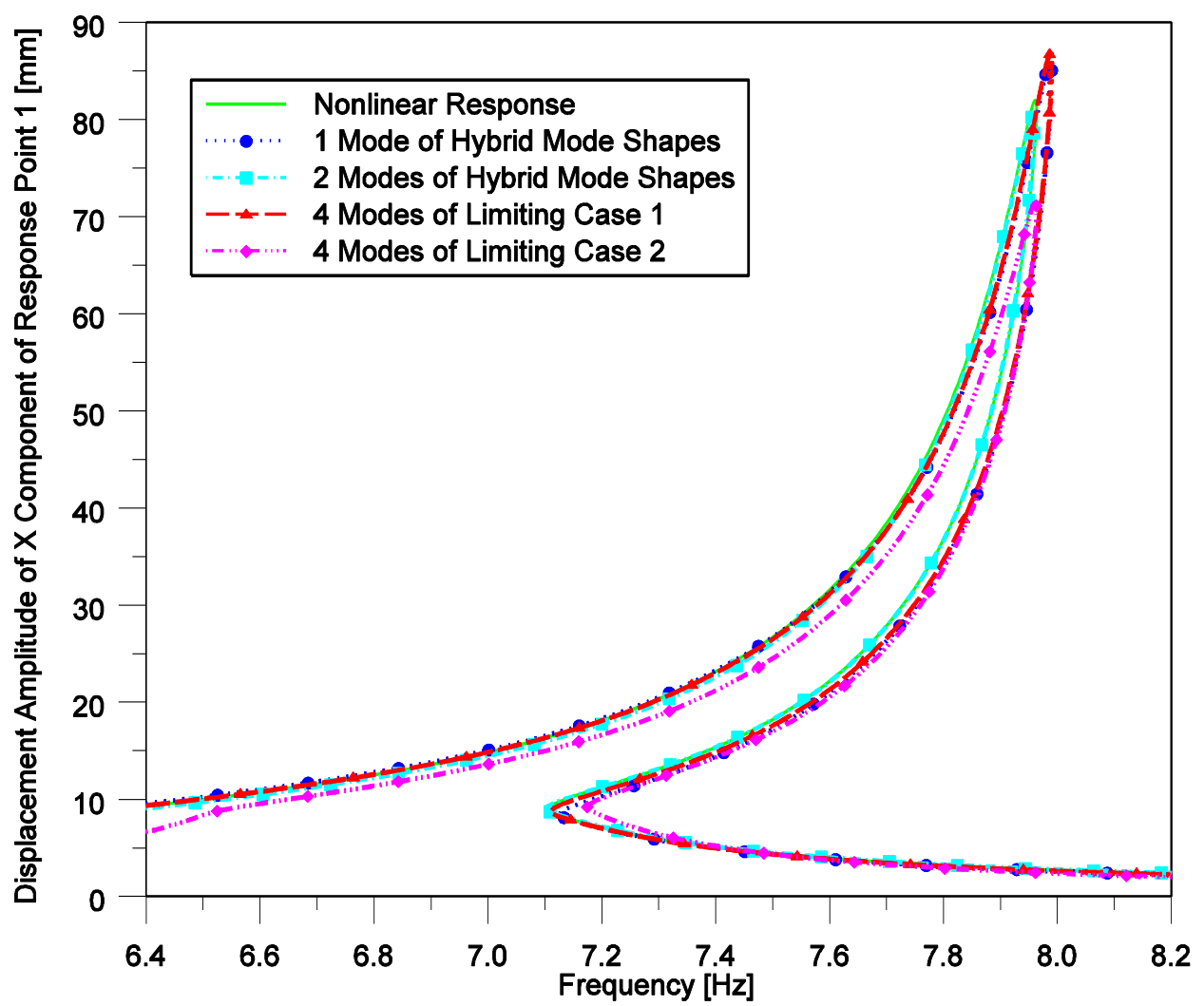

Figure 26 Displacement amplitude of $X$ component of the $1^{\text {st }}$ point vs. frequency 
Table 12 Error analysis for the $1^{\text {st }}$ point around the first resonance

\begin{tabular}{cccc} 
Number of Mode Shapes & Integral Error & Amplitude Error $(\%)$ & Frequency Error $(\%)$ \\
\hline LC1 -4 Modes & 32.3 & 5.9 & 0.3 \\
LC2 -4 Modes & 11.6 & 12.8 & 0.01 \\
1 Hybrid Mode & 32.5 & 5.0 & 0.3 \\
2 Hybrid Modes & 14.3 & 1.9 & 0.06
\end{tabular}

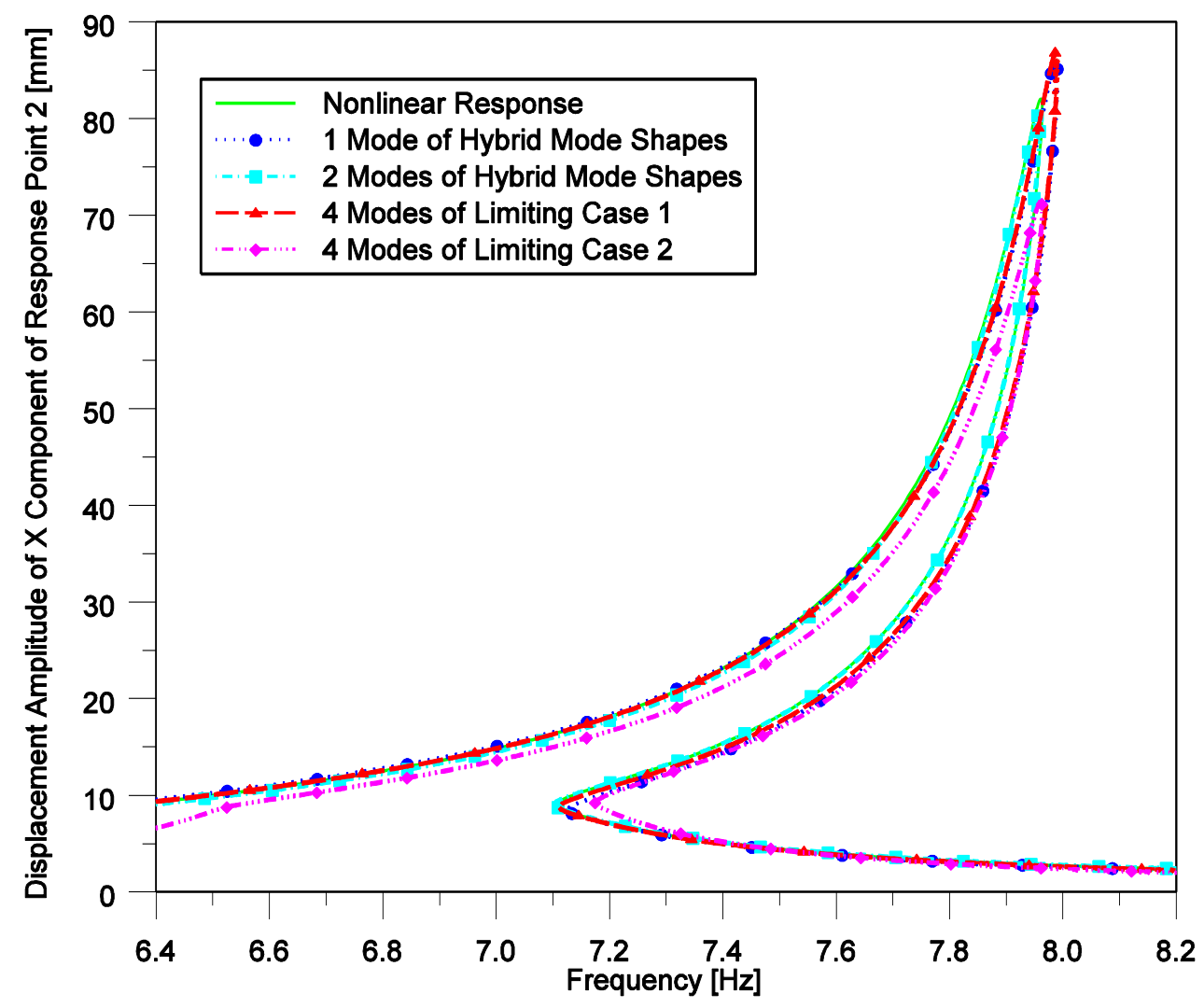

Figure 27 Displacement amplitude of $X$ component of the $2^{\text {nd }}$ point vs. frequency

Table 13 Error analysis for the $2^{\text {nd }}$ point around the first resonance

Number of Mode Shapes Integral Error Amplitude Error (\%) Frequency Error (\%)

$\begin{array}{cccc}\text { LC1 }-4 \text { Modes } & 32.9 & 5.9 & 0.3 \\ \text { LC2 }-4 \text { Modes } & 11.6 & 12.9 & 0.01 \\ 1 \text { Hybrid Mode } & 32.6 & 5.0 & 0.3 \\ 2 \text { Hybrid Modes } & 14.3 & 1.9 & 0.06\end{array}$


Furthermore, in order to show that method proposed is also applicable for a wide frequency range of interest in which the nonlinearity affects the response at several modes, and not just at one mode, as shown in Figure 23, additional analyses that illustrate the frequency response curve in a much wider frequency band have been performed. However, the effect of nonlinearity at each mode is a function of the displacement amplitude (of the nonlinear DOFs) at the interested mode which depends on the forcing amplitude as well. For this purpose, two additional point forces which have $6 \mathrm{~N}$ and $3 \mathrm{~N}$ magnitude values in $\mathrm{Y}$ and $\mathrm{Z}$ directions are exerted at the tip of the model as shown in Figure 28 in order to increase the vibration amplitude at nonlinear DOFs in a wide frequency range.

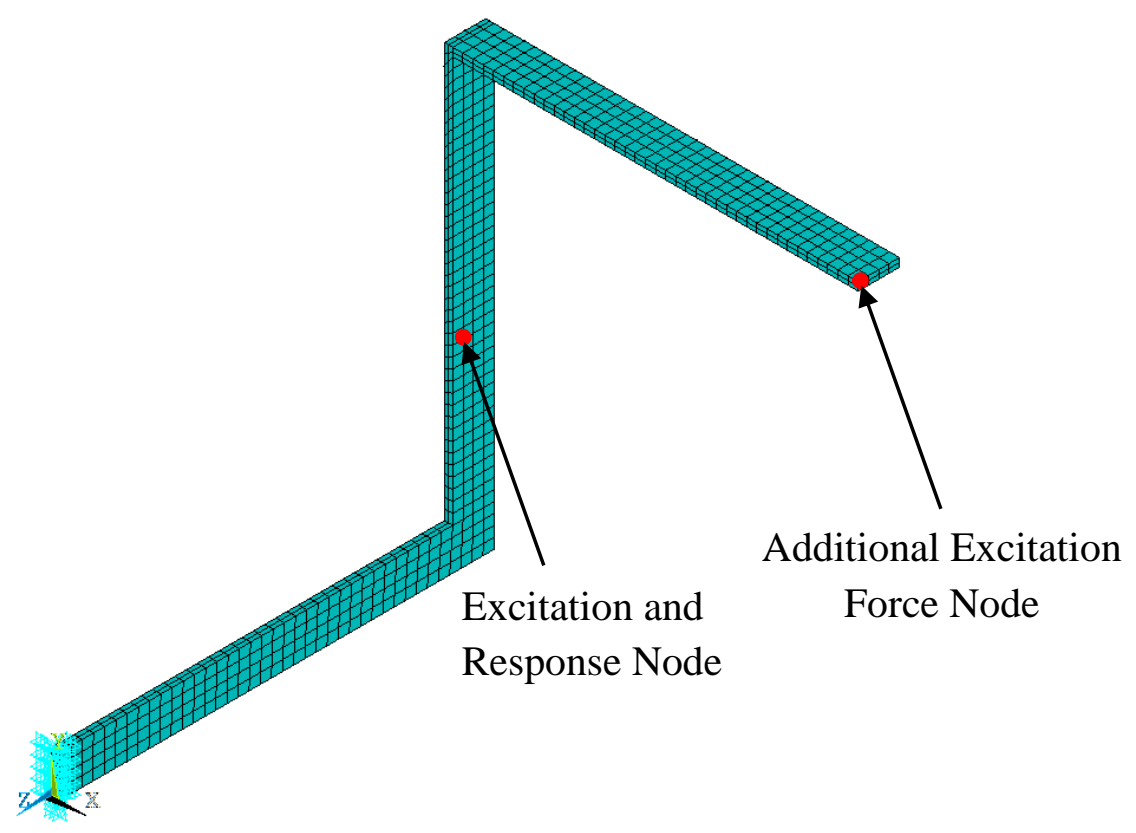

Figure 28 FE Model with additional excitation forces

The response of the interested node covering the first four modes is given in Figure 29, where the detailed results comparing the performance of the hybrid and linear mode shapes used are given in Figure 30 - Figure 33 and Table 14 - Table 17. It is clearly seen that modal superposition method with hybrid mode shapes performs as expected and the number of hybrid mode shapes used is significantly smaller than the linear modes available for the system. 


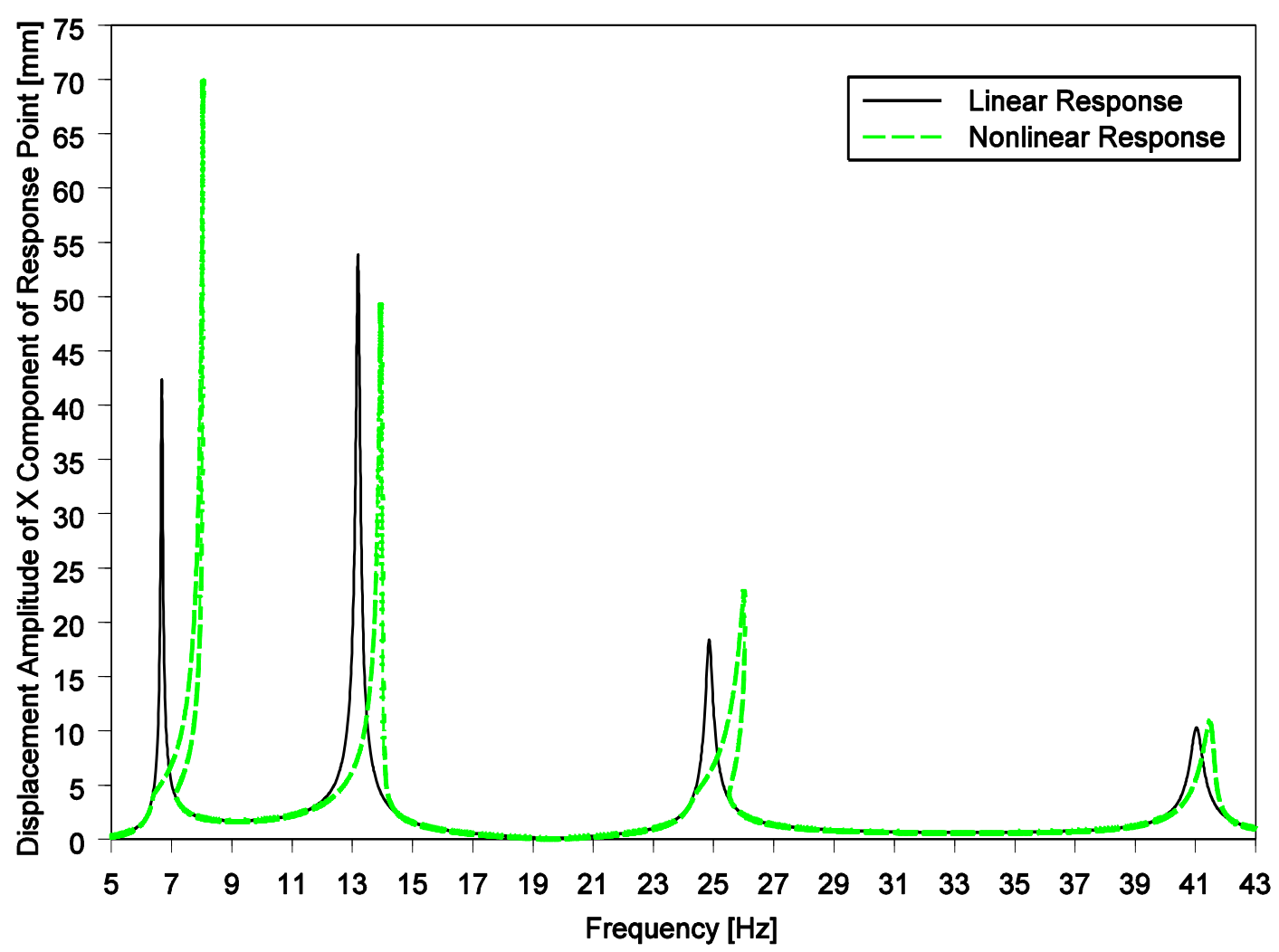

Figure 29 Displacement amplitude of $\mathrm{X}$ component of response node with respect to frequency

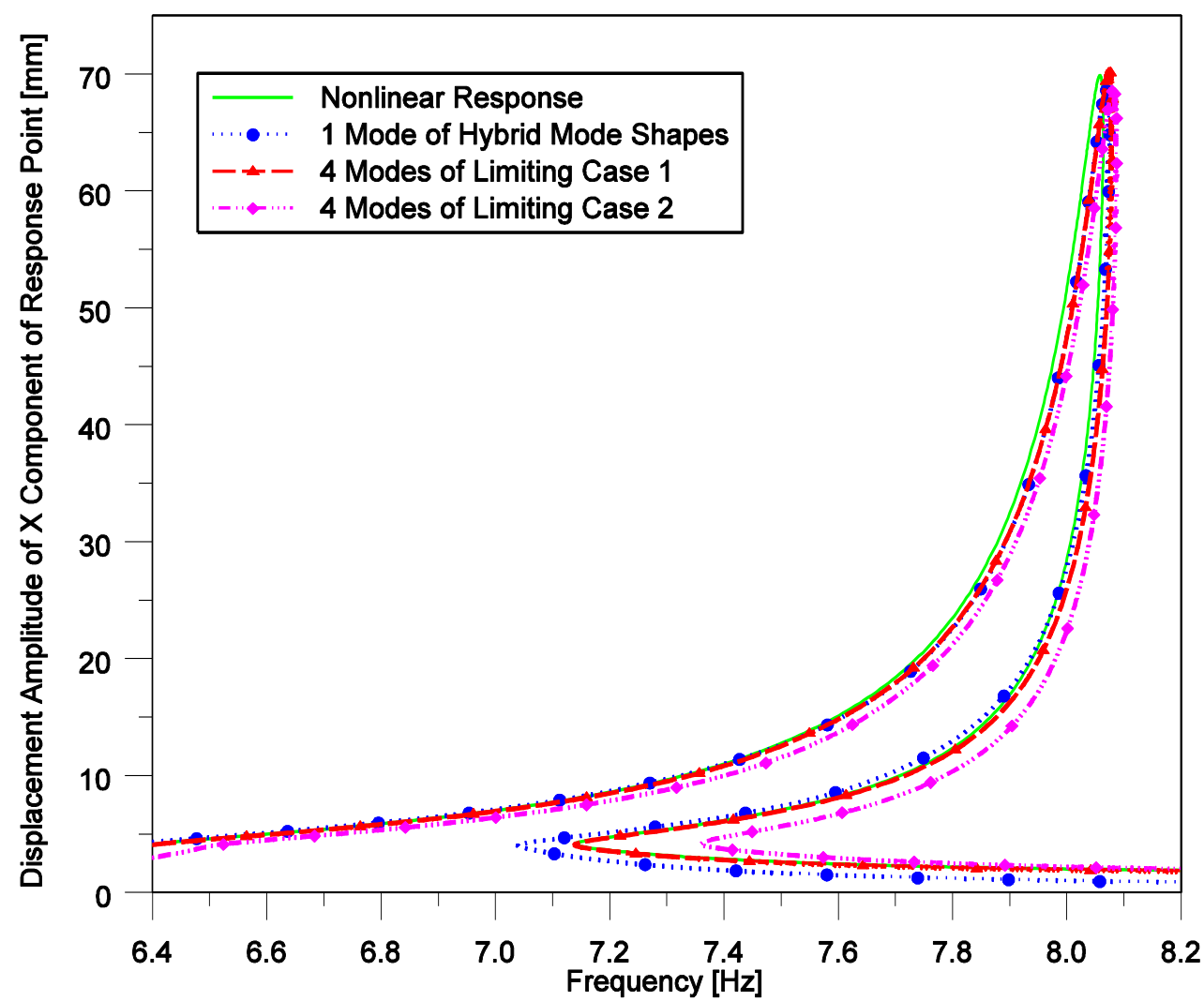

Figure 30 Displacement amplitude of $\mathrm{X}$ component of response node with respect to frequency around the first resonance 
Table 14 Error analysis for the response node around the first resonance

\begin{tabular}{cccc} 
Number of Mode Shapes & Integral Error & Amplitude Error (\%) & Frequency Error (\%) \\
\hline LC1 -4 Modes & 21.5 & 0.6 & 0.2 \\
LC2 - 4 Modes & 25.9 & 1.7 & 0.3 \\
1 Hybrid Mode & 16.9 & 1.7 & 0.1
\end{tabular}

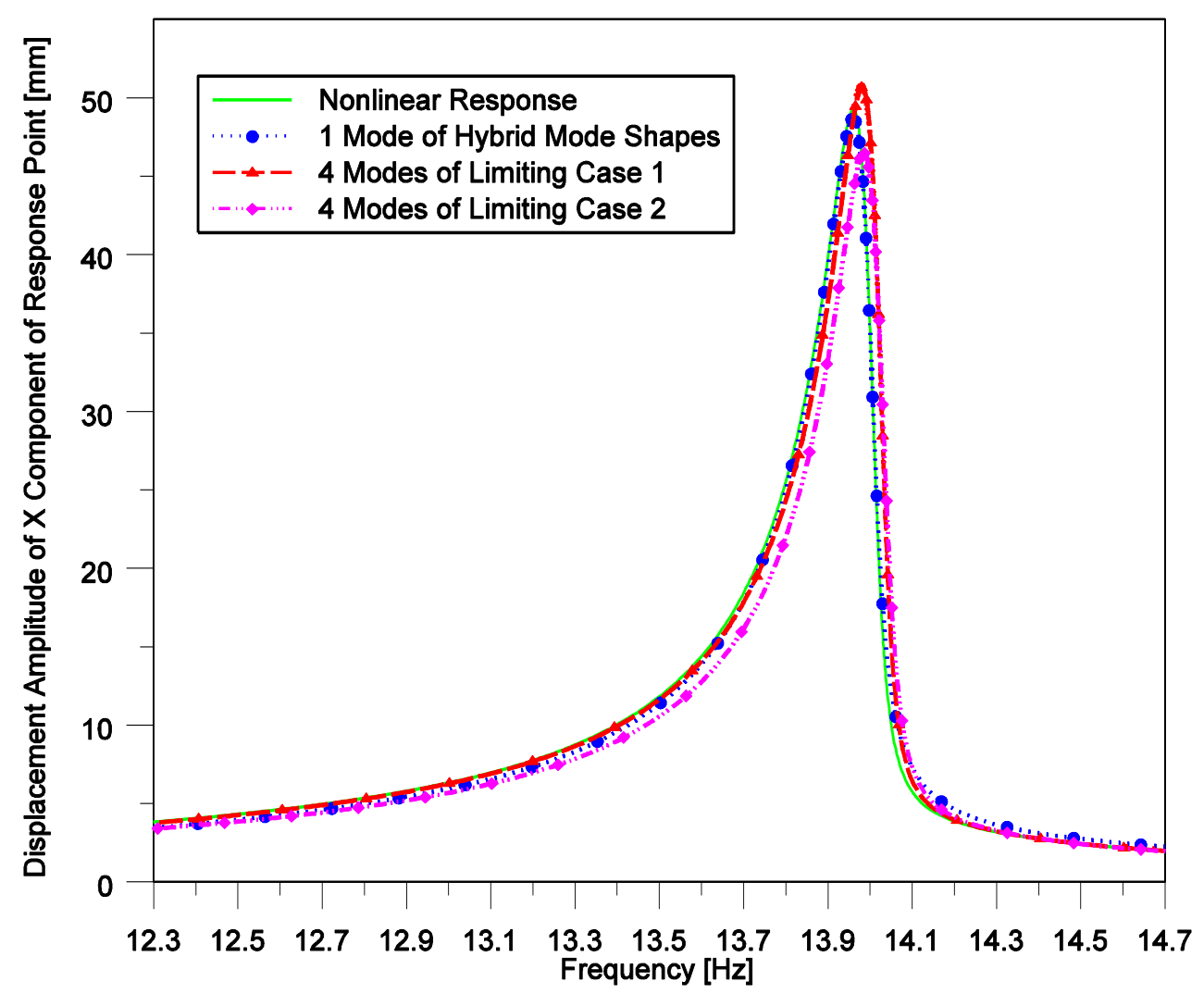

Figure 31 Displacement amplitude of $\mathrm{X}$ component of response node with respect to frequency around the second resonance

Table 15 Error analysis for the response node around the second resonance Number of Mode Shapes Integral Error Amplitude Error (\%) Frequency Error (\%)

$\begin{array}{lccc}\text { LC1 }-4 \text { Modes } & 7.8 & 3.0 & 0.1 \\ \text { LC2 }-4 \text { Modes } & 10.0 & 5.5 & 0.2 \\ \text { 1 Hybrid Mode } & 2.1 & 1.0 & 0.01\end{array}$




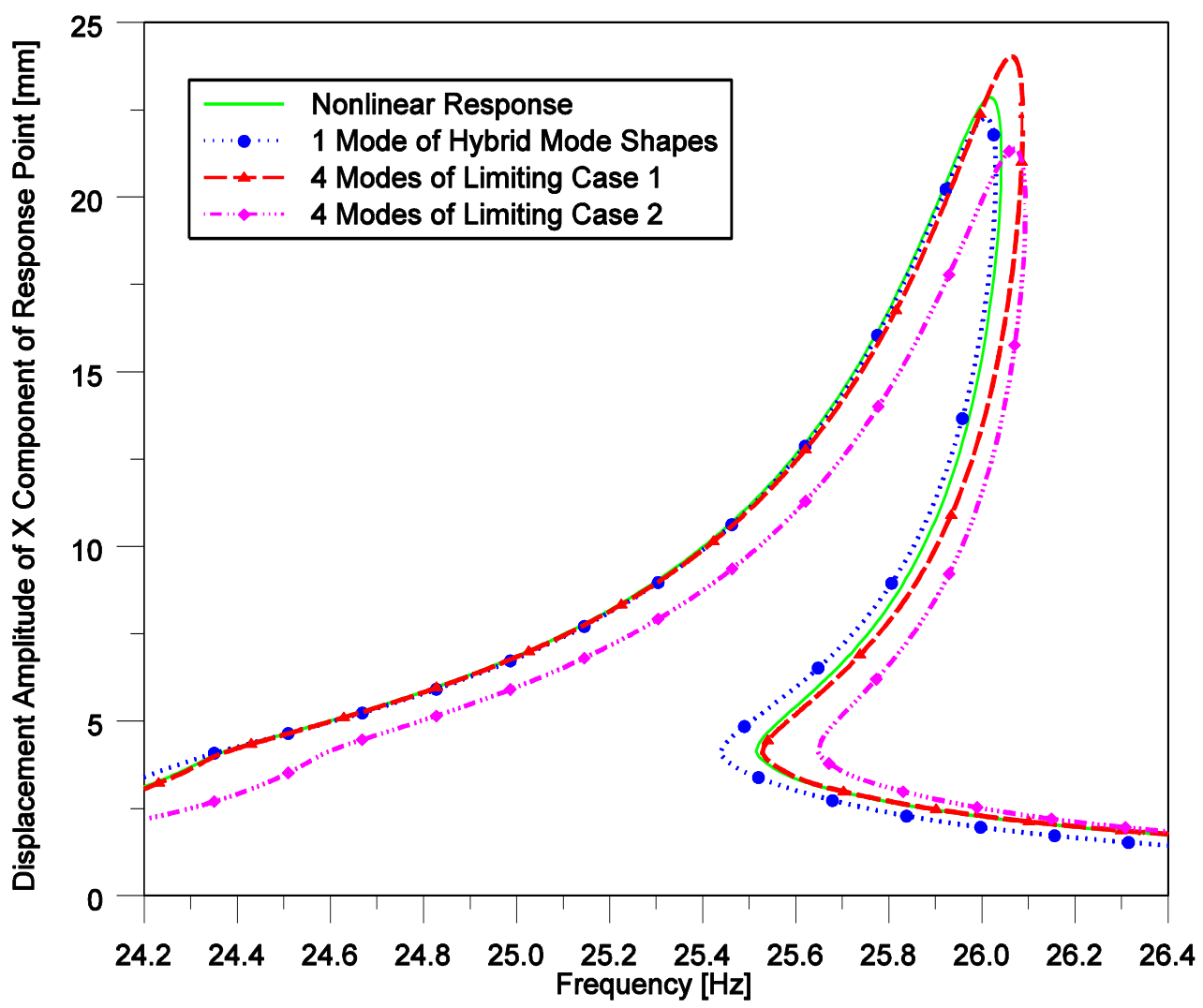

Figure 32 Displacement amplitude of $\mathrm{X}$ component of response node with respect to frequency around the third resonance

Table 16 Error analysis for the response node around the third resonance

Number of Mode Shapes Integral Error Amplitude Error (\%) Frequency Error (\%)

$\begin{array}{lccc}\text { LC1 }-4 \text { Modes } & 11.5 & 5.2 & 0.2 \\ \text { LC2 }-4 \text { Modes } & 11.8 & 6.4 & 0.2 \\ 1 \text { Hybrid Mode } & 6.0 & 2.5 & 0.05\end{array}$




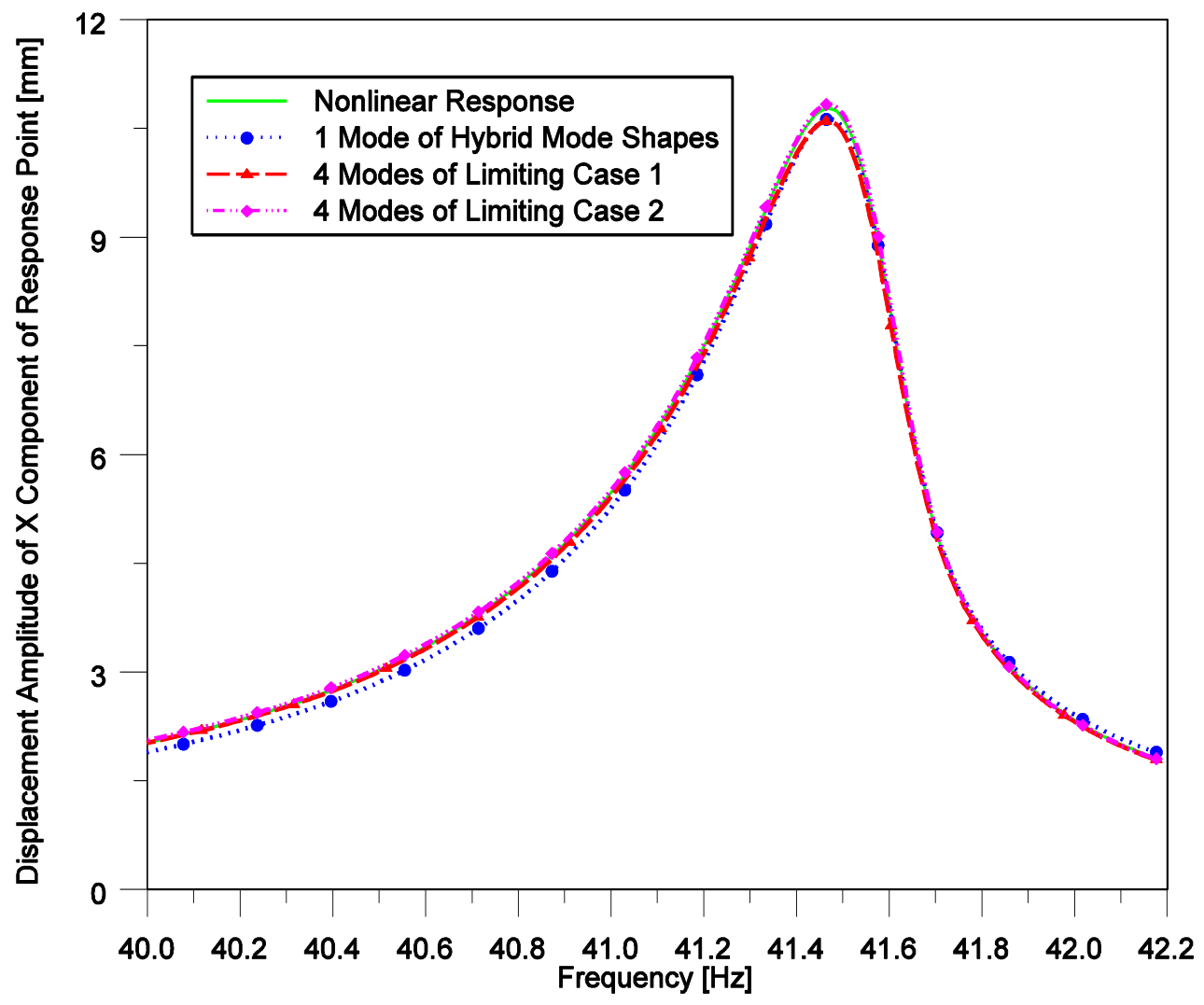

Figure 33 Displacement amplitude of $\mathrm{X}$ component of response node with respect to frequency around the fourth resonance

Table 17 Error analysis for the response node around the fourth resonance

\begin{tabular}{cccc} 
Number of Mode Shapes & Integral Error & Amplitude Error $(\%)$ & Frequency Error (\%) \\
\hline LC1 -4 Modes & 0.3 & 1.5 & 0.002 \\
LC2 - 4 Modes & 0.2 & 0.6 & 0.0009 \\
1 Hybrid Mode & 0.5 & 1.2 & 0.003
\end{tabular}

\subsubsection{Case Study 7: Gap and Dry Friction Elements Together}

In this case study, gap and dry friction nonlinear elements are used together in order to increase nonlinear effects. Limiting cases are the same as the ones defined in Section 4.1.3. In Figure 34, X component of linear and nonlinear response of the selected node is given in which the effects of strong nonlinearity in the system can be 
clearly seen. It is seen from Figure 35 and the error values given in Table 18 that using 2 hybrid modes gives very accurate results, which can be obtained if 8 modes of limiting case 1 or limiting case 2 are used. This observation is very important since the model contains relatively high number of DOFs. Therefore, it can be concluded that computational effort can be drastically reduced by using the modal superposition method with hybrid mode shapes proposed in this study. Moreover, computational time for each case is also presented in Table 18 which is calculated as described in Section 4.1.3. Utilizing a single hybrid mode shape results in approximately $82 \%$ decrease in the computational time; whereas, if two hybrid modes are used the computational saving is approximately $72 \%$.

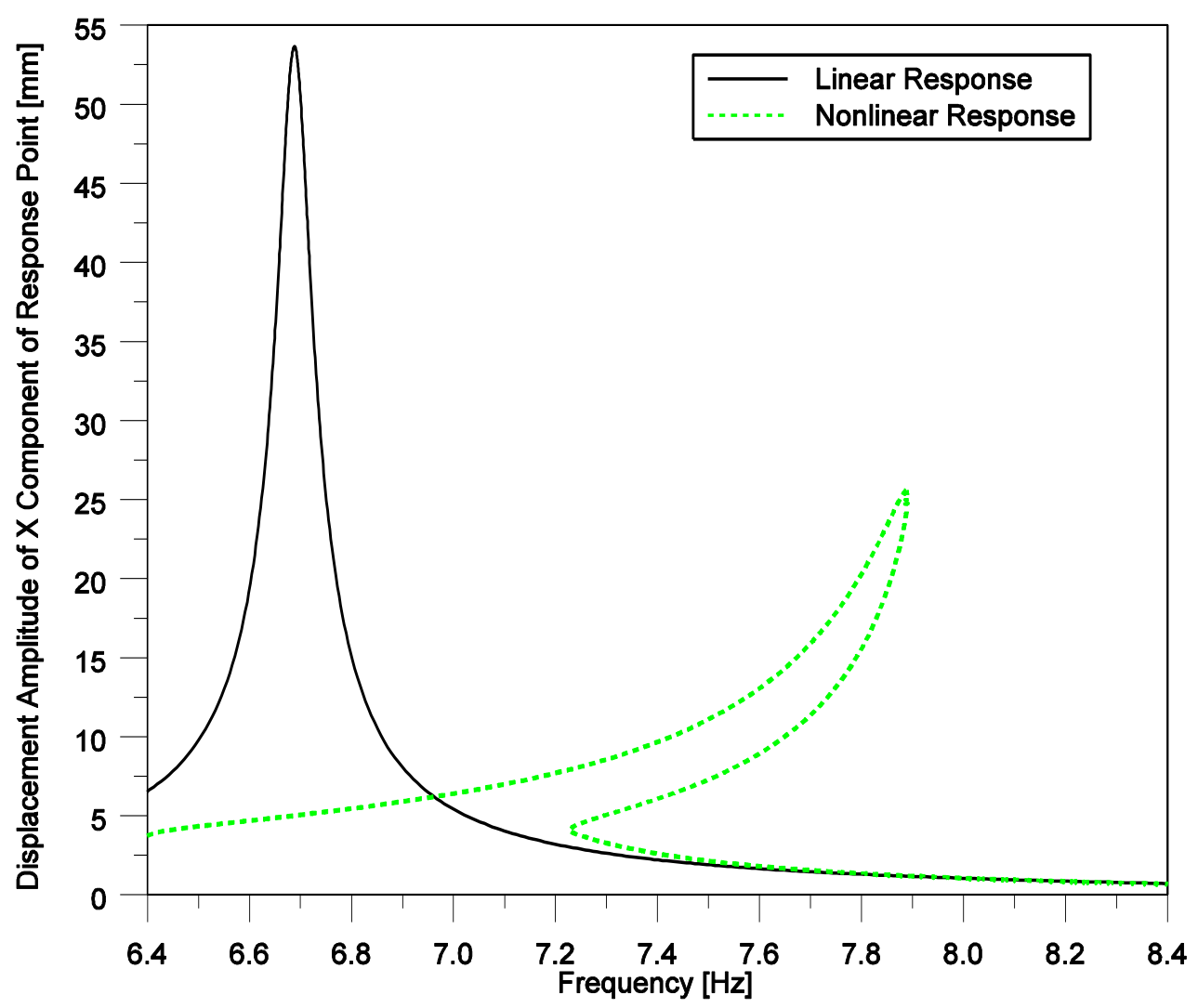

Figure 34 Displacement amplitude of $\mathrm{X}$ component of response node with respect to frequency around first resonance region 
(a)

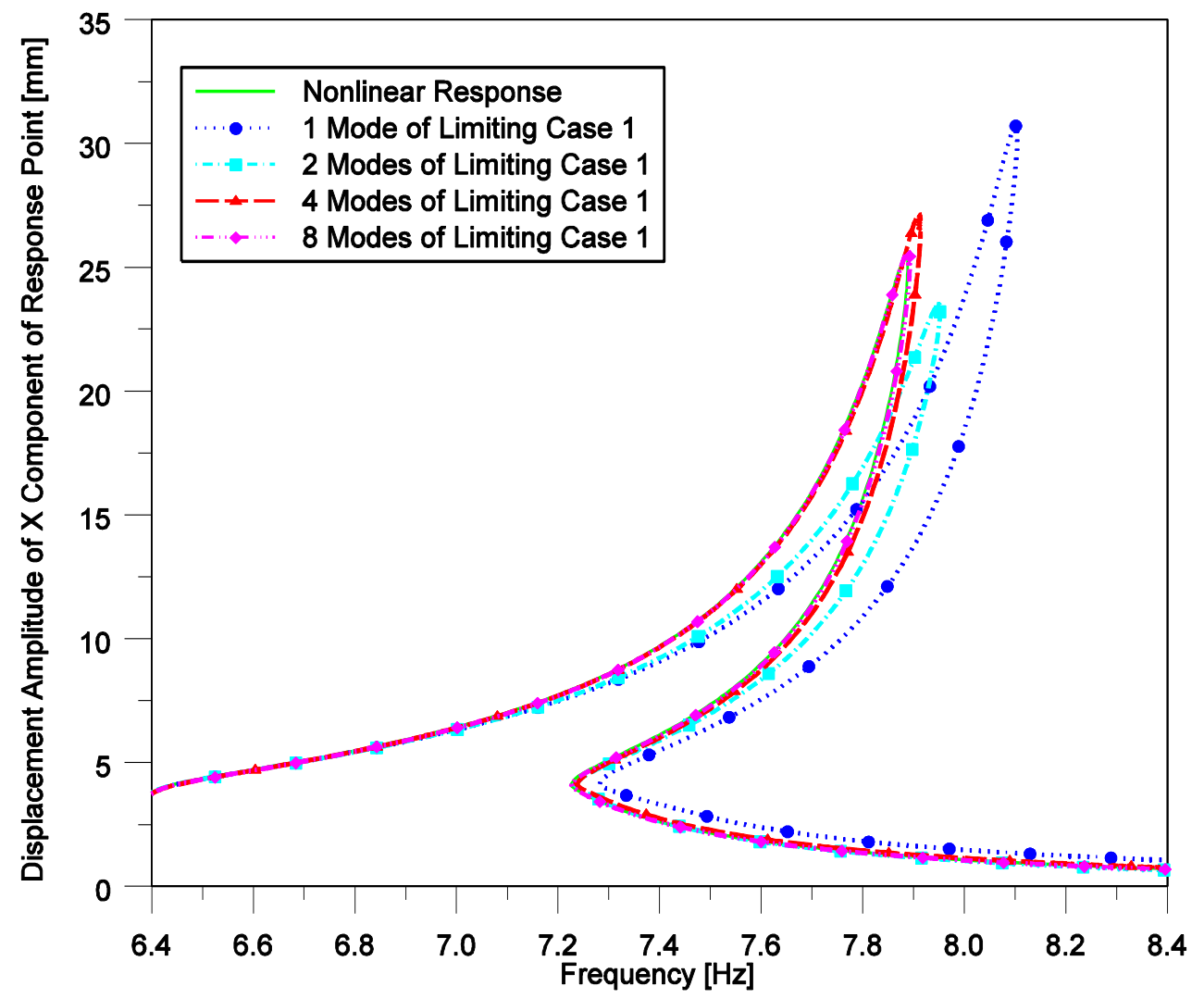

(b)

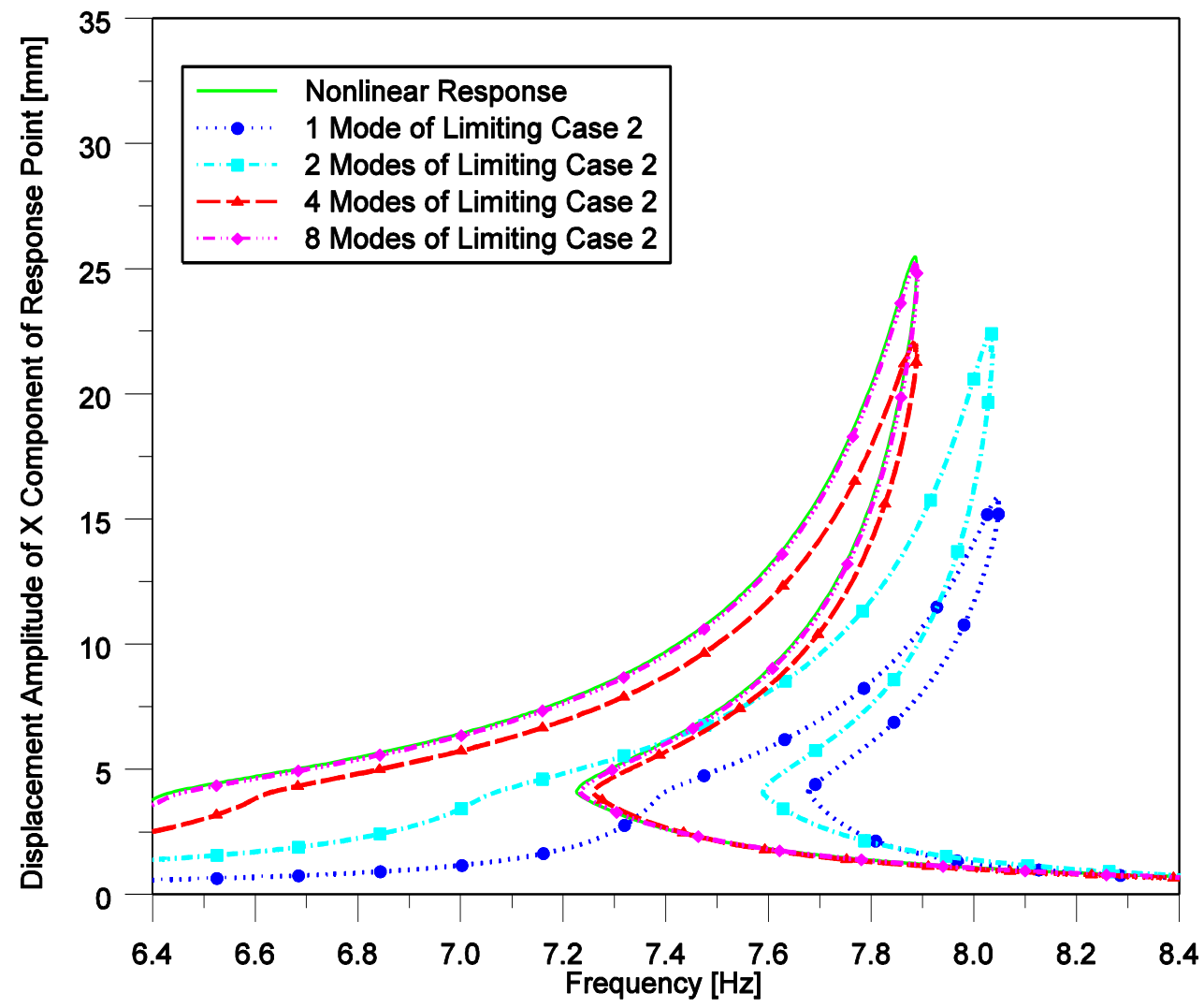


(c)

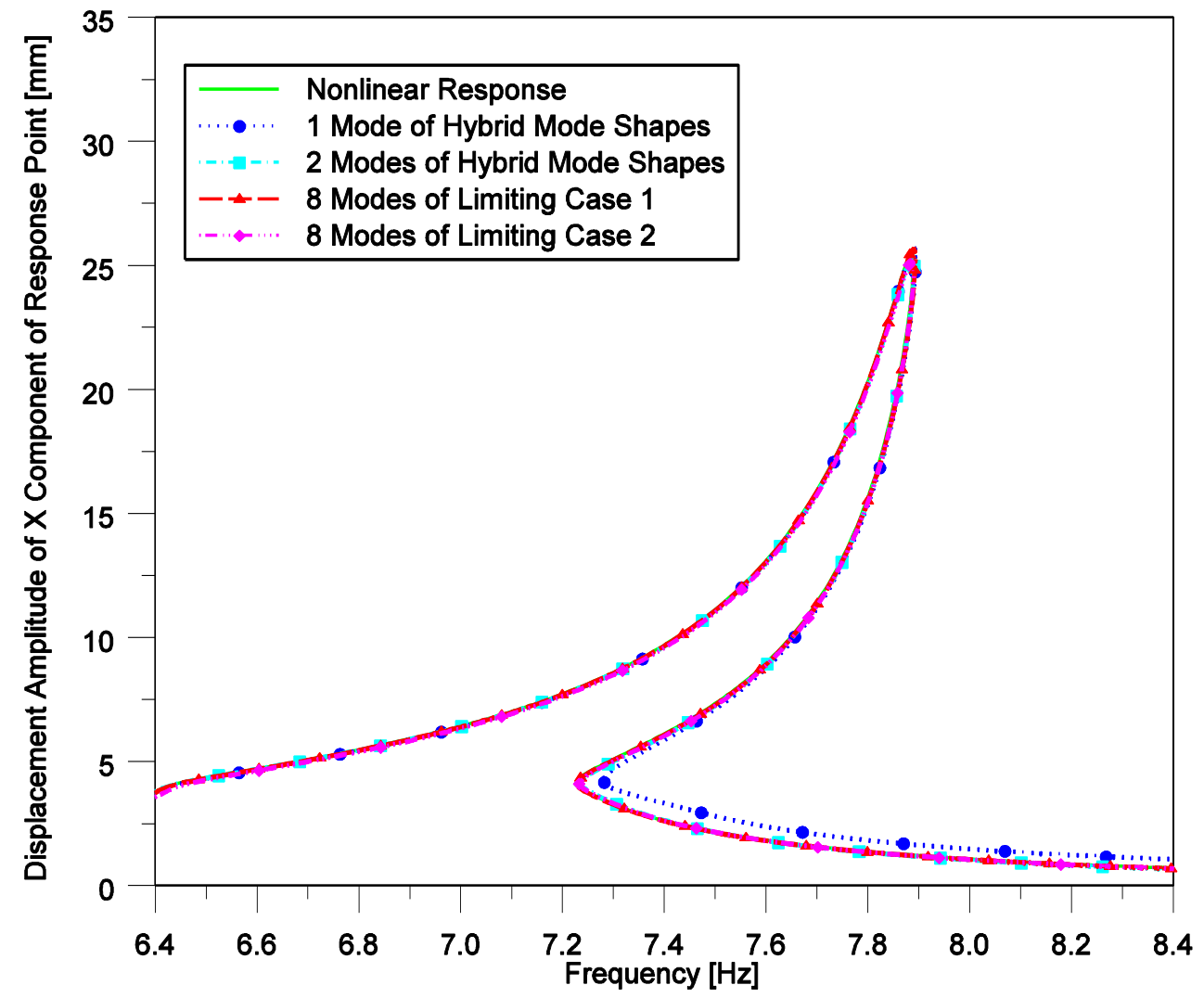

Figure 35 Effect of number of modes used on the displacement amplitude of the response node in X-direction around the first resonance

Table 18 Error analysis for the response node around the first resonance

\begin{tabular}{ccccc}
$\begin{array}{c}\text { Number of } \\
\text { Mode Shapes }\end{array}$ & $\begin{array}{c}\text { Integral } \\
\text { Error }\end{array}$ & $\begin{array}{c}\text { Amplitude } \\
\text { Error }(\%)\end{array}$ & $\begin{array}{c}\text { Frequency } \\
\text { Error }(\%)\end{array}$ & $\begin{array}{c}\text { Computational } \\
\text { Time }[\mathrm{s}]\end{array}$ \\
\hline Exact Soln. (30 Modes) & - & - & - & 1063 \\
LC1 - 1 Mode & 27.7 & 20.7 & 2.7 & 50.1 \\
LC1 - 2 Modes & 13.6 & 7.7 & 0.8 & 71.3 \\
LC1 - 4 Modes & 9.7 & 6.5 & 0.3 & 137.3 \\
LC1 - 8 Modes & 3.1 & 0.7 & 0.04 & 282.3 \\
LC2 - 1 Mode & 23.7 & 37.7 & 2.0 & 37.5 \\
LC2 - 2 Modes & 21.7 & 11.9 & 1.9 & 67.7 \\
LC2 - 4 Modes & 4.0 & 13.1 & 0.004 & 124.8 \\
LC2 - 8 Modes & 0.8 & 1.2 & 0.003 & 279.8 \\
1 Hybrid Mode & 3.5 & 0.9 & 0.06 & 48.4 \\
2 Hybrid Modes & 1.7 & 0.4 & 0.02 & 78.1
\end{tabular}




\section{CHAPTER 5}

\section{DISCUSSION AND CONCLUSION}

In this study, a new modal superposition approach based on hybrid mode shapes is proposed to obtain steady state response of nonlinear structures. For certain types of nonlinear elements, the equivalent stiffness of the nonlinearity saturates, in other words it has limiting values. Thus, it is possible to define limiting linear systems where the nonlinear system behaves as if it is linear, since the equivalent stiffness of the nonlinearity does not change with system response. It should be noted that even though the nonlinearity does not possess a limiting equivalent stiffness, the limiting linear case can be defined for any type of nonlinearity by restricting the maximum vibration amplitude. Therefore, at this limiting case, the response of the nonlinear system can be obtained completely by using the mode shapes of the limiting linear systems. On the other hand, for other cases, the response of the nonlinear system is in between these limiting cases and none of the linear system modes can capture it accurately. Hence, hybrid mode shapes are defined as a linear combination of the mode shapes of the linear systems corresponding to each limiting linear case. The contribution of each linear mode to the hybrid mode shape is determined by comparing the ratio of the equivalent stiffness of nonlinear elements to the equivalent stiffness of limiting linear system for the interested DOF. As a result of this, hybrid mode shapes span the nonlinear response space better than the linear mode shapes and, in the limiting cases, they are identical to the mode shapes of the limiting linear systems. Therefore, using hybrid mode shapes in modal superposition method leads to accurate solution of the nonlinear system by using less number of mode shapes than the number of mode shapes used in the traditional modal superposition method. This decreases the computational time significantly and increases the stability of the nonlinear solver due to the decrease in the number of nonlinear equations, which is very important for large nonlinear systems. 
In the case studies presented, piecewise linear stiffness, gap element and dry friction element are the nonlinearities used for which limiting linear behaviors can be easily defined. Additionally, cubic element is another nonlinearity considered where it does not possess limiting or saturating behavior. A 20-DOF lumped parameter model and a finite element model having many DOFs with different number of nonlinear elements attached are considered in the case studies. It is observed that modal superposition method with hybrid mode shapes proposed in this study give very satisfactory results compared to the mode shapes of the linear system obtained by disregarding the nonlinear elements. In the case studies considered, use of one or two hybrid mode shapes is sufficient to obtain very accurate results. However, in order to have similar accuracy, depending on the case study, the number of mode shapes of the linear system should be increased at least 2 to 16 times, which results in 4 to 32 times more number of nonlinear equations if single harmonic solution is used. It should be noted that, since computation of hybrid mode shapes do not require additional calculation, computational time of both methods are identical if the same number of modes are used. Consequently, use of hybrid mode shapes decreases the number of nonlinear equations significantly, which reduces the computational time substantially and also increases the stability of nonlinear solvers used in the solution. Therefore, the new modal superposition method with hybrid mode shapes serves as a very suitable reduction method for the dynamic analysis of nonlinear structures.

As a future work, the same method can be extended for multi harmonic vibration response of nonlinear systems. In this case, hybrid mode shapes may also be used as basis function in the modal superposition method for higher harmonics. In addition to this, instead using a linear fit to calculate the hybrid mode shapes different fitting functions can be used to determine the hybrid mode shapes. This will increase the complexity of the method and gain in speed should justify the increase in complexity. 


\section{REFERENCES}

[1] D. Göge, M.U. Sinapius, U. Füllekrug, M. Link, Detection and description of non-linear phenomena in experimental modal analysis via linearity plots, Int. J. Nonlinear Mech 40 (2005) 27-48

[2] T.M. Cameron, J.H. Griffin, An alternating frequency/time domain method for calculating the steady-state response of nonlinear dynamic systems, J. Appl. Mech. 56(1) (1989) 149-154.

[3] M. Rezaiee-Pajand, M. Hashemian, A. Bohluly, A novel time integration formulation for nonlinear dynamic analysis, Aerospace Science and Tech. 69 (2017) 625-635.

[4] U. Andreaus, P. Casini, F. Vestroni, Non-linear dynamics of a cracked cantilever beam under harmonic excitation, Int. J. Non Linear Mech. 42(3) (2007) 566-575.

[5] M. Peeters, R. Viguié, G. Sérandour, G. Kerschen, C.J. Golinval, Nonlinear normal modes, Part II: Toward a practical computation using numerical continuation techniques, Mech. Syst. Signal Process. 23(1) (2009) 195-216.

[6] T. Liu, Q. Li, C. Zhao, An efficient time-integration method for nonlinear dynamic analysis of solids and structures, Sci. China Phys. Mech. Astron. 56(4), (2013), 798-804.

[7] M. Urabe, Galerkin's procedure for nonlinear periodic systems, Arch. Ration. Mech. Anal. 20(2) (1965) 120-152.

[8] C-H. Menq, J.H. Griffin, A comparison of transient and steady state finite element analyses of the forced response of a frictionally damped beam, J. Vib., Acoust., Stress, and Reliab. 107(1) (1985) 19-25.

[9] C-H. Menq, J.H. Griffin, J. Bielak, The forced response of shrouded fan stages, J. Vib., Acoust., Stress, and Reliab. 108(1) (1986) 50-55.

[10] S. Setio, H.D. Setio L. Jezequel Modal analysis of nonlinear multi-degree-offreedom structures, Int. J. Anal. Exp. Modal Analysis 7(2) (1992) 75-93.

[11] E. Budak, H.N. Özgüven, A dynamic analysis method for harmonically excited nonlinear structures, Struct. Vib. and Acoust. ASME 18(3) (1989) 23-29. 
[12] E. Budak, H.N. Özgüven, Iterative receptance method for determining harmonic response of structures with symmetrical non-linearities, Mech. Syst. Signal Process. 7(1) (1993) 75-87

[13] O. Tanrikulu, B. Kuran, H.N. Özgüven, M. Imregun, Forced harmonic response analysis of nonlinear structures using describing functions, AIAA J. 31(7) (1993) 1313-1320.

[14] B.Kuran, H.N. Özgüven, A modal superposition method for non-linear structures, J Sound Vib. 189(3) (1996) 315-339.

[15] J.J. Chen, C.H. Menq, Prediction of the resonant response of frictionally constrained blade systems using constrained mode shapes, Int. Gas Turbine Aeroengine Congress Exhibition 5 (1998) 1-10.

[16] E. Cigeroglu, N. An, C.H. Menq, A microslip friction model with normal load variation induced by normal motion, Nonlinear Dyn. 50(3) (2007) 609.

[17] E. Cigeroglu, N. An, C.H. Menq, Forced response prediction of constrained and unconstrained structures coupled through frictional contacts, J. Eng. Gas Turbines Power 131(2) (2009) 022505.

[18] E.P. Petrov, A high-accuracy model reduction for analysis of nonlinear vibrations in structures with contact interfaces, J. Eng. Gas Turbines Power 133(10) (2011) 102503

[19] M. Krack, L. Panning-von Scheidt, J. Wallaschek, A method for nonlinear modal analysis and synthesis: application to harmonically forced and self-excited mechanical systems, J Sound Vib. 332(25) (2013) 6798-6814.

[20] S. Zucca, B.I. Epureanu, Reduced order models for nonlinear dynamic analysis of structures with intermittent contacts, J. Vib. Control (2017) 1077546316689214

[21] C. Jung, B.I. Epureanu, Nonlinear amplitude approximation for bilinear systems, J Sound Vib. 333(13) (2014) 2909-2919.

[22] M.H. Tien, K.A. D’Souza, Generalized bilinear amplitude and frequency approximation for piecewise-linear nonlinear systems with gaps or prestress, Nonlinear Dyn. (2017) 1-14.

[23] V. Jaumouillé, J.J. Sinou, B. Petitjean, An adaptive harmonic balance method for predicting the nonlinear dynamic responses of mechanical systems - application to bolted structures, 329(19) (2010) 4048-4067. 
[24] D. Süß, K. Willner, Investigation of a jointed friction oscillator using the multiharmonic balance method, Mech. Syst. Signal Process. 52 (2015) 73-87.

[25] G. Von Groll, D.J. Ewins, The harmonic balance method with arc-length continuation in rotor/stator contact problems, J Sound Vib. 241(2) (2001) 223-233.

[26] E.P. Petrov, D.J. Ewins, Analytical formulation of friction interface elements for analysis of nonlinear multi-harmonic vibrations of bladed discs, ASME Turbo Expo 2002: Power for Land, Sea, and Air 4 (2002) 899-908.

[27] R. Lewandowski, Computational formulation for periodic vibration of geometrically nonlinear structures-part 2: numerical strategy and examples, Int. J. Solids Struct. 34(15) (1997) 1949-1964.

[28] P. Riberio, M. Petyt, Geometrical non-linear, steady state, forced, periodic vibration of plates, part I: model and convergence studies, J Sound Vib. 226(5) (1999) 955-983.

[29] L. Xu, M.W. Lu, Q. Cao, Nonlinear vibrations of dynamical systems with a general form of piecewise-linear viscous damping by incremental harmonic balance method, Phys. Letters A, 301(1) (2002) 65-73.

[30] M. Guskov, J.J. Sinou, F. Thouverez, Multi-dimensional harmonic balance applied to rotor dynamics, Mech. Research Communications 35(8) (2008) 537-545.

[31] A. Grolet, F. Thouverez, On a new harmonic selection technique for harmonic balance method, Mech. Syst. Signal Process. 30 (2012) 43-60.

[32] R.M. Rosenberg, On nonlinear vibrations of systems with many degrees of freedom, Advances Appl. Mech. 9 (1966) 155-242

[33] R.H. Rand, A higher order approximation for non-linear normal modes in two degree of freedom systems, Int J. Nonlinear Mech. 6(4) (1971) 545-547.

[34] L.I. Manevich, I.V. Mikhlin, On periodic solutions close to rectilinear normal vibration modes,J Appl. Math. Mech. 36(6) (1972) 988-994.

[35] R.H. Rand, A direct method for non-linear normal modes, Int J. Nonlinear Mech. 9(5) (1974) 363-368.

[36] T.K. Caughey, A.Vakakis, J.M. Sivo, Analytical study of similar normal modes and their bifurcations in a class of strongly non-linear systems, Int $\mathrm{J}$. Nonlinear Mech. 25(5) (1990) 521-533. 
[37] S.W. Shaw, C. Pierre, Non-linear normal modes and invariant manifolds, J Sound Vib. 150(1) (1991) 170-173.

[38] A.F. Vakakis, Non-similar normal oscillations in a strongly non-linear discrete system, J Sound Vib. 158(2) (1992) 341-361.

[39] S.W. Shaw, C. Pierre, Normal modes for non-linear vibratory systems, J Sound Vib. 164(1) (1993) 85-124.

[40] M.E. King, A.F. Vakakis, An energy-based formulation for computing nonlinear normal modes in undamped continuous systems, J. Vib. Acoust. 116(3) (1994) 332-340.

[41] S.W. Shaw, C. Pierre, Normal modes of vibration for non-linear continuous systems, J Sound Vib. 169(3) (1994) 319-347.

[42] A.F. Vakakis, Non-linear normal modes (NNMs) and their applications in vibration theory: an overview, Mech. Syst. Signal Process. 11(1) (1997) 3-22.

[43] C.E.N. Mazzilli, M.E.S. Soares, O.G.P.B Neto, Non-linear normal modes of a simply supported beam: continuous system and finite-element models, Computers \& structures 82(31) (2004) 2683-2691.

[44] C. Touzé, M. Amabili, Nonlinear normal modes for damped geometrically nonlinear systems: application to reduced-order modelling of harmonically forced structures, J Sound Vib. 298(4) (2006) 958-981.

[45] S. Bellizzi, R. Bouc, An amplitude-phase formulation for nonlinear modes and limit cycles through invariant manifolds, J Sound Vib. 300(3) (2007) 896-915.

[46] N.V. Perepelkin, Y.V. Mikhlin, C. Pierre, Non-linear normal forced vibration modes in systems with internal resonance, Int J. Nonlinear Mech. 57 (2013) 102-115.

[47] C. Touzé, Normal form theory and nonlinear normal modes: Theoretical settings and applications, Modal Anal. Nonlinear Mech. Syst. 555 (2014) 75-160.

[48] R. Szalai, D. Ehrhardt, G. Haller, Nonlinear model identification and spectral submanifolds for multi-degree-of-freedom mechanical vibrations, (2016) arXiv:1610.02252.

[49] A.H. Nayfeh, B. Balachandran, Applied Nonlinear Dynamics WILEY, Interscience, New York (1995)

[50] E. Ciğeroğlu, H.N. Özgüven, Nonlinear vibration analysis of bladed disks with dry friction dampers, J Sound Vib. 295(3) (2006) 1028-1043. 
[51] L. Peletan, S. Baguet, M. Torkhani, G. Jacquet-Richardet, A comparison of stability computational methods for periodic solution of nonlinear problems with application to rotordynamics, Nonlinear Dyn. 72(3) (2013) 671-682

[52] P. Sundararajan, S.T. Noah, Dynamics of forced nonlinear systems using shooting/arc-jength continuation method-application to rotor systems, J. Vib. Acoust. 119(1) (1997) 9-20.

[53] E. Cigeroglu, H. Samandari, Nonlinear free vibration of double walled carbon nanotubes by using describing function method with multiple trial functions, Phys. E, 46 (2012) 160-173.

[54] E. Cigeroglu, ME709 Lecture Notes, Middle East Technical University 


\section{APPENDIX A}

For the nonlinearities considered in this study, internal nonlinear force and the corresponding harmonic input describing functions [13] for an input motion of $x(t)=A \sin (\omega t)$ are given here.

Piecewise Linear Stiffness Element:

$$
\begin{gathered}
f_{N}(x)=\left\{\begin{array}{cc}
k_{1} x & x(\mathrm{t})<\delta \& x(\mathrm{t})>-\delta \\
k_{2} x+\left(k_{1}-k_{2}\right) \delta & x(\mathrm{t}) \geq \delta \\
k_{2} x-\left(k_{1}-k_{2}\right) \delta & x(\mathrm{t}) \leq-\delta
\end{array}\right. \\
v=\left\{\begin{array}{cc}
k_{1} & A<\delta \\
\frac{2\left(k_{1}-k_{2}\right)}{\pi}\left[\varphi+\left(\frac{\delta}{A}\right) \sqrt{1-\left(\frac{\delta}{A}\right)^{2}}\right]+k_{2} & A \geq \delta
\end{array}\right.
\end{gathered}
$$

where

$$
\varphi=\arcsin \left(\frac{\delta}{A}\right) \text { and } 0 \leq \varphi \leq \frac{\pi}{2}
$$

\section{Gap Element:}

$f_{N}(x)=\left\{\begin{array}{cc}0 & x(\mathrm{t})<\delta \\ k(x-\delta) & x(\mathrm{t}) \geq \delta\end{array}\right.$

$v=\left\{\begin{array}{cc}0 & A<\delta \\ \frac{k}{\pi}\left[\frac{\pi}{2}-\varphi+\frac{\delta}{A} \cos (\varphi)\right]-\frac{2 k \delta}{\pi A} \cos (\varphi) & A \geq \delta\end{array}\right.$

where

$$
\varphi=\arcsin \left(\frac{\delta}{A}\right) \text { and } 0 \leq \varphi \leq \frac{\pi}{2}
$$




\section{Dry Friction Element:}

$$
f_{N}(x)=\left\{\begin{array}{cc}
\mu N & A \geq x(\mathrm{t}) \geq \delta \\
-\mu N+k_{d}(x+\delta) & A \geq x(\mathrm{t}) \geq-\delta \\
-\mu N & -\delta \geq x(\mathrm{t}) \geq-A \\
-\mu N+k_{d}(x-\delta) & \delta \geq x(\mathrm{t}) \geq-A
\end{array}\right.
$$

where

$$
\delta=\frac{2 \mu N}{k_{d}}-x,
$$

$v=\left\{\begin{array}{cc}k_{d} & A \leq \frac{\mu N}{k_{d}} \\ \frac{1}{\pi}\left(\frac{2 \mu N}{A}-k_{d}\right) \sqrt{1-\left(1-\frac{2 \mu N}{k_{d} A}\right)^{2}}+\frac{k_{d}}{\pi} \varphi-\frac{k_{d}}{2}-i\left(\frac{4 \mu N\left(\mu N-k_{d} A\right)}{\pi k_{d} A^{2}}\right) & A>\frac{\mu N}{k_{d}}\end{array}\right.$

where

$$
\varphi=\arcsin \left(1-\frac{2 \mu N}{k_{d} A}\right) \text { and } \frac{\pi}{2} \leq \varphi \leq \frac{3 \pi}{2}
$$

